\title{
Avaliação do colo uterino pela ultrassonografia transvaginal para predição do sucesso da indução do parto
}

Dissertação apresentada à Faculdade de Medicina da Universidade de São Paulo para a obtenção do título de Mestre em Ciências

Programa de : Obstetrícia e Ginecologia

Orientador: Prof. Dr. Rodrigo Ruano 
Dados Internacionais de Catalogação na Publicação (CIP)

Preparada pela Biblioteca da

Faculdade de Medicina da Universidade de São Paulo

Creprodução autorizada pelo autor

Pitarello, Patricia da Rocha Pennachiotti

Avaliação do colo uterino pela ultrassonografia transvaginal para predição do sucesso da indução do parto / Patricia da Rocha Pennachiotti Pitarello. -- São Paulo, 2011.

Dissertação(mestrado)--Faculdade de Medicina da Universidade de São Paulo. Programa de Obstetrícia e Ginecologia.

Orientador: Rodrigo Ruano.

Descritores: 1.Colo uterino/ultrassonografia 2.Trabalho de parto induzido 3.Comprimento do colo do útero 4.Sucesso da indução do parto

USP/FM/DBD-120/11 
Nós somos o que fazemos repetidamente, a excelência não é um feito, e sim um hábito.

Aristóteles 
DEDICATÓRIA 
À minha mãe Regina e meu pai Luiz, meus anjos e grandes incentivadores, que sempre acreditaram que seria possível. Sem o amor de vocês eu não teria conseguido.

Ao meu amor e marido Daniel, pelo apoio, carinho, companheirismo e coragem.

Aos meus avós Maria Aparecida, José e Catarina, pelo amor, exemplo, dedicação e sabedoria.

Aos amados tios Rita e Marcos, por tudo que representam em minha vida, pelo amor, apoio e exemplos a serem seguidos.

Aos meus irmãos Rodrigo e Rafael e meus primos Beatriz e João Pedro, pelas alegrias, amor e companheirismo.

Aos meus queridos tios José Antônio, Cristiane,

Paulo, Rosa, Marcela, Otto, Mônica e primos Izadora, Brenda, Verônica e Matheus. 
AGRADECIMENTOS ESPECIAIS 
Ao Prof. Dr. Rodrigo Ruano, pelos ensinamentos, pela amizade e pelo grande exemplo profissional a ser seguido.

Às amigas Cristina Anton e Cristiane Pavão Spaulonci pelo incentivo e amizade.

Ao colega Carlos Tadashi Yoshizaki, pelo apoio e importante ajuda neste estudo

A todos os médicos da Clínica Obstétrica do Hospital Universitário da Universidade de São Paulo : Dr Paulo Bucheroni, Dr Edmundo, Dr Paulo Basto, Dr José Luiz, Dra Sônia, Dra Maria Delizete, Dra Sueli, Dra Suzi, Dr Gino, Dra Ana Lúcia, Dra Mariza, Dra Fernanda Maria, Dr Wu, Dra Ivone, Dr Toyoji, Dr Juang Dr Chuu,Dr Jorge,Dr Vladimir, Dra Adriana, Dra Tânia Dr Paulo Miyada, Dra Maria Aparecida, Dra Fernanda Erci e Dr Nilton, pelo apoio, grande ajuda na realização deste estudo, companheirismo, profissionalismo e contribuição para minha formação pessoal e profissional.

À Anie Bernabé Moreira, pelo apoio, dedicação e importante colaboração 
Ao Prof. Dr. Marcelo Zugaib, digníssimo Professor Titular de Obstetrícia, da Faculdade de Medicina da Universidade de São Paulo, pela oportunidade de cursar a Residência Médica e a pós graduação na mais conceituada Clínica Obstétrica do país, bem como de ser assistente da Clínica Obstétrica do excelente Hospital Universitário da Universidade de São Paulo, e pelo exemplo acadêmico, profissional e de liderança.

Ao Prof. Dr. Mário Henrique Burlacchini de Carvalho, pelos ensinamentos, exemplo pessoal e profissional, humanidade, ética e integridade, e pela grande contribuição no Exame de Qualificação.

Aos membros da banca examinadora do Exame de Qualificação, Prof. Dr. Roberto Eduardo Bittar e Dr. Silvio Martinelli, pelas excelentes contribuições a esta dissertação.

Ao Prof. Dr. Adolfo Wenjaw Liao, Prof. Dr. Seizo Miyadahira e ao Prof. Dr. Victor Bunduki, pelos ensinamentos e incentivos.

Aos médicos da Clínica Obstetrícia da FMUSP, que contribuíram muito para minha formação profissional e científica.

Às enfermeiras: Fatme,Cláudia, Edilene, Camila, Ana Cláudia, Ruth, Sandra, Mariângela, Chang, Luciana e toda equipe de enfermagem do Hospital Universitário da USP, pelo apoio e ajuda na realização deste estudo.

Aos colegas e amigos do HCFMUSP, Clarissa Oliveira Lamberty, Karine Tosta, Juliana Carvalho Silva, Carla Fagundes, Carolina Hoffmeister, Vinicius Zanlorenci, Luciana de Freitas Garcia, Rita de Cássia Souza, Eduardo Pimenta e Tatiana Bernath Liao.

Aos funcionários, Inez Muras Fuentes Jazra, Márcia Batista, Myrian Souto, Amadeu Santos, Willian Torres pela importante colaboração.

A todas as pacientes da Clínica Obstétrica do Hospital Universitário da Universidade de São Paulo, por permitirem meu aprendizado e realização de pesquisas científicas. Sem elas este trabalho seria impossível. 
Esta dissertação está de acordo com as seguintes normas, em vigor no momento desta publicação:

Referências: adaptado de International Committee of Medical Journals Editors (Vancouver).

Universidade de São Paulo. Faculdade de Medicina. Serviço de Biblioteca e Documentação. Guia de apresentação de dissertações, teses e monografias. Elaborado por Anneliese Carneiro da Cunha, Maria Julia de A. L.Freddi, Maria F. Crestana, Marinalva de Souza Aragão, Suely Campos Cardoso, Valéria Vilhena. $2^{\mathrm{a}}$ Ed. São Paulo: Serviço de Biblioteca e Documentação; 2005

Abreviaturas dos títulos dos periódicos de acordo com List of Journals Indexed in Index Medicus 
SUMÁRIO 
LISTA DE ABREVIATURAS E SIGLAS

LISTA DE FIGURAS E GRÁFICOS

RESUMO

SUMMARY

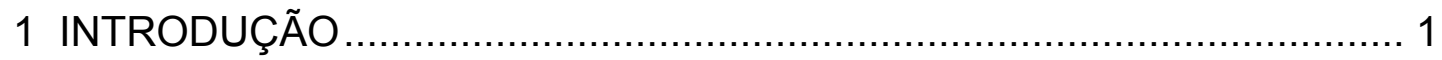

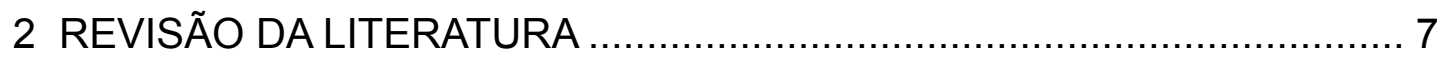

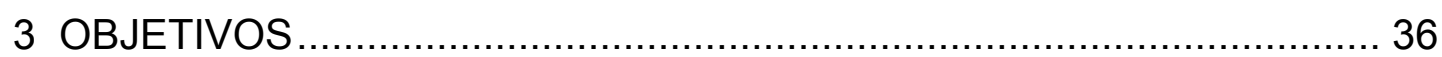

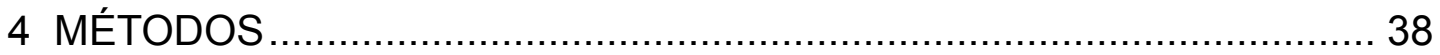

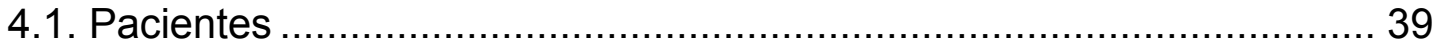

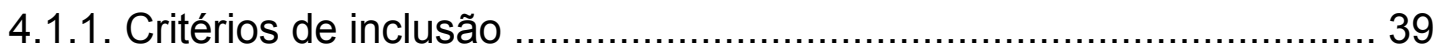

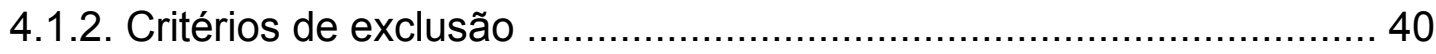

4.2. Processo de coleta de dados e acompanhamento das gestantes ....... 40

4.3. Avaliação clínica do escore de Bishop ................................................ 43

4.4. Uso de misoprostol e ocitocina na indução do parto............................. 44

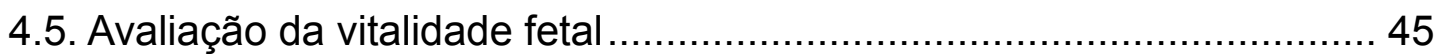

4.6. Avaliação das variáveis ultrassonográficas do colo uterino .................. 45

4.6.1. Medida do comprimento do colo uterino ........................................ 46

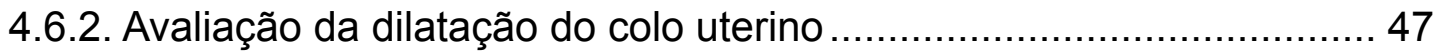

4.6.3. Medida da distância da apresentação fetal ao OCE ......................... 48

4.6.4. Definição da presença do afunilamento do colo uterino (imagem em

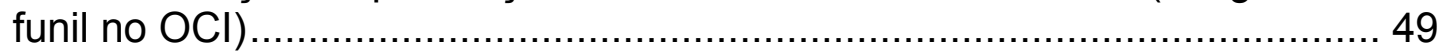

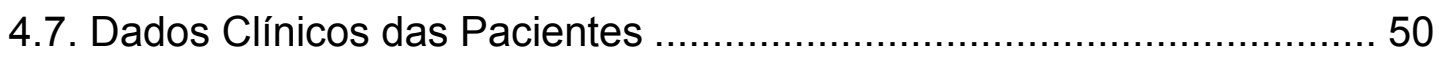

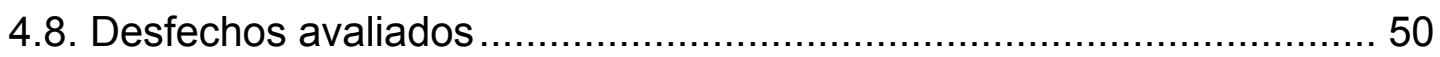

4.8.1. Sucesso da Indução do Parto ....................................................... 50

4.8.2. Parto vaginal em 24 horas da IP ................................................. 51

4.8.3. Presença de fase ativa do trabalho de parto..................................... 51

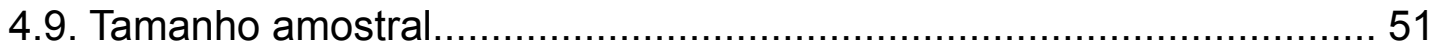

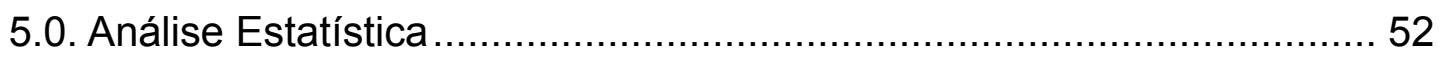

5.1. Caracterização da população estudada............................................ 54

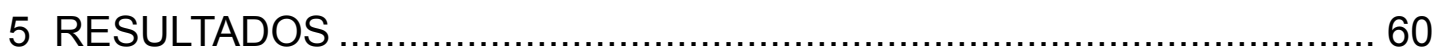

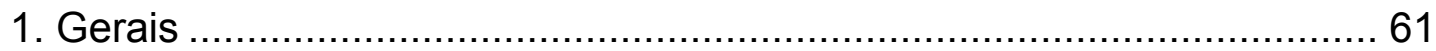

2. Avaliação do colo uterino pela ultrassonografia transvaginal na indução do parto.

2.1. Associação do comprimento do colo uterino, distância da apresentação fetal ao OCE, dilatação cervical e imagem em funil no $\mathrm{OCl}$ ao sucesso da IP 
2.2. Associação do comprimento do colo uterino, distância da apresentação fetal ao OCE, dilatação cervical e imagem em funil no $\mathrm{OCl}$ à ocorrência do parto vaginal em até 24 horas após a indução do parto

2.3. Associação do comprimento do colo uterino, distância da apresentação fetal ao OCE, dilatação cervical e imagem em funil no $\mathrm{OCl}$ à presença de fase ativa do trabalho de parto após a IP

3. Associação do Índice de Bishop e Indução do Parto

4. Associação da paridade, IMC, idade materna e idade gestacional com o sucesso da indução do parto outros desfechos.

5. Predição do sucesso da indução do parto e outros desfechos 76

5.1. Análise de regressão logística

5.2. Fórmulas de predição do sucesso da IP, parto vaginal em 24 horas e trabalho de parto ativo

5.3. Curvas ROC e o sucesso da indução do parto, parto vaginal em 24 horas e trabalho de parto ativo

5.4. Análise da Variação Intra e Interobservador das medidas ultrassonográficas do colo uterino

5.5. Correlação entre o Índice de Bishop e as variáveis ultrassonográficas 88

6 DISCUSSÃO 94

7 CONCLUSÃO 102

8 ANEXOS 105

9 REFERÊNCIAS BIBLIOGRÁFICAS 
LISTAS 


\section{LISTA DE ABREVIATURAS E SIGLAS}

$\begin{array}{ll}\text { AUC } & \text { área sobre a curva ROC } \\ \text { cm } & \text { centímetros } \\ \text { DHEG } & \text { doença hipertensiva específica da gestação } \\ \text { DUM } & \text { data da última menstruação } \\ \text { HAC } & \text { hipertensão arterial crônica } \\ \text { HCFMUSP } & \text { Hospital das Clínicas da Faculdade de Medicina da } \\ \text { HR } & \text { Universidade de São Paulo } \\ \text { HU-USP } & \text { hazard ratio } \\ \text { IM } & \text { Hospital Universitário da Universidade de São Paulo } \\ \text { IMC } & \text { intramuscular } \\ \text { IP } & \text { índice de massa corpórea } \\ \text { LR } & \text { indução do parto } \\ \text { Mcg } & \text { likelihood ratio } \\ \text { MG } & \text { microgramas } \\ \text { mm } & \text { miligramas } \\ \text { mU/min } & \text { milímetros } \\ \text { OCE } & \text { miliunidades por minuto } \\ \text { OCI } & \text { orifício cervical externo } \\ \text { OR } & \text { orifício cervical interno } \\ \text { RCF } & \text { udds ratio } \\ \text { SFA } & \text { transtrição de crescimento fetal } \\ \text { TV } & \text { unidades internacionais } \\ \text { UI } & \text { uSG }\end{array}$




\section{LISTA DE FIGURAS E GRÁFICOS}

Figura 1 - Índice de Bishop. (página 43)

Figura 2 - Medida do comprimento do colo uterino pela ultrassonografia transvaginal .(página 47)

Figura 3 - Medida da dilatação cervical pela ultrassonografia transvaginal .(página 48)

Figura 4 - Medida da distância da apresentação fetal ao OCE pela ultrassonografia transvaginal. .(página 49)

Figura 5 - Presença de imagem em funil no $\mathrm{OCl}$, pela ultrassonografia transvaginal .(página 50)

Gráfico 1: Distribuição quanto à paridade das 190 gestantes submetidas à avaliação do colo uterino pela ultrassonografia transvaginal para predição do sucesso da indução do parto. HU-USP, fevereiro de 2008 a fevereiro de 2010 (página 57)

Gráfico 2: Descrição das indicações clínicas de indução do parto das 190 gestantes submetidas à avaliação do colo uterino pela ultrassonografia transvaginal para predição do sucesso da IP. HU-USP, fevereiro de 2008 a fevereiro de 2010. (página 58)

Gráfico 3: Distribuição das medicações utilizadas na IP das 190 gestantes submetidas à avaliação do colo uterino pela ultrassonografia transvaginal para predição do sucesso da IP. HU-USP, fevereiro de 2008 a fevereiro de 2010 (página 59)

Gráfico 4: Distribuição quanto ao tipo de parto das 190 gestantes submetidas à avaliação do colo uterino pela ultrassonografia transvaginal para predição do sucesso da IP. HU-USP, fevereiro de 2008 a fevereiro de 2010 (página 61) 
Gráfico 5: Distribuição das 57 gestantes quanto às indicações de cesárea após a IP. HU-USP, fevereiro de 2008 a fevereiro de 2010 . (página 62)

Gráfico 6: Distribuição da presença ou ausência da variável ultrassonográfica, imagem em funil, nas 190 gestantes submetidas à avaliação do colo uterino pela ultrassonografia transvaginal para predição do sucesso da indução do parto. HU-USP, fevereiro de 2008 a fevereiro de 2010. (página 64)

Gráfico 7: Distribuição das 190 gestantes quanto à presença ou ausência de fase ativa do parto durante a IP. HU-USP, fevereiro de 2008 a fevereiro de 2010. (página 65)

Gráfico 8 : Curva ROC do comprimento do colo uterino para predição do sucesso da IP. HU-USP, fevereiro de 2008 a fevereiro de 2010 (página 83)

Gráfico 9: Curva ROC da distância da apresentação fetal ao OCE, para predição do sucesso da IP. HU-USP, fevereiro de 2008 a fevereiro de 2010. (página 84)

Gráfico 10: Curva ROC da dilatação cervical para a predição do sucesso da IP. HU-USP, fevereiro de 2008 a fevereiro de 2010 (página 85)

Gráfico 11: Diagrama de dispersão entre comprimento do colo e Índice de Bishop. HU-USP, fevereiro de 2008 a fevereiro de 2010 (página 89)

Gráfico 12: Diagrama de dispersão entre a distância da apresentação fetal ao OCE e Índice de Bishop. HU-USP, fevereiro de 2008 a fevereiro de 2010. (página 89)

Gráfico 13: Diagrama de dispersão entre dilatação cervical e Índice de Bishop. HU-USP, fevereiro de 2008 a fevereiro de 2010 (página 90)

Tabela 1 - Distribuição da raça e estado civil das 190 gestantes submetidas à avaliação do colo uterino pela ultrassonografia transvaginal para predição do sucesso da indução do parto. HU-USP, fevereiro de 2008 a fevereiro de 2010 (página 55) 
Tabela 2- Descrição da idade materna, idade gestacional, paridade e IMC das 190 gestantes submetidas à avaliação do colo uterino pela ultrassonografia transvaginal para predição do sucesso da indução do parto. HU-USP, fevereiro de 2008 a fevereiro de 2010 (página 56)

Tabela 3- Descrição do Índice de Bishop, Tempo entre IP e parto, Tempo de trabalho de parto, peso dos RN e variáveis ultrassonográficas das 190 gestantes submetidas à avaliação do colo uterino pela ultrassonografia transvaginal para predição do sucesso da IP. HU-USP, fevereiro de 2008 a fevereiro de 2010 . (página 63)

Tabela 4- Descrição das medidas ultrassonográficas, segundo o tipo de parto e testes de comparação, das 190 gestantes submetidas à avaliação do colo uterino pela ultrassonografia transvaginal para predição do sucesso da IP. HU-USP, fevereiro de 2008 a fevereiro de 2010 .(página 67)

Tabela 5- Descrição da variável ultrassonográfica imagem em funil, segundo o tipo de parto e testes de comparação, das 190 gestantes submetidas à avaliação do colo uterino pela ultrassonografia transvaginal para predição do sucesso da IP. HU-USP, fevereiro de 2008 a fevereiro de 2010......(página 68)

Tabela 6- Descrição das medidas ultrassonográficas, segundo o desfecho parto vaginal em até 24 horas após a IP e testes de comparação, das 190 gestantes submetidas à avaliação do colo uterino pela ultrassonografia transvaginal para predição do sucesso da IP. HU-USP, fevereiro de 2008 a fevereiro de 2010 . (página 69)

Tabela 7- Descrição da variável ultrassonográfica imagem em funil, segundo a ocorrência de parto vaginal em até 24 horas após o início da IP e testes de comparação, das 190 gestantes submetidas à avaliação do colo uterino pela ultrassonografia transvaginal para predição do sucesso da IP- HU-USP, fevereiro de 2008 a fevereiro de 2010. (página 70)

Tabela 8- Descrição das medidas ultrassonográficas, segundo o desfecho fase ativa do parto e testes de comparação, das 190 gestantes submetidas à avaliação do colo uterino pela ultrassonografia transvaginal para predição do sucesso da IP. HU-USP, fevereiro de 2008 a fevereiro de 2010......(página 71) 
Tabela 9- Descrição da variável ultrassonográfica imagem em funil, segundo a presença da fase ativa do parto, ou trabalho de parto ativo após o início da IP e testes de comparação, das 190 gestantes submetidas à avaliação do colo uterino pela ultrassonografia transvaginal para predição do sucesso da IP. HU-USP, fevereiro de 2008 a fevereiro de 2010 (página 72)

Tabela 10- Descrição do Índice de Bishop, segundo os desfechos: sucesso da IP, parto vaginal em 24 horas após a IP, fase ativa do parto e testes de comparação, das 190 gestantes submetidas à avaliação do colo uterino pela ultrassonografia transvaginal para predição do sucesso da IP. HU-USP, fevereiro de 2008 a fevereiro de 2010. .(página 73)

Tabela 11- Descrição da IM, IG, paridade, IMC, segundo o tipo de parto e testes de comparação, das 190 gestantes submetidas à avaliação do colo uterino pela ultrassonografia transvaginal para predição do sucesso da IP. HU-USP, fevereiro de 2008 a fevereiro de 2010. .(página 74)

Tabela 12- Descrição da IM, IG, paridade, IMC, segundo o desfecho presença de trabalho de parto ativo após a IP e testes de comparação, das 190 gestantes submetidas à avaliação do colo uterino pela ultrassonografia transvaginal para predição do sucesso da IP. HU-USP, fevereiro de 2008 a fevereiro de 2010. (página 75)

Tabela 13- Descrição da IM, IG, paridade, IMC, segundo o desfecho parto vaginal em até 24 horas após a IP e testes de comparação, das 190 gestantes submetidas à avaliação do colo uterino pela ultrassonografia transvaginal para predição do sucesso da IP. HU-USP, fevereiro de 2008 a fevereiro de 2010 . (página 76)

Tabela 14- Resultado dos modelos de regressão logística para os desfechos da IP, sem a variável Índice de Bishop, das 190 gestantes submetidas à avaliação do colo uterino pela ultrassonografia transvaginal para predição do sucesso da IP. HU-USP, fevereiro de 2008 a fevereiro de 2010......(página 79)

Tabela 15- Resultado dos modelos de regressão logística para os desfechos da IP, com a variável Índice de Bishop, das 190 gestantes submetidas à avaliação do colo uterino pela ultrassonografia transvaginal para predição do sucesso da IP. HU-USP, fevereiro de 2008 a fevereiro de 2010......(página 81) 
Tabela 16- Resultado das correlações intraclasse e interobservadores com os respectivos intervalos de confiança, das 190 gestantes submetidas à avaliação do colo uterino pela ultrassonografia transvaginal para predição do sucesso da IP. HU-USP, fevereiro de 2008 a fevereiro de 2010.......(página 87)

Tabela 17- Resultado das correlações de Pearson entre I-Bishop e os parâmetros ultrassonográficos, das 190 gestantes submetidas à avaliação do colo uterino pela ultrassonografia transvaginal para predição do sucesso da IP. HU-USP, fevereiro de 2008 a fevereiro de 2010. (página 88)

Tabela 18- Comparação das variáveis ultrassonográficas, comprimento do colo,distância da apresentação fetal ao OCE e dilatação cervical, segundo o tipo de parto, para I-Bishop $>\mathrm{e}<6$, em 190 gestantes submetidas à avaliação do colo uterino pela ultrassonografia transvaginal para predição do sucesso da IP. HU-USP, fevereiro de 2008 a fevereiro de 2010......(página 91)

Tabela 19- Comparação das variáveis ultrassonográficas, comprimento do colo,distância da apresentação fetal ao OCE e dilatação cervical, segundo o desfecho parto vaginal em 24 horas, para I-Bishop > e < 6, em 190 gestantes submetidas à avaliação do colo uterino pela ultrassonografia transvaginal para predição do sucesso da IP. HU-USP, fevereiro de 2008 a fevereiro de 2010 . (página 92)

Tabela 20- Comparação das variáveis ultrassonográficas, comprimento do colo, distância da apresentação fetal ao OCE e dilatação cervical, segundo o desfecho trabalho de parto ativo, para I-Bishop $>$ e $<6$, em 190 gestantes submetidas à avaliação do colo uterino pela ultrassonografia transvaginal para predição do sucesso da IP. HU-USP, fevereiro de 2008 a fevereiro de 2010 (página 93) 
RESUMO 
Pitarello PRP. Avaliação do colo uterino pela ultrassonografia transvaginal para predição do sucesso da indução do parto [Dissertação]. São Paulo: Faculdade de Medicina, Universidade de São Paulo; 2011.122p.

Objetivo: Correlacionar as variáveis ultrassonográficas do colo uterino ao sucesso da indução do parto e ao Índice de Bishop. Métodos: Estudo observacional prospectivo envolvendo 190 gestantes candidatas à indução do parto, que foram submetidas à ultrassonografia transvaginal para avaliação do comprimento do colo uterino, da distância da apresentação fetal ao OCE, dilatação cervical e identificação da imagem em funil no $\mathrm{OCl}$, no período de fevereiro de 2008 a fevereiro de 2010. As pacientes foram categorizadas segundo o escore de Bishop em favoráveis e desfavoráveis à IP. Os seguintes desfechos foram analisados: probabilidade de sucesso da IP, parto vaginal em 24 horas e presença de fase ativa do parto. A análise estatística foi realizada usando testes qui-quadrado, teste t-Student e MannWhitney para as variáveis numèricas, além do cálculo das curvas ROCs para cada variável e cada desfecho. Através de regressão logística foram avaliados os preditores dos desfechos assim como determinadas equações de probabilidade dos eventos. Resultados: O sucesso da IP, o parto vaginal em 24 horas e a presença de fase ativa do parto foram observados em 133 $(70 \%) 119(62 \%)$ e $155(82 \%)$ das gestantes, respectivamente. O comprimento do colo uterino, a distância da apresentação fetal ao OCE, a dilatação cervical e a presença da imagem em funil no $\mathrm{OCl}$ influenciaram o sucesso da IP, a presença de parto vaginal em 24 horas e a presença de fase ativa do parto, principalmente em gestantes com escore de Bishop desfavorável à IP. As variáveis ultrassonográficas apresentaram sensibilidade entre 63 e $71 \%$ e especificidade entre 63 e 82\% e acurácia média de $70 \%$. O escore de Bishop se correlacionou diretamente à dilatação cervical e inversamente ao comprimento do colo uterino e à distância da apresentação fetal ao OCE e foi preditor independente de todos os desfechos da indução do parto $(p<0,001)$. Conclusão: $O$ comprimento do colo uterino, a distância da apresentação fetal ao OCE, a dilatação cervical e presença da imagem em funil no OCl se relacionaram ao sucesso da IP, porém com baixo poder de predição.

Descritores: 1. Colo uterino/ Ultrassonografia 2. Trabalho de parto induzido 3. Comprimento do colo do útero 4. Sucesso da indução do parto 
SUMMARY 
Pitarello PRP. Cervix evaluation by transvaginal ultrasound for success prediction on labor induction [dissertation]. São Paulo: "Faculdade de Medicina, Universidade de São Paulo"; 2011.122p

Objective: To correlate the ultrasonographic variables of cervix to the success on labor induction (LI) and Bishop's Index. Methods: A prospective, observational study involving 190 pregnant women that were applicant for labor induction, submitted to transvaginal ultrasound to evaluate the cervix's length, fetal head-external os distance, cervical dilatation and identification of funnel image on internal os, during the period between February 2008 and February 2010. Patients were classified according to Bishop's score as favorable and unfavorable to labor induction. The following conclusions were studied: success probability to LI, vaginal delivery in 24 hours and presence of labor's active phase. Statistical analysis was performed using chi-square tests, t-Student and Mann-Whitney test for numerical variables, in addition to ROCs curves calculation for each variable and each conclusion. By logistic regression, the conclusion predictors were evaluated, as well as some determined equations from events' probability. Results: The labor induction success, vaginal delivery in 24 hours, and presence of labor's active phase were noticed on $133(70 \%), 119(62 \%)$ and $155(82 \%)$ pregnant women, respectively. Cervix's length, fetal head-external os distance, cervical dilatation and identification of funnel image on internal os influenced the LI success, vaginal delivery at 24 hours and presence of labor's active phase, especially on pregnant with Bishop's score unfavorable to labor induction. Ultrasonographic variables had sensitivity between 63 and $71 \%$, specificity between 63 and $82 \%$, and $70 \%$ of average accuracy. Bishop's score was directly correlated to cervical dilatation and inversely correlated to cervix's length and fetal head-external os distance and was a independent predictor to all conclusions of labor induction $(p<0.001)$. Conclusion: The cervix's length, fetal head-external os distance, cervical dilatation and identification of funnel image were related to LI success but with low prediction potency.

Descriptors: 1. Cervix / Ultrasound

2. Labor induced 3. Cervical lenght

4. Sucessful labor induction 
1 INTRODUÇÃO 
A indução do parto (IP) é a iniciação artificial deste antes de seu desencadeamento espontâneo com o intuito de antecipar o parto da unidade fetoplacentária ${ }^{(1)}$. Esta representa uma das intervenções mais comuns em Obstetrícia, tanto que recentemente a taxa de indução do parto dobrou de 9,5\% em 1991, para 20,6\% em 2003 (2), estando sua frequência seguramente aumentada no pós datismo ${ }^{(3)}$. Nos EUA houve elevação considerável da IP, sendo descritos valores de $20 \%$ em 1989 e $38 \%$ em $2002{ }^{(4)}$. A IP deve ser considerada quando o benefício do parto vaginal superar os potenciais riscos para a mãe e para o feto, como por exemplo, aumento da taxa de partos operatórios ${ }^{(4)}$, cesáreas ${ }^{(4,5)}$, hiperatividade uterina, padrões anormais da frequência cardíaca fetal ${ }^{(1)}$ e eventualmente parto prematuro em casos em que a datação da idade gestacional foi incorreta. As indicações mais comuns da indução do parto são: pós datismo, gestação prolongada, oligoâmnio, doenças sistêmicas maternas, como hipertensão e diabetes melittus ou gestacional, restrição de crescimento fetal, dentre outras.

Estima-se que a principal indicação para a IP seja o pós datismo, que é caracterizado como o período da gestação entre 40 e 42 semanas. 
Em gestações pós data, o risco de óbito intrauterino e pós natal aumenta de 2,4 casos por 1000 gestações com 40 semanas e 5,8 óbitos com idade gestacional de 43 semanas ${ }^{(6)}$. Desse modo, inúmeros estudos destacam que a conduta ativa, ou seja, indução do parto em gestações pós data contribui significativamente para a redução da morbimortalidade perinatal ${ }^{(7)}$.

A indução do parto geralmente é prolongada e necessita de maior dose e tempo de analgesia, e monitorações materna e fetal mais intensivas, além de estar associada a maior custo, risco de partos operatórios e de emergência com resultados maternos e perinatais por vezes desfavoráveis, quando comparada aos partos conduzidos espontaneamente ${ }^{(8)}$. Estudos recentes demonstram taxas de cesárea de aproximadamente $35 \%$ em primigestas cujos partos foram induzidos por pós-datismo ${ }^{(9)}$ e $20 \%$ em mulheres submetidas a procedimentos para indução ${ }^{(10,11)}$, principalmente por falha deste processo, falha na progressão do parto e sofrimento fetal. Desse modo, o maior desafio da indução do parto nos dias atuais é justamente tentar predizer quais pacientes terão sucesso ou insucesso com essa conduta. Isso se aplica a todos os casos, e principalmente às situações de indução eletiva do parto, que atualmente contribui com $25 \%$ de todos os casos de indução do parto ${ }^{(12)}$.

A IP, seja por indicação médica ou por decisão da paciente, denominada indução eletiva, está associada a um aumento na taxa de cesáreas, particularmente em pacientes nulíparas e ou com colo 
desfavorável à indução ${ }^{(13)}$. Isso se deve basicamente às condições do colo uterino (que incluem dilatação, posição, consistência e forma), e influenciam nos resultados da indução do parto, bem como na escolha do método da indução.

O ponto central na questão da indução do parto são justamente os riscos da falha da indução, e nesse sentido novas ferramentas vêm sendo utilizadas e desenvolvidas para predizer o sucesso ou insucesso da IP.

Crane (2006) (1) relatou que existem variáveis maternas, fetais, novas ferramentas, como o uso da ultrassonografia transvaginal do colo uterino e marcadores bioquímicos como a fibronectina fetal, fator de crescimento Insulina-like e fatores de ligação à proteína 1, que podem ser preditores do sucesso ou insucesso da indução do parto. Dentre os fatores maternos destacam-se o estado cervical, que é um dos preditores mais importantes do sucesso da indução. Trata-se da avaliação pré indução das condições do colo uterino, realizada por meio de sistemas de escores clínicos. Tradicionalmente, utiliza-se como método padrão para a determinação de protocolos de indução e predição da IP o exame digital transvaginal, que avalia as condições do colo uterino, denominado escore de Bishop (1964) ${ }^{(14)}$. Com esse intuito, no nosso meio é empregado o escore de Bishop (Figura 1) ${ }^{(1)}$, o qual categoriza as pacientes em escore favorável (índice $>$ ou $=6$ ) e desfavorável à indução do parto (índice < 6), e desse modo estima as chances de sucesso e falha na obtenção do parto vaginal. 
No entanto, os escores clínicos apresentam variáveis subjetivas com valores preditivos baixos ${ }^{(15)}$, além de limitações em pacientes com escores baixos $(<6)$, que são frequentes quando a indicação da indução do parto é por razões médicas ${ }^{(16)}$.

Apesar de o escore de Bishop ser reconhecido como uma ferramenta útil e largamente utilizada, alguns estudos questionam a acurácia e subjetividade desse método no que diz respeito a sua variação intra e interobservador, demonstrando que esse índice apresenta um baixo poder de predição dos resultados da indução do parto ${ }^{(14,17,18,1)}$. Na tentativa de reduzir a subjetividade e variação dos escores clínicos, novos métodos vêm sendo descritos e utilizados no processo da indução do parto, e dentre estes está a ultrassonografia transvaginal do colo uterino. Já foi demonstrado que aproximadamente $50 \%$ do comprimento do colo uterino não é palpável ao exame digital, devido principalmente à localização do segmento supravaginal deste. Assim, a ultrassonografia transvaginal do colo uterino, por ter acesso mais amplo a essa região, permite a realização de medidas mais fidedignas e eficientes dos parâmetros do colo uterino, o que contribui para o aumento da acurácia do método na predição do sucesso e insucesso da indução do parto. É nesse preceito que se baseia a análise da ultrassonografia transvaginal do colo uterino na IP, objetivando, assim, o desenvolvimento de um método mais preciso e eficiente no intuito de reduzir os riscos de cesárea, morbidade materna e fetal, bem como reduzir tempo e custos envolvidos no processo da indução do parto. 
Diversos estudos têm demonstrado benefício da ultrassonografia transvaginal do colo uterino na predição do sucesso da indução do parto. 0 comprimento do colo inferior a $26 \mathrm{~mm}$ em pacientes com escore de Bishop desfavorável à indução se relacionou significativamente com baixo índice de cesárea ${ }^{(19)}$, bem como o comprimento cervical inferior a $24 \mathrm{~mm}$ foi considerado preditor do sucesso da indução do parto, ou seja, parto vaginal em gestantes submetidas à indução do parto ${ }^{(20)}$. No entanto, outros estudos não demonstraram correlação entre a medida transvaginal do comprimento cervical e o sucesso da indução do parto ${ }^{(21,22)}$.

Nesse sentido, o presente estudo tem como objetivo avaliar as características do colo uterino ao exame de ultrassonografia transvaginal na predição do sucesso da indução do parto, com o intuito de se subtrair a subjetividade do índice clínico de Bishop. Além disso, outros fatores maternos serão analisados para avaliar a influência destes nas medidas ultrassonográficas do colo uterino, bem como no sucesso da indução do parto. Assim, propusemo-nos a realizar este estudo prospectivo com o intuito de avaliar a utilização da ultrassonografia transvaginal na predição do sucesso da indução do parto e, desse modo, auxiliar na criação de protocolos de indução mais seletivos, diminuindo, assim, os custos e as potenciais falhas do método. 
2 REVISÃO DA LITERATURA 
Estudos recentes têm avaliado o uso da ultrassonografia transvaginal na análise dos parâmetros do colo uterino na indução do parto. Isso se deve ao fato de que a ultrassonografia envolve métodos mais objetivos que o exame digital, podendo reduzir, assim, a variação intra e interobservador ${ }^{(16)}$. Além disso, a ultrassonografia transvaginal permite a visualização do colo acima do orifício cervical externo fechado, ou impérvio.

Já foi demonstrado que aproximadamente $50 \%$ do comprimento do colo uterino não é palpável pelo exame de toque, devido principalmente ao segmento supravaginal deste. A ultrassonografia transvaginal, por ter acesso mais amplo a essa região, permite a realização de uma medida mais fiel e eficiente dos parâmetros do colo uterino, e é nesse preceito que se baseia toda a análise dessa ferramenta na indução do parto. Desse modo, utilizando um método mais preciso na indução de parto, estaremos reduzindo os riscos de cesárea e morbidade materna e fetal, bem como reduzindo tempo e custos.

No entanto, artigos de diferentes países têm demonstrado uma grande variação na acurácia e técnica desse novo método, bem como na predição do sucesso da indução do parto, necessitando, assim, de mais 
estudos para a padronização e utilização da ultrassonografia transvaginal na indução do parto. Estudos prévios têm descrito o uso da ultrassonografia transvaginal como fator preditivo do risco de parto prematuro relacionando inversamente o comprimento cervical à incidência de parto prematuro ${ }^{(23)}$. Utilizando o mesmo princípio descrito, ou seja, a potencial vantagem do acesso ultrassonográfico transvaginal do colo uterino em detrimento ao exame digital, seu uso tem sido ampliado também para a predição do sucesso da indução do parto.

A avaliação da eficácia da ultrassonografia transvaginal na indução do parto tem sido estudada ao longo de aproximadamente vinte e cinco anos, demonstrando heterogeneidade na literatura quanto à definição do sucesso da indução, bem como dos resultados da avaliação dos parâmetros ultrassonográficos e clínicos envolvidos nesse processo. Considerando a heterogeneidade de objetivos e resultados dos estudos da literatura vigente, a revisão da literatura ora apresentada segue a cronologia do desenvolvimento dos estudos envolvendo a utilização da ultrassonografia transvaginal na indução do parto.

Um dos primeiros estudos envolvendo o presente tema foi desenvolvido por Paterson-Brown et al. (1991) ${ }^{(21)}$. Estes realizaram uma coorte prospectiva com 50 pacientes que seriam submetidas à indução do parto e utilizaram a ultrassonografia transvaginal para a medida do comprimento do colo uterino, largura, dilatação do colo (medida de 
espessura da linha endocervical anecogênica), distância do vértice da apresentação fetal ao orifício cervical externo (altura da apresentação), e ângulo posterior do colo (ângulo entre a linha endocervical e a parede vaginal posterior, com o intuito de estimar a posição do colo uterino), espessura do segmento inferior do útero, aplicabilidade do método, além da realização do exame digital do colo uterino (escore de Bishop), na predição do sucesso da indução do parto, que era o parto vaginal. Como resultados, obtiveram que o escore de Bishop foi menor nas 7 pacientes que evoluíram para cesárea em relação a 43 pacientes que evoluíram para parto vaginal ( $p$ $<0,017)$. Além disso, as medidas ultrassonográficas como comprimento do colo uterino, dilatação, altura da apresentação, largura do colo, espessura do segmento inferior e aplicabilidade do método foram semelhantes em ambos os grupos (pacientes que evoluíram para parto vaginal e cesárea). O ângulo posterior do colo foi mais agudo em pacientes submetidas à cesárea (60 graus) em detrimento das que evoluíram para parto vaginal (90 graus, $p=$ $0,002)$.

O ângulo de 90 graus demonstrou a melhor predição do sucesso da indução do parto, comparado ao escore de Bishop (Kappa $=0,48 \times 0,21$, respectivamente). Pacientes relataram ainda menor desconforto com a realização do exame ultrassonográfico em comparação ao exame digital. Assim, os autores concluíram que a associação de escore de Bishop superior a 5 (colo favorável) com a medida do ângulo posterior do colo uterino superior a 70 graus representou o melhor modelo preditor do 
sucesso da indução de parto (sensibilidade de $88 \%$ e especificidade de $100 \%$, Kappa $=0,68)$.

Em 1994, Boozarjomehri et al. ${ }^{(24)}$ desenvolveram um estudo para testar a hipótese da utilização da ultrassonografia transvaginal do colo uterino na predição da duração do parto pós IP. Realizaram um estudo prospectivo com 53 gestantes de termo, que foram submetidas à indução do parto por diferentes indicações clínicas. Após os procedimentos iniciais para determinação do método da indução do parto, as pacientes eram submetidas à ultrassonografia transvaginal para a avaliação do comprimento do colo uterino, bem como definir a presença da imagem em $U$ ou $V$ semelhante a um funil e adentrando o orifício cervical interno, e a presença de dilatação do colo uterino, apresentada como a presença de qualquer abertura no canal endocervical. Esse exame era seguido de outros periódicos, a cada 4 a 6 horas, até a presença de contrações uterinas regulares e mudanças cervicais (dilatação superior a $3-4 \mathrm{~cm}$, e esvaecimento de 90 a 100\%) que configurassem o término da fase latente e início da fase ativa do parto. Trinta e uma pacientes, das 53 totais, apresentaram imagem em funil pela ultrassonografia transvaginal, sendo que não houve diferenças no grupo com imagem e sem imagem em funil quanto à idade materna, idade gestacional e esvaecimento clínico. Notou-se uma tendência à paridade superior, desejo de indução eletiva no grupo com imagem em funil, em detrimento do maior uso de prostaglandinas no outro grupo. Os autores notaram que a presença da imagem em funil esteve 
associada a uma maior dilatação clínica $(1,00 \mathrm{~cm} \times 0,48 \mathrm{~cm}, \mathrm{p}=0.022)$, menor comprimento cervical (28 mm x $34.8 \mathrm{~mm}, \mathrm{p}<0.001)$, menor duração da fase latente do parto $(15,9$ horas $\times 34,1$ horas, $p<0.001)$, e menor duração do intervalo entre indução e parto $(22,0$ horas x 38,3 horas, $p<$ 0.001) em comparação ao grupo em que essa imagem não foi identificada. O comprimento cervical obtido pela ultrassonografia transvaginal não se relacionou ao esvaecimento obtido pelo exame digital $(r=0,227, p=0.102)$, assim como a dilatação ultrassonográfica não demonstrou associação à dilatação clínica $(r=0,168, p=0,230)$. Desse modo, a presença à ultrassonografia da imagem em funil se associou significativamente à menor duração da fase latente, bem como da duração de todo o processo do parto. A dilatação obtida pelo exame digital mostrou-se associada à menor duração da fase latente $(r=-0,4215, p=0.003)$ e do parto $(r=-0,3987, p=0.003)$. $O$ mesmo não se aplicou ao esvaecimento clínico, que não demonstrou associação à duração, tanto da fase latente como do próprio trabalho de parto $(r=-0,0820, p=0.576$ e $r=-0,0720, p=0.608$, respectivamente).

Assim, concluíram que maiores comprimentos cervicais estiveram relacionados à maior duração da fase latente do parto. Já a paridade, presença de imagem de funil no orifício cervical interno e o escore de Bishop não foram preditores do sucesso da indução do parto, bem como do intervalo entre indução e parto e presença de fase ativa do parto. Os autores concluíram que a presença da imagem em forma de funil foi capaz de predizer com acurácia a duração da fase latente e duração do trabalho de parto. 
Watson et al. (1996) ${ }^{(22)}$ propuseram um estudo para avaliar a paridade materna, o comprimento cervical pela ultrassonografia transvaginal e os cinco componentes do escore de Bishop na predição da duração da fase latente do parto em gestantes submetidas à indução do parto. Foram incluídas 109 gestantes com idade gestacional entre 36 e 43 semanas, sendo 40 nulíparas e 69 multíparas, com critérios de indicação para indução do parto. O sucesso da indução do parto foi definido pela presença da fase ativa do trabalho de parto. A dilatação cervical foi o único parâmetro preditor da duração da fase latente do parto após o controle do outros fatores envolvidos, sendo que a fase latente apresentou duração média de 10,1 horas (2 a 36 horas). O modelo final demonstrou uma relação inversa e significativa entre o logaritmo natural da duração da fase latente do parto e o grau de dilatação $(r=0,49, F=32,1, p<0.001)$. Os resultados demonstraram ainda, relação entre a determinação clínica do esvaecimento do colo uterino e a medida ultrassonográfica transvaginal do comprimento cervical $(r=-0,523, p<0.001)$, além de correlação linear entre a dilatação e o esvaecimento clínico $(r=0,37, p<0.001)$.

Assim, os autores concluíram que os resultados do presente estudo foram consistentes com estudos prévios, demonstrando que a dilatação cervical clínica é o fator preditor mais importante do escore de Bishop, bem como confirmando os achados de que a paridade não se mostrou preditora da duração da fase latente do parto. Além disso, demonstraram que a 
medida ultrassonográfica do comprimento cervical aparentemente não se relacionou ao objetivo primário.

Munoz et al. (1997) ${ }^{(25)}$ e Ware e Raynor $(2000)^{(26)}$ relataram que ambos o comprimento cervical e o escore de Bishop demonstraram correlação com a evolução para o parto vaginal, sendo que o índice cervical (medida transvaginal do colo uterino dividida pelo diâmetro ântero-posterior) foi um fator preditor independente da ocorrência do parto vaginal.

Khoury et al. (1997) ${ }^{(27)}$ e Ware e Raynor $(2000)^{(26)}$ demonstraram que gestantes que apresentaram comprimento cervical inferior a 30 milímetros evoluíram mais frequentemente para parto vaginal $(73 \%, p=$ 0.01) com menor duração do trabalho de parto, em comparação às pacientes com comprimento cervical superior.

Gonen et al. (1998) ${ }^{(28)}$, com o objetivo de comparar a ultrassonografia transvaginal ao escore de Bishop na predição do sucesso da indução do parto, realizaram um estudo prospectivo e observacional em 86 gestantes com critérios médicos para a indução do parto. O comprimento médio do colo uterino foi de $30 \mathrm{~mm}$ (IC de $95 \%$ - 28-33 mm), sendo que as multíparas apresentaram colos mais longos $(32 \mathrm{~mm})$ em comparação às nulíparas $(29 \mathrm{~mm})$, bem como maior presença de imagem de funil no orifício cervical interno ( $47 \% \times 43 \%$, respectivamente) e escore de Bishop superior em relação às nulíparas $(5,4 \times 4,8)$. $O$ escore de Bishop e o comprimento cervical se relacionaram significativamente ao sucesso da indução do parto 
$(p=0.001$ e $p=0.006$, respectivamente $)$ e a duração do trabalho de parto $(r$ $=-0,42$ com $p=0.02$ e $r=0,36$ com $p=0.008$ ), sendo que os valores preditores para o sucesso da indução foram: comprimento cervical inferior a $27 \mathrm{~mm}$ (sensibilidade de 59\%, especificidade de $78 \%$, acurácia de $66 \%$ ) e Bishop superior a 5 (sensibilidade de $65 \%$, especificidade de $78 \%$, acurácia de $70 \%$ ). A presença da imagem em funil no $\mathrm{OCI}$ foi preditora do sucesso da indução $(p=0.009)$, porém o mesmo não se aplicou à duração do trabalho de parto. Em análise de regressão logística múltipla, após o controle de fatores de confusão e incluindo como variáveis independentes o Bishop, comprimento cervical, paridade e imagem em funil do $\mathrm{OCl}$, somente $\mathrm{o}$ escore de Bishop $(p=0.005)$ e a paridade $(p=0.01)$, se relacionaram significativamente ao sucesso da indução e duração do parto.

Assim, apesar de a medida transvaginal do comprimento cervical estar associada ao sucesso da indução e duração do parto, esta não contribuiu para implementar ou melhorar a predição do sucesso da indução, em relação ao método já previamente utilizado, o escore de Bishop.

Ware e Raynor (2000) ${ }^{(26)}$ compararam a ultrassonografia transvaginal com a medida do comprimento do colo uterino e o escore de Bishop na predição da duração do trabalho de parto e do sucesso da indução do parto. O escore de Bishop, bem como o comprimento cervical apresentaram uma relação linear com a duração do trabalho de parto $(\mathrm{r} 2=$ $0,48, p<0.001$ e r2 $=0,43, p<0.001$, respectivamente ). Quanto ao tipo de 
parto, pacientes com comprimento cervical inferior a $3.0 \mathrm{~cm}$ e escore de Bishop superior a 4 apresentaram maior probabilidade de evoluir para parto vaginal $(p<0.001)$. Baseado na avaliação pela curva ROC, o valor de 3.0 $\mathrm{cm}$, utilizado como ponto de corte, foi o melhor preditor para o parto vaginal, apresentando sensibilidade de 0.91 e especificidade de 0.92. Após a análise realizada por regressão logística e incluindo a paridade, o escore de Bishop, o comprimento cervical, o agente indutor do parto e o tipo de parto, os autores definiram que o comprimento cervical $(r 2=0,28, p<0.002)$ e a paridade $(r 2=-0,16, p<0.04)$ foram preditores independentes do tipo de parto. O presente estudo reforça a utilização da ultrassonografia transvaginal da indução do parto como uma ferramenta tão útil e reprodutível quanto o escore de Bishop, já que ambos se mostraram eficazes na predição da duração do trabalho e no tipo de parto.

Pandis et al. (2001) ${ }^{(7)}$, em estudo randomizado envolvendo 240 gestantes com idade gestacional entre 37 e 42 semanas e candidatas à indução do parto, avaliaram a relação entre o comprimento cervical e o sucesso da IP. O parto vaginal ocorreu em $194(80,8 \%)$ pacientes, sendo que dessas, $142(73,2 \%)$ evoluíram com o sucesso da indução do parto, que no presente estudo foi definido como a ocorrência de parto vaginal em 24 horas após o início da indução do parto. Os autores concluíram que houve relação entre o escore de Bishop $(r=0,5156, p<0.0001)$ e o intervalo entre indução e parto, assim como o comprimento cervical e o intervalo entre indução e parto $(r=0.7061, p<0.0001)$. Além disso, houve associação entre 
o escore de Bishop e o comprimento cervical $(r=0.6434, p<0.0001)$. A análise da curva ROC demonstrou que o comprimento cervical inferior a 28 $\mathrm{mm}$ e o escore de Bishop superior a 3 foram preditores do sucesso da indução do parto, apresentando sensibilidade e especificidade de 0.87 e 0.71 e 0.58 e 0.77 , respectivamente. Em virtude disso, a medida ultrassonográfica do comprimento cervical se mostrou melhor preditora do sucesso da indução do parto que o escore de Bishop.

Em 2001, Chandra et al. (29) compararam a ultrassonografia transvaginal e o exame digital (escore de Bishop) na predição da ocorrência de parto vaginal após IP. Como objetivos secundários, avaliaram ainda a ocorrência do parto vaginal em 12 e 24 horas, bem como estimaram o desconforto das pacientes ao exame transvaginal por meio de uma escala de dor. Nenhuma das medidas ultrassonográficas (comprimento do colo, dilatação e presença do funil) pode predizer o objetivo primário (parto vaginal) ou os objetivos secundários, já que a curva ROC falhou em identificar um valor apropriado de corte para as variáveis contínuas relacionadas às medidas ultrassonográficas. Já o escore de Bishop (OR 2,98 - IC de 95\% (1,71-5,20)), a posição do colo (OR 4,35 - IC de 95\% $(1,41$ 12,50)), e a idade materna (OR 1,15 - IC de 95\% (1,01-1,30)) foram preditores independentes do sucesso da indução do parto.

Como fatores independentes preditores de parto vaginal em 12 horas estão: método de indução ( $p<0,001)$, dilatação cervical (OR 11,16 IC de $95 \%(3,17-39,29)$ ) e peso materno (OR 0,96 - IC de 95\% $(0,93-0,99)$ ). 
O esvaecimento cervical (OR 2,70 - IC de 95\% $(1,59-4,27)$ ) e a paridade (OR 7,10 - IC de $95 \%(2,22-22,72)$ ), foram variáveis independentes e eficazes na predição do parto vaginal em 24 horas do início da indução. Quanto à questão do desconforto na realização do exame transvaginal em comparação ao exame digital, o estudo concluiu que o desconforto postulado pela escala visual foi menor com o uso da ultrassonografia transvaginal em detrimento do exame digital, com diferença média de 3,95 e $p<0.001$. Assim, a ultrassonografia transvaginal não se demonstrou melhor preditor do sucesso da indução do parto em gestações pós data em comparando-se ao exame digital do colo uterino.

Gabriel et al. (2002) ${ }^{(19)}$ avaliaram 179 gestantes (86 primíparas e 93 multíparas) nas quais os partos foram induzidos no intuito de comparar o escore de Bishop à medida transvaginal do colo uterino quanto à predição do tipo de parto. As curvas ROC do escore de Bishop e do comprimento cervical na predição do risco de cesárea demonstraram ponto de corte de 5 para o escore de Bishop, com sensibilidade de $66 \%$ e especificidade de 49\%. Já para o comprimento cervical esse ponto foi de 26 milímetros com sensibilidade de $62 \%$ e especificidade de $61 \%$. Em pacientes com escore de Bishop inferior a 5, o comprimento cervical se relacionou significativamente à taxa de cesárea e à duração do intervalo entre indução, sendo que no grupo com comprimento cervical superior a $26 \mathrm{~mm}$ a taxa de cesárea foi de $42,9 \%$ em relação ao outro, que apresentou parto cesárea em 20,6\% das pacientes $(p=0.006)$. 
Desse modo, Gabriel et al. (2002) ${ }^{(19)}$ demonstraram que para pacientes com escore de Bishop inferior a 5, a medida transvaginal do comprimento do colo uterino inferior a 26 milímetros se associou a menor risco de cesárea, bem como o oposto. Logo, em pacientes com colos desfavoráveis à indução do parto, a ultrassonografia do colo uterino auxiliou na separação destas em dois grupos com resultados obstétricos diversos, o que não ocorreu para pacientes com colos favoráveis à indução.

Rane et al. (2003) ${ }^{(30)}$, em estudo com 382 gestantes candidatas à indução do parto, avaliaram o efeito da paridade e da medida ultrassonográfica do comprimento cervical na predição do intervalo entre indução e parto e o sucesso da indução, que no presente estudo foi definido como parto vaginal em 24 horas após o início da indução. As pacientes foram divididas em dois grupos principais de acordo com a paridade, ou seja, nulíparas e multíparas, bem como em quatro subgrupos de acordo com o comprimento cervical apresentado (1-10, 11-20, 21-30, 31-40 mm). O intervalo e o sucesso da indução se relacionaram significativamente com a paridade, demonstrando menor intervalo $(p<0.0001)$ e maior taxa de sucesso $(p<0.0001)$ em multíparas em detrimento das nulíparas. O melhor parâmetro preditor do parto vaginal em 24 horas foi o comprimento cervical, apresentando na análise da curva ROC e ponto de corte de $24 \mathrm{~mm}$ sensibilidade de $84 \%$ e especificidade de $59 \%$. O comprimento cervical também se associou significativamente à duração do intervalo entre indução e parto ( $p<0.0001$ ). Logo, a medida transvaginal do comprimento cervical e 
a paridade foram preditores significativos e independentes da duração do intervalo entre indução e parto, bem como do sucesso da indução do parto.

Novamente Rane et al. (2003) ${ }^{(20)}$ estudaram o efeito da paridade relacionada ao comprimento cervical e ao risco de cesárea em gestantes submetidas à indução por pós datismo. A taxa de cesárea desse estudo foi de $18,9 \%$ (71 pacientes), estando significativamente associada à paridade (28,1\% em nulíparas e $8,1 \%$ em multíparas, $p<0.0001)$ e ao comprimento cervical, que apresentou área sobre a curva ROC de 0.72 para o parto cesáreo. Após análise de regressão logística, os autores concluíram que o comprimento cervical e a paridade foram preditores independentes do risco de cesárea e, desse modo, a chance de evolução para cesárea aumentava $10 \%$ para cada aumento de $1 \mathrm{~mm}$ no comprimento cervical determinado como ponto de corte de $20 \mathrm{~mm}$ para nulíparas e $18 \mathrm{~mm}$ para multíparas. Além disso, demonstrou-se que para um mesmo comprimento cervical a chance de uma multípara evoluir para cesárea é $75 \%$ menor em comparação às nulíparas, confirmando, assim, a relação entre paridade, comprimento cervical e risco de cesárea desenvolvida no presente estudo.

Rane et al. (2004) ${ }^{(31)}$ avaliaram o valor da ultrassonografia transvaginal pré-indução do parto na predição do intervalo entre indução e parto em 24 horas, bem como estimaram a probabilidade de parto vaginal em 24 horas, probabilidade de cesárea, além de comparação das medidas ultrassonográficas ao escore de Bishop. A ultrassonografia transvaginal visou a medida do comprimento cervical e do ângulo cervical posterior 
(ângulo entre o canal endocervical e parede posterior da vagina). Além disso, realizaram o exame por via transabdominal para a determinação da posição do occipício. A análise de regressão logística demonstrou que o comprimento cervical e paridade foram preditores independentes da probabilidade de parto vaginal em 24 horas para as variedades OA (Hazard Ratio - HR de 0,89; $p<0.0001$ ) e OT (HR de 0,89; $p<0.0001$ ) (occipício anterior e transversa, respectivamente). Para variedade OP os preditores significativos e independentes foram o comprimento cervical (HR de 0,85; $p$ $<0.0001$ ), a paridade, o IMC e o ângulo posterior do colo uterino ( $\mathrm{p}<$ 0.0001). Quanto ao parto cesárea, para as variedades OP, OA e OT os preditores significativos foram o comprimento cervical pré indução do parto, a paridade, a idade materna e o IMC. Os autores concluíram ainda que a variedade OP, por si só está relacionada a uma significativa redução da probabilidade de parto vaginal em 24 horas e um significativo aumento da probabilidade de cesárea. Isso se deve, provavelmente, ao fato de as posições do occipício anterior e transversa estarem relacionadas a um menor comprimento cervical, aumentando, assim, o poder da predição do sucesso da indução do parto. Quanto ao escore de Bishop, a análise de regressão logística demonstrou que para estimar a probabilidade de parto vaginal em 24 horas, bem como a ocorrência de cesárea, os fatores significativamente preditores foram o Índice de Bishop, a paridade e o IMC.

Assim, em gestantes submetidas à indução de parto, a avaliação ultrassonográfica do colo uterino por meio da medida do comprimento do 
colo uterino, do ângulo posterior do colo e posição do occipício se mostrou superior ao escore de Bishop na predição dos resultados do parto. Utilizando como exemplo, para uma especificidade de $75 \%$, a sensibilidade da ultrassonografia do colo uterino na predição de cesárea e de parto vaginal em 24 horas após a indução de parto foi $20 \%$ superior à sensibilidade do escore de Bishop. Além disso, o presente estudo demonstrou uma contribuição adicional da medida do ângulo posterior e da posição do occipício na predição dos resultados da indução do parto.

Em 2004, Daskalakis et al. ${ }^{(32)}$ demonstraram que em gestantes com comprimento cervical inferior a $27 \mathrm{~mm}$ a ultrassonografia transvaginal apresentou sensibilidade de $76 \%$ e especificidade de $75,5 \%$ em predizer o parto vaginal, em contraste com o escore de Bishop, que não foi preditivo para o tipo de parto, estando somente associado estatisticamente à duração do parto. Logo, o comprimento do colo foi considerado um preditor independente e significativo do parto vaginal em gestantes submetidas à IP.

Também em 2004, Roman et al. (2004) ${ }^{(33)}$ compararam o comprimento cervical, imagem em funil no $\mathrm{OCl}$ e área dos lábios anterior e posterior do colo uterino (definida como a área delimitada pelo canal endocervical, superfície externa do colo e limite interno do $\mathrm{OCl}$ ) ao escore de Bishop na predição da falha da IP, em gestantes com colos desfavoráveis. A imagem em funil ( $p=0.23$ ) e a área dos lábios cervicais $(p=0.28)$ não se correlacionaram ao objetivo primário. Já o escore de Bishop $(\mathrm{OR}=2,25, \mathrm{p}=$ 
0.003) e o esvaecimento clínico (OR-3,95, p = 0.01) foram preditores independentes da falha da IP, destacando que o escore inferior a 4 apresentou sensibilidade de $87,5 \%$ e especificidade de 45,6\%. Já á área sobre a curva ROC do escore clínico foi de 0,71 , assim como o comprimento cervical, que apresentou área sobre a curva de 0,635 ( $p=0.47)$. Assim, a despeito dos parâmetros ultrassonográficos apresentarem maior objetividade e acurácia, não foram superiores ao escore de Bishop na predição dos resultados da indução do parto. Além disso, o próprio escore de Bishop apresentou baixo poder de predição do objetivo primordial.

Yang et al. (2004) ${ }^{(34)}$ avaliaram o poder da ultrassonografia transvaginal na predição do sucesso do parto, definido como a presença de fase ativa do parto ou trabalho de parto ativo, dentro de 48 horas após o início da indução. As variáveis ultrassonográficas analisadas foram: o comprimento cervical, a presença de imagem em funil ou em $\mathrm{V}$ no $\mathrm{OCl}$, bem como sua profundidade e comprimento. O sucesso da indução do parto ocorreu em 93 pacientes (89\%) sendo a área sobre a curva ROC construída para o comprimento cervical (área $=0,77, p=0.02$ ) superior a do escore de Bishop (área $=0,69, p=0.04$ ). O comprimento cervical que demostrou sensibilidade de $75 \%$ e especificidade $83 \%$ foi de 30 milimetros, sendo esses os melhores valores demonstrados no presente estudo. Com a análise de regressão logística múltipla, houve associação estatisticamente significativa entre o comprimento cervical e a presença de fase ativa do parto em 48 horas do início da indução (OR: 0,24, p = 0.02), o que não ocorreu 
com o escore de Bishop ou com os outros parâmetros ultrassonográficos. A medida transvaginal do colo uterino foi um preditor independente do sucesso da indução do parto, apresentando melhor eficiência em relação ao consagrado escore de Bishop.

Novamente Rane et al. ${ }^{(10)}$, porém agora em 2005, avaliando o efeito do comprimento cervical na ocorrência de parto vaginal em gestantes submetidas à indução do parto, demonstraram que o comprimento cervical $(O R=0,86(I C$ de $95 \%-0,84-0,88 ; p<0.0001)$ foi preditor do sucesso da indução do parto, bem como do risco de evolução para cesárea $(\mathrm{OR}=1,09$ (IC de 95\%-1,06-1,11, p < 0.0001).

Rovas et al. (2005) ${ }^{(35)}$ analisaram o colo uterino de pacientes com gestação prolongada que foram submetidas à indução do parto com prostaglandinas, utilizando a ultrassonografia bidimensional e tridimensional. Esses autores concluíram que as medidas do colo uterino (comprimento do colo, identificação da imagem em funil no $\mathrm{OCl}$ ) e o escore de Bishop se associaram significativamente ao sucesso da indução do parto. O mesmo não se aplicou ao volume cervical e aos outros parâmetros mensurados pela ultrassonografia tridimensional.

Crane (2006) ${ }^{(1)}$ desenvolveu uma metanálise na tentativa de obter consenso na literatura sobre a eficácia da medida transvaginal do colo uterino na predição do sucesso da indução do parto comparada ao já amplamente utilizado e consagrado escore de Bishop. O objetivo desse 
estudo foi o sucesso da indução do parto, que variou entre os diversos autores e artigos pesquisados, incluindo parto vaginal, parto vaginal em 24 horas após o início da indução, presença de fase ativa de trabalho de parto em 48 horas do início da indução ou a presença de $5 \mathrm{~cm}$ de dilatação. Inicialmente foram selecionados 37 estudos, porém apenas sete desses preencheram todos os critérios da revisão sistemática (estudos prospectivos, descrição dos métodos, dados e resultados completos). Como resultados, a autora descreveu que o escore de Bishop (LR = 2,10 - IC de 95\% (1,67 $2,64)$ e a medida transvaginal do colo uterino ( $L R=1,82-$ IC de $95 \%(1,51-$ $2,20)$ puderam predizer o sucesso da indução do parto e parto vaginal após o início da indução $(\operatorname{LR}=1,69$ - IC de $95 \%(1,35$ - 2,12) para ultrassonografia e LR $=1,74-$ IC de $95 \%(1,29-2,34)$ para o escore de Bishop.

O escore de Bishop foi preditor de parto vaginal em 24 horas $(L R=$ $2,61$ - IC de $95 \%(1,59-4,28))$ e a ultrassonografia transvaginal se relacionou estatisticamente à presença de fase ativa de trabalho de parto em 48 horas após o início da indução (LR = 4,52 - IC de 95\% $(1,27-16,09))$. O estudo concluiu, então, que apesar de a ultrassonografia transvaginal poder predizer o objetivo primário, ou seja, o sucesso da indução do parto, o seu intervalo de confiança de $95 \%$ foi superior ao intervalo de confiança do escore de Bishop, provando, assim, que aquele método não foi superior a este na estimativa do sucesso da indução do parto. 
Em 2006, Gomes et al. ${ }^{(36)}$ avaliaram a relação entre o comprimento do colo uterino e o escore de Bishop ao sucesso e duração da indução do parto. A correlação entre o comprimento do colo uterino e duração da indução do parto foi baseada no coeficiente de regressão $(b)=44,040, p=$ 0.00000, r2 = 0,19, assim como a correlação entre o índice de Bishop e a duração da indução $-(b)=-227,585, p=0.00000, r 3=0,33$. Além disso, as pacientes que evoluíram para parto vaginal apresentaram comprimento cervical inferior (média de $26.9 \mathrm{~mm} \times 33.6 \mathrm{~mm}, \mathrm{p}=0.0000$ ), bem como escore de Bishop superior (mediana $6 \times 3, p=0.0000$ ) às que evoluíram para cesárea. O presente estudo demonstrou ainda que pacientes com escore de Bishop desfavorável (inferior a 6) têm maior risco de evoluir para parto 24 horas após a indução (OR $=21,16, p<0.001)$, assim como pacientes com comprimento cervical superior a $26 \mathrm{~mm}(\mathrm{OR}=5,06, \mathrm{p}<$ 0.001). Quanto ao tipo de parto, somente o escore de Bishop se relacionou estatisticamente a este, sendo que pacientes com escore desfavorável $(<6)$ têm maior risco de evoluir para cesárea $(O R=2.67, p=0.004)$. Já o comprimento cervical não se relacionou com o tipo de parto $(\mathrm{OR}=1.81, \mathrm{p}=$ 0.54). Logo, o comprimento cervical e o escore de Bishop foram preditores da duração do parto, porém somente o escore de Bishop se relacionou significativamente ao tipo de parto.

Já em 2007, Yanik et al. ${ }^{(37)}$, propuseram um estudo para avaliar a eficácia da medida transvaginal do comprimento do colo uterino na predição do tipo de parto em pacientes submetidas à indução do parto com ocitocina endovenosa. A idade materna $(p<0,05)$, escore de Bishop $(p<0,05)$ e a 
paridade $(p<0,05)$ foram superiores, assim como a medida do comprimento cervical $(p<0,05)$ e do peso do recém-nascido $(p<0,05)$ foram inferiores no grupo das pacientes que evoluíram para parto vaginal, em comparação ao grupo da cesárea. Utilizando-se de regressão logística, encontrou-se que o escore de Bishop $(\operatorname{LR}=0,472$, IC de 95\% $(0,338-0,658) ; p<0,05)$ foi $o$ único fator preditor independente do tipo de parto. Logo, as gestantes com escore de Bishop inferiores e comprimento cervical superiores estão mais propensas a evoluir para parto cesáreo.

Também em 2007, Tan et al. ${ }^{(38)}$ demonstraram que o comprimento cervical via transvaginal e o escore de Bishop foram preditores do risco de cesárea após indução do parto, sendo que o comprimento cervical superior a $20 \mathrm{~mm}(p<0.05)$ e o escore de Bishop inferior a $5(p<0.05)$ foram preditores independentes do risco de cesárea.

Park (2007) ${ }^{(39)}$, com o intuito de avaliar o valor da ultrassonografia transvaginal na predição da falha da indução do parto, realizou um estudo prospectivo e observacional. O objetivo primário, a falha da indução do parto, foi estabelecido como a inabilidade das gestantes em atingirem a fase ativa do trabalho de parto, que correspondeu à dilatação igual ou superior a 4 centímetros dentro de 12 horas do início da ocitocina, ou dentro de 21 horas após a inserção vaginal da dinoprostona. O parto vaginal ocorreu em $127(79 \%)$ pacientes, sendo que 95 (59\%) ocorreram dentro de 24 horas após o início da indução do parto. O parto cesáreo ocorreu em 34 (21\%) das pacientes, sendo que 11 ocorreram dentro de 24 horas após o início da IP. 
Houve $66 \%$ de sucesso da indução do parto (106/161 pacientes), já que 55 pacientes falharam em entrar na fase ativa do trabalho de parto em 24 horas após a indução. $\mathrm{Na}$ análise pela curva $\mathrm{ROC}$, notou-se uma relação significativa entre o comprimento cervical e a falha da indução do parto (área do comprimento cervical: 0,$678 ; p<0.0001$ ), sendo que o melhor valor de corte na predição da falha da indução foi de $28 \mathrm{~mm}$ de comprimento cervical e apresentando sensibilidade de $62 \%$ e especificidade de $60 \%$, e OR $=2,80$ (IC de 95\% (1,46-5,38), $p<0,005)$. A presença de imagem em forma de funil adentrando o canal endocervical não demonstrou ser preditora da falha da indução (OR de 0.83 , IC de 95\% 0.21 -3,25, NS) ou do risco de cesárea (OR de 0.42 , IC de 95\% 0.22-2.49, NS).

Assim, os resultados do presente estudo demonstraram que a medida transvaginal do comprimento cervical pode predizer de forma independente a probabilidade de as pacientes atingirem a fase ativa do parto dentro de 24 horas após a indução do parto, bem como a falha da indução do parto.

Gomez Laencina et al. $(2007){ }^{(40)}$ incluíram 177 gestantes com idade gestacional entre 36 e 42 semanas candidatas à indução de parto em estudo para avaliar e comparar a performance do escore de Bishop e da ultrassonografia vaginal na predição do sucesso da indução do parto. $O$ sucesso da indução do parto foi definido como a evolução da indução para parto vaginal em 12 horas após o uso da ocitocina e parto vaginal em 60 horas com o uso da dinoprostona intracervical. Após análise estatística com 
regressão logística, os autores demonstraram que o índice de Bishop e o comprimento cervical foram preditores independentes do sucesso da indução do parto (HR:1,350,IC de 95\% - 1,186-1,537, p < 0.0001; HR: 0,936, IC de $95 \%-0,914-0,958, p<0.0001)$. A utilização da curva ROC permitiu demonstrar que o ponto de corte do comprimento cervical de $24 \mathrm{~mm}$ apresentou sensibilidade e especificidade de 66 e $77 \%$, respectivamente, podendo ser utilizado como ferramenta útil na indução do parto.

Hatfield et al. (2007) ${ }^{(41)}$ realizaram uma revisão sistemática com o intuito de investigar e revisar na literatura vigente a avaliação ultrassonográfica do colo uterino na predição do sucesso da indução do parto. Os autores incluíram estudos prospectivos que realizaram a medida ultrassonográfica transvaginal do colo uterino antes da indução do parto. Inicialmente selecionaram 56 artigos, porém, devido à ausência de relevância, duplicação de artigos, falha na metodologia e dados descritos, somente 20 estudos foram incluídos nessa revisão. A população incluída no estudo foi de 3101 pacientes submetidas à indução de parto por diferentes indicações e diferentes métodos (misoprostol, dinoprostona, aminiotomia, descolamento de membranas ovulares, ocitocina endovenosa, cateter balão cervical, estimulação mamilar). Os objetivos do estudo foram o cálculo da sensibilidade e especificidade do uso da ultrassonografia transvaginal na predição do sucesso da indução do parto. Os artigos incluídos eram prospectivos e avaliaram a acurácia da ultrassonografia transvaginal na predição do sucesso da indução de parto por meio da medida do comprimento do colo uterino, sendo que alguns incluíram também a 
presença da imagem em funil no colo uterino. Compararam também as medidas ultrassonográficas com o escore de Bishop. Os objetivos secundários foram: análise do tipo de parto, ocorrência de parto vaginal em 24 horas do início da indução, falha de indução, presença de trabalho de parto ativo e a estimativa do intervalo entre indução e parto. A definição de sucesso na indução do parto variou entre os estudos, sendo que 11 estudos consideraram sucesso o parto vaginal, 6 destes o parto vaginal em 24 horas do início da indução, 2 consideraram como sucesso a presença de fase ativa de trabalho de parto com dilatação cervical de 4 a $5 \mathrm{~cm}$, e 1 artigo valorizou a presença de trabalho de parto em 48 horas do início da indução.

Os resultados da análise estatística foram: o comprimento cervical do colo uterino mostrou-se preditivo do sucesso da indução do parto quando incluídos todos os estudos e os objetivos primários e secundários (LR de positividade do teste de 1,66, IC de $95 \%(1,20$ - 2,31)) e de falha de indução (LR de negatividade do teste de 0,51 (IC de 95\% $(0,39-0,67)$ ). Analisando os quatro objetivos em subgrupos: parto vaginal, parto vaginal em 24 horas, parto em 24 horas após a indução e presença da fase ativa do parto, houve pouca ou nenhuma significância estatística na acurácia do método utilizado (ultrassonografia transvaginal), apresentando LR de: 1,40 (IC 95\% - 0,95$2,07)$ para parto vaginal; LR: 1,83 (IC 95\% - 1,27 - 2,74) para parto vaginal em 24 horas; LR: 1,44 (IC 95\% - 0, 47 - 4,44) para fase ativa do parto e LR: 1,72 (IC 95\% - 015- 19,69) para parto em geral dentro de 24 horas. No que diz respeito ao parto cesáreo, a LR de negatividade foi preditiva para a 
ocorrência de parto cesáreo e ausência de parto vaginal em 24 horas após a indução do parto. Sete estudos compararam ainda o comprimento médio do colo uterino no grupo que obteve sucesso na indução e no grupo de falha, e como resultados encontraram que o comprimento do colo foi $4,8 \mathrm{~mm}$ (IC $95 \%, 3-4-6,2)$ menor no grupo de sucesso, em comparação aos que obtiveram falha. Além disso, dez estudos analisaram a comparação das medidas ultrassonográficas com o escore de Bishop e não obtiveram diferença estatística na predição do sucesso da indução do parto (OR: 0,82, IC de $95 \%(0.37-1,80))$; parto vaginal (OR: 0,72, IC de $95 \%(0,17-2,98)$ ); parto vaginal em 24 horas (OR: 0,82, IC de 95\% (0,27-2,54)) e presença da fase ativa do parto (OR; 0,59 com IC de 95\% $(0,28-1,23)$ ). A presença de imagem em funil no $\mathrm{OCl}$ foi capaz de predizer o sucesso da indução do parto, com LR de positividade de 2,64 (IC de 95\% $(1,79-3,88)$ ), LR de negatividade de 0,64 (IC de $95 \%(0,46-0,88)$ ), sensibilidade de $43,8 \%$ (IC de $95 \%(29,2$ - 65,6)), especificidade de 82,7\% (IC de 95\% $(75,4-90,7)$ ), área sobre a curva: 0,80 .

Na presente revisão, talvez em virtude da variação do número de participantes em cada estudo (35 - 822 pacientes), valor de corte para as medidas ultrassonográficas $(16,5-35 \mathrm{~mm})$, diferentes métodos de indução do parto, múltiplos objetivos, uma certa heterogeneidade entre pacientes, já que poucos estudos excluíram as pacientes multíparas, gestações pré termo e pacientes com rotura prematura de membranas ovulares, os autores acharam surpreendente que a medida transvaginal no geral pode predizer o 
sucesso e a falha na indução do parto. No entanto, quando realizada uma análise do subgrupo dos objetivos, o comprimento cervical falhou na acurácia de sua predição.

Vankayalapati et al. (2008) ${ }^{(42)}$ avaliaram a eficácia e utilidade da medida transvaginal do comprimento do colo uterino na predição do início espontâneo do trabalho de parto e na predição do parto vaginal pós parto espontâneo e após indução deste. O comprimento cervical foi significativamente inferior em pacientes que apresentaram início espontâneo do parto (25 mm +/- $8.3 \mathrm{~mm}$ ), em detrimento das pacientes submetidas à indução (29.7 mm +/- $8.5 \mathrm{~mm})$, com $\mathrm{p}=0.001$. Desse modo, o comprimento cervical esteve associado ao início espontâneo do parto e ao sucesso do parto vaginal (pós início espontâneo e indução). O mesmo não se aplicou à paridade, que somente esteve relacionada ao sucesso da IP ( $p=0.00019)$. O presente estudo demonstrou que quanto mais curto o colo uterino, mais rápido será o início do trabalho de parto, com área abaixo da curva $\mathrm{ROC}$ para início do parto em até 4 dias de 0.683 para nulíparas e 0.588 para multíparas. Os resultados comprovam que gestantes com colo curto têm mais chance de evoluir não só para parto espontâneo como para o sucesso da IP.

Eggebo et al. (2009) ${ }^{(43)}$ avaliaram a comparação entre os elementos do escore de Bishop aos parâmetros correspondentes da ultrassonografia transvaginal, antes da indução do parto, e o poder de predição do sucesso da indução utilizando esses marcadores. Na análise da curva ROC, o exame 
digital da dilatação do colo uterino foi o melhor elemento discriminador entre o sucesso e a falha da indução do parto, com área sobre a curva de $61 \%$ (IC de $95 \%(51-71 \%), p=0.03))$. Além disso, a combinação entre a altura da apresentação, comprimento cervical, ângulo cervical posterior e a dilatação clínica utilizadas como variáveis contínuas pode predizer o sucesso e a falha da indução do parto com 68\% (IC de 95\% - 58-78\%, p < 0.01) de área sobre a curva. O modelo preditor misto foi preditor do sucesso e insucesso da indução do parto em 71\% (IC de 95\% - 61-80\%, p < 0.01) de área sobre a curva. A combinação da altura da apresentação, comprimento cervical, ângulo cervical posterior e dilatação clínica pode contribuir para uma melhor predição do sucesso da indução do parto.

Novamente Park et al. ${ }^{(44)}$, porém em 2009, avaliaram o valor preditivo da história obstétrica prévia, do escore de Bishop e da medida ultrassonográfica transvaginal do colo uterino na predição da falha da indução do parto em pacientes nulíparas de termo. A falha da indução do parto foi definida como a inabilidade de atingir a fase ativa do trabalho de parto, que correspondeu à dilatação cervical superior a $4 \mathrm{~cm}$ em 12 horas do início do uso da ocitocina endovenosa ou 21 horas da inserção intravaginal da dinoprostona. A indução do parto foi considerada bem sucedida em $86 \%$ das pacientes (95/110), sendo que 15 pacientes falharam em entrar na fase ativa do parto dentro do intervalo de 24 horas da indução. Não houve diferença nos grupos de sucesso e insucesso da indução do parto quanto ao comprimento cervical médio $(25,2 \mathrm{~mm}$ no grupo de sucesso $\times 27,4 \mathrm{~mm}$ no 
grupo de insucesso, $p=0.124$ e OR: 1,063 , IC de $95 \%-0,441-2,560, p=$ 0.892). No entanto, a presença de história obstétrica prévia, como parto prematuro e perda fetal tardia (fetos com idade gestacional superior a 20 semanas), se relacionou significativamente à falha na indução do parto (3\% x $20 \%$ no grupo do sucesso e do insucesso, respectivamente $p=0.032$ e OR: 16.028, IC de 95\%, $2.047-125.5 ; p=0.008)$. O escore de Bishop foi um preditor significativo e independente da falha da indução do parto (OR: 0,621, IC de 95\% - 0.391-0.988 $\mathrm{p}=0.044)$ e utilizando a curva ROC, demonstrou-se que o melhor valor do escore de Bishop para a predição do insucesso da indução foi 3 , com sensibilidade de $73 \%$ e especificidade de $44 \%$.

Assim, a história obstétrica prévia de perdas tardias e parto prematuro e o escore de Bishop inferior a 3 foram preditores significativos da falha da indução do parto. Já a medida ultrassonográfica do comprimento cervical demonstrou baixo valor preditivo do insucesso da indução do parto.

Uyar et al. (2009) ${ }^{(45)}$ avaliaram o papel da ultrassonografia transvaginal e de fatores maternos e fetais na predição do sucesso da indução do parto. Após a regressão logística múltipla, o Índice de Massa Corpórea e o comprimento cervical se mostraram variáveis independentes e significativas na predição do intervalo da indução e parto $(t=2,680, p=$ 0.009 , IC de $95 \%(0,103-0,690) ; t=5.738, p=0.000, I C$ de $95 \%(0,293-$ 0,603), respectivamente), em detrimento do escore de Bishop e do peso do 
recém-nascido, que não se mostraram estatisticamente significativos $(\mathrm{t}=$ $0.347, p=0.73, I C$ de $95 \%(-0.498$ a -0.305$) ; t=0.089, p=0.93, I C$ de $95 \%$ (- 0.002 a 0.002), respectivamente). Quanto à predição do risco de cesárea, os únicos fatores que se mostraram preditivos e eficazes e independentes foram o IMC $(\mathrm{OR}=1,223, \mathrm{p}=0,005$ com IC de $95 \%=1,058-1,414)$ e o comprimento cervical $(\mathrm{OR}=1,206, \mathrm{p}=0.000$ com IC de $95 \%=1,117$ 1,303). A curva ROC demonstrou que o melhor parâmetro na predição do risco de cesárea foi o comprimento cervical, sendo que este e o IMC foram superiores em comparação ao escore de Bishop (com área sobre a curva de 0.819, 0.701 e 0.416, respectivamente). Desse modo, os autores demonstraram que o valor de corte para o IMC foi de $23 \mathrm{~kg} / \mathrm{m}^{2}$, com sensibilidade de $100 \%$ e especificidade de $19 \%$ e $19 \mathrm{~mm}$ para o comprimento cervical, com sensibilidade de $100 \%$ e especificidade de $28 \%$.

O comprimento transvaginal do colo do útero e o índice de massa corpórea (IMC) foram significantes na determinação do intervalo entre indução e parto, sendo o comprimento cervical o parâmetro mais importante e significativo. Além disso, o comprimento cervical e o IMC foram eficazes na predição do risco de cesárea, em detrimento ao escore de Bishop, que não se mostrou uma variável independente e significativa. 
3 OBJETIVOS 
O presente estudo tem como objetivos:

Correlacionar as medidas do colo uterino pela ultrassonografia transvaginal em gestantes de termo e com indicações clínicas para a indução do parto, com:

1- O sucesso da indução do trabalho de parto.

2- $\quad$ A ocorrência de parto vaginal em até 24 horas do início da IP.

3- $\quad$ A presença da fase ativa do trabalho de parto, após a IP.

4- $\quad$ Avaliação clínica do Índice de Bishop. 
4 MÉTODOS 
No período de fevereiro de 2008 a fevereiro de 2010, foi realizado estudo prospectivo e observacional, envolvendo gestantes de termo com critérios clínicos à indução do parto. Essa pesquisa foi desenvolvida no Pronto Atendimento (PA) / Centro Obstétrico (CO) do Hospital Universitário da Universidade de São Paulo, sendo iniciada após a aprovação pelo Comitê de Ética em pesquisa do Hospital Universitário da USP (CONEP) (Anexo 1).

\subsection{Pacientes}

\subsubsection{Critérios de inclusão}

- $\quad$ gestações com fetos únicos e vivos

- $\quad$ indicações para indução do parto: presença de oligoâmnio, restrição do crescimento fetal, pós datismo, síndromes hipertensivas e diabetes gestacional

- idade gestacional entre 37 semanas e 42 semanas de gestação, determinada pela DUM (data da última menstruação), e ultrassonografia de primeiro trimestre

- fetos em apresentação cefálica

- membranas ovulares íntegras 
- $\quad$ vitalidade fetal preservada

- $\quad$ ausência de cesáreas ou cicatrizes uterinas prévias

- $\quad$ ausência de suspeita de macrossomia fetal

- $\quad$ concordância, por escrito, com o Termo de Consentimento Livre

e Esclarecido do Protocolo e Pesquisa, aprovado pela Comissão de Ética para Análise de Projetos de Pesquisa da Diretoria Clínica do HCFMUSP e da Diretoria Clínica do Hospital Universitário da USP (Anexo 2).

A idade gestacional foi calculada a partir da data da última menstruação (DUM), quando concordante com a ultrassonografia de primeiro trimestre; ou por este último quando a diferença era superior a sete dias.

\subsubsection{Critérios de exclusão}

- $\quad$ gestantes em trabalho de parto

- $\quad$ cesáreas por sofrimento fetal realizadas antes do início da indução do TP

- $\quad$ recém-nascidos macrossômicos

4.2. Processo de coleta de dados e acompanhamento das gestantes

As gestantes que utilizam os serviços de pré-natal, PA/CO com 
critérios clínicos de indução do trabalho de parto eram encaminhadas para a internação. No PA/CO, após a confirmação da indicação clínica da indução do parto e dos critérios necessários para a inclusão da pacientes no presente estudo, procedeu-se ao exame digital para a avaliação do escore de Bishop, bem como a definição do medicamento a ser utilizado, que no presente estudo foi baseado unicamente na categorização pelo escore de Bishop. Conforme protocolo clínico vigente no serviço $(46,47,48,49)$, a preparação do colo está indicada quando o escore de Bishop (1964) ${ }^{(14)}$ é inferior a 6, sendo então utilizado o misoprostol intravaginal de 25 microgramas a cada 4 horas, e no máximo de 6 comprimidos ou 150 microgramas (em 24 horas). No entanto, se o Índice de Bishop for igual ou superior a 6 , inicia-se a indução do parto com ocitocina intravenosa e aminiotomia, quando oportuno. O detalhamento e categorização do Índice de Bishop foi realizado por obstetras experientes do serviço, que eram os assistentes responsáveis pela internação e conduta de cada paciente.(Anexo 3). A médica pesquisadora não obteve acesso prévio a esses dados.

No momento de sua internação, entrevistou-se a gestante para a obtenção dos dados demográficos, antecedentes pessoais e obstétricos. Após a internação, iniciou-se também a avaliação da vitalidade fetal por meio da cardiotocografia basal de repouso, bem como do perfil biofísico simplificado, além da realização da ultrassonografia transvaginal para a avaliação do comprimento cervical, da distância da apresentação fetal ao 
orifício cervical externo (OCE), dilatação do colo uterino e definição da presença da imagem em funil no orifício cervical interno, objetos do presente estudo e realizados pela médica pesquisadora. Em quarenta casos as medidas foram realizadas pela pesquisadora e seu orientador.

Com a finalização dos procedimentos relacionados à internação, as pacientes que apresentaram escore de Bishop igual ou superior a 6, ou seja, estado cervical favorável à indução do parto, eram prontamente encaminhadas ao centro obstétrico para o início da indução do parto. No entanto, pacientes com escore inferior a 6 , com estado cervical desfavorável à indução e com necessidade de preparo e maturação cervical, eram encaminhadas ao alojamento conjunto para aguardar o início da maturação cervical, que conforme protocolo do serviço, inciar-se-ia a zero hora do dia seguinte. Após o início da indução, essas gestantes eram monitoradas rigorosamente com cardiotocografia basal e controle clínico da equipe do centro obstétrico em todo o processo de indução e parto. As parturientes eram submetidas à analgesia e anestesia de parto, quando necessário.

Em todas as pacientes foram acompanhados os resultados da indução do trabalho de parto, como hora de início da indução, presença e duração da fase ativa do parto, que foi definida como a presença de dilatação cervical igual ou superior a 5 centímetros ${ }^{(33)}$ e no mínimo duas contrações regulares em 10 minutos do parto; intervalo entre indução e tipo de parto, suas indicações e intercorrências. Além disso, foram 
acompanhados os resultados neonatais imediatos, como peso do recémnascido (RN) e Apgar de primeiro, quinto e décimos minuto ${ }^{(50)}$.

\subsection{Avaliação clínica do escore de Bishop}

Após a admissão e autorização do termo por escrito, as pacientes eram submetidas ao exame digital transvaginal para avaliação do colo uterino e determinação do escore de Bishop, segundo a figura 1 (Bishop, 1964) ${ }^{(14)}$, pelo obstetra assistente responsável pelo caso.

\section{ÍNDICE DE BISHOP}

\begin{tabular}{|c|c|c|c|c|}
\hline Variáveis & & Pontuação & & \\
\hline & Zero & Um & Dois & Três \\
\hline Dilatação (cm) & $0 \mathrm{~cm}$ & $1-2 \mathrm{~cm}$ & $3-4 \mathrm{~cm}$ & $5-6 \mathrm{~cm}$ \\
\hline Esvaecimento (\%) & $0-30$ & $40-50$ & $60-70$ & 80 \\
\hline Altura da apresentação & -3 & -2 & -1 ou 0 & $+1 /+2$ \\
\hline Consistência & Firme & Média & Amolecida & - \\
\hline Posição & Posterior & Medianizada & Anteriorizada & - \\
\hline
\end{tabular}

Figura 1 - Índice de Bishop (Bishop,1964). 


\subsection{Uso de misoprostol e ocitocina na indução do parto}

O medicamento utilizado para a maturação do colo uterino e posterior indução do parto em colos desfavoráveis foi o misoprostol ${ }^{(51)}$. Utilizou-se esse medicamento pela via intravaginal, na dose de 25 microgramas, administrado a intervalos de 4 horas, atingindo o máximo de 6 doses (150 microgramas), ou até o escore de Bishop se tornar favorável (índice igual ou superior a 6), quando então inicia-se a indução do parto com a ocitocina intravenosa ${ }^{(46,49)}$. A presença de contrações uterinas regulares e persistentes era um critério de suspensão da continuidade do uso do misosprostol, com o intuito de reduzir a incidência de taquissistolia e suas possíveis consequências.

A ocitocina intravenosa era administrada na forma de soro, contendo 5 UI desta e 500 mililitros de solução glicosada a $5 \%$, obtendo-se, assim, uma solução com concentração de ocitocina de $10 \mathrm{mUl} / \mathrm{mL}$. Inicia- se então a indução com a infusão de $2 \mathrm{mUl}$ por minuto e aumentando essa mesma dose a cada quinze minutos, até a dose máxima de $32 \mathrm{mUI}$ por minuto, ou até atingir a fase ativa do parto, conforme previamente descrito ${ }^{(52)}$. 


\subsection{Avaliação da vitalidade fetal}

Todos os exames para avaliar a vitalidade fetal, como a cardiotocografia basal e estimulada e o perfil biofísico fetal simplificado para avaliação do Índice de Líquido Aminiótico (ILA), foram realizados no PA/CO do Hospital Universitário da Universidade de São Paulo, pela médica pesquisadora. A cardiotocografia basal e estimulada era realizada por um período mínimo de 10 minutos, antes da indução do parto, bem como a quantificação do ILA. Fetos com suspeita de sofrimento fetal diagnosticados por esse exame foram excluídos do estudo.

\subsection{Avaliação das variáveis ultrassonográficas do colo uterino}

Todos os exames para avaliar as variáveis ultrassonográficas foram executados na sala de ultrassonografia do Pronto Atendimento da Clínica Obstétrica do Hospital Universitário da USP, pela médica pesquisadora, em quarenta casos, também por seu orientador. As pacientes foram acomodadas em posição de litotomia dorsal com esvaziamento vesical prévio ao exame.

O estudo das variáveis ultrassonográficas para avaliação do colo uterino na indução do parto empregou os aparelhos de ultrassonografia com transutor endocavitário de $6 \mathrm{Mhz}$, da marca Toshiba e modelos PVG- $601 \mathrm{~V}$, e PowerVision 6000 (SSA - 370 A ). 


\subsubsection{Medida do comprimento do colo uterino}

Após o esvaziamento vesical prévio, era realizada a introdução da sonda endovaginal no fórnice anterior da vagina e a 3 centímetros do colo uterino $^{(7,30,36)}$, sendo exercida a mínima pressão de forma a não distorcer sua posição ou forma. Desse modo, era obtida uma visão sagital e completa do colo uterino, incluindo o orifício cervical interno, a mucosa ecogênica e o canal endocervical e o orifício cervical externo. Após a visualização do corte sagital, a imagem era magnificada até ocupar aproximadamente $75 \%$ da tela, sendo os marcadores eletrônicos ou calipers locados de modo a medir o comprimento do colo uterino, ou seja, a linha da distância entre os orifícios cervicais interno e externo. Foram realizadas três medidas do comprimento cervical, sendo considerada a menor medida entre elas $(24,53,54,55)$. (Figura 2). 


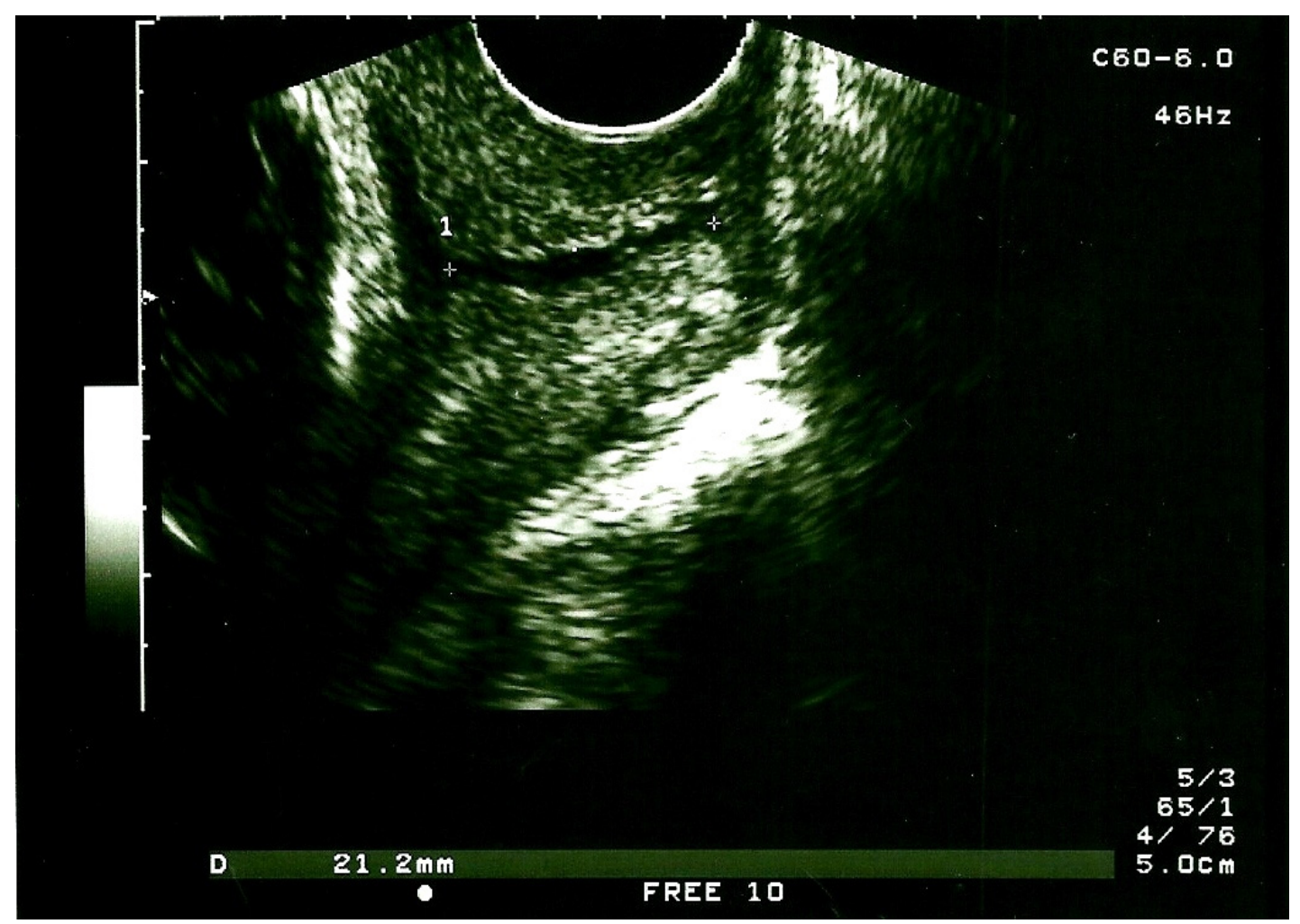

Figura 2 - Medida do comprimento do colo uterino pela ultrassonografia transvaginal.

\subsubsection{Avaliação da dilatação do colo uterino}

Após realizar a locação da sonda transvaginal como explanado anteriormente e obtido o corte sagital com visibilização de todo o comprimento cervical, foi realizada uma leve pressão no fundo uterino com o intuito de pressionar a apresentação fetal contra o orifício cervical interno. Desse modo, identificamos a linha anecogênica endocervical, e após a locação dos calipers próximos ao vértice, realizamos a medida transversa da espessura da linha anecogênica. Essa medida visava avaliar a dilatação cervical $^{(21)}$. 
Foram realizadas também três medidas, sendo considerada a menor entre essas. (Figura 3).

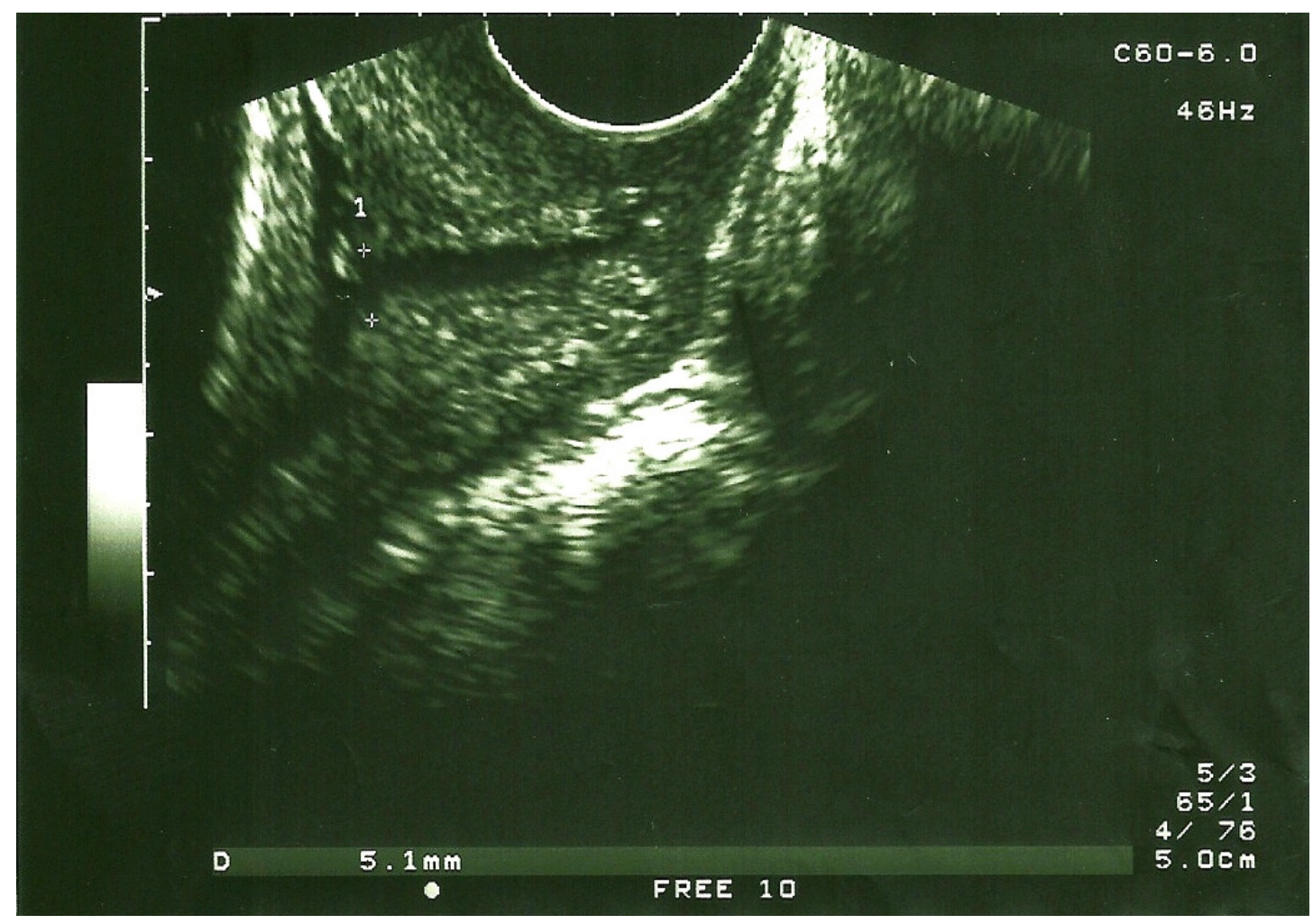

Figura 3 - Medida da dilatação cervical pela ultrassonografia transvaginal.

\subsubsection{Medida da distância da apresentação fetal ao OCE}

Com o objetivo de estimar a altura da apresentação fetal, após a localização do corte sagital do colo uterino era mensurada com os calipers a distância do ponto mais inferior da apresentação fetal, localizado na tábua externa da cabeça fetal em contato com a pele, até o orifício cervical externo. Também foram realizadas três medidas, sendo considerada a inferior. (Figura 4). 


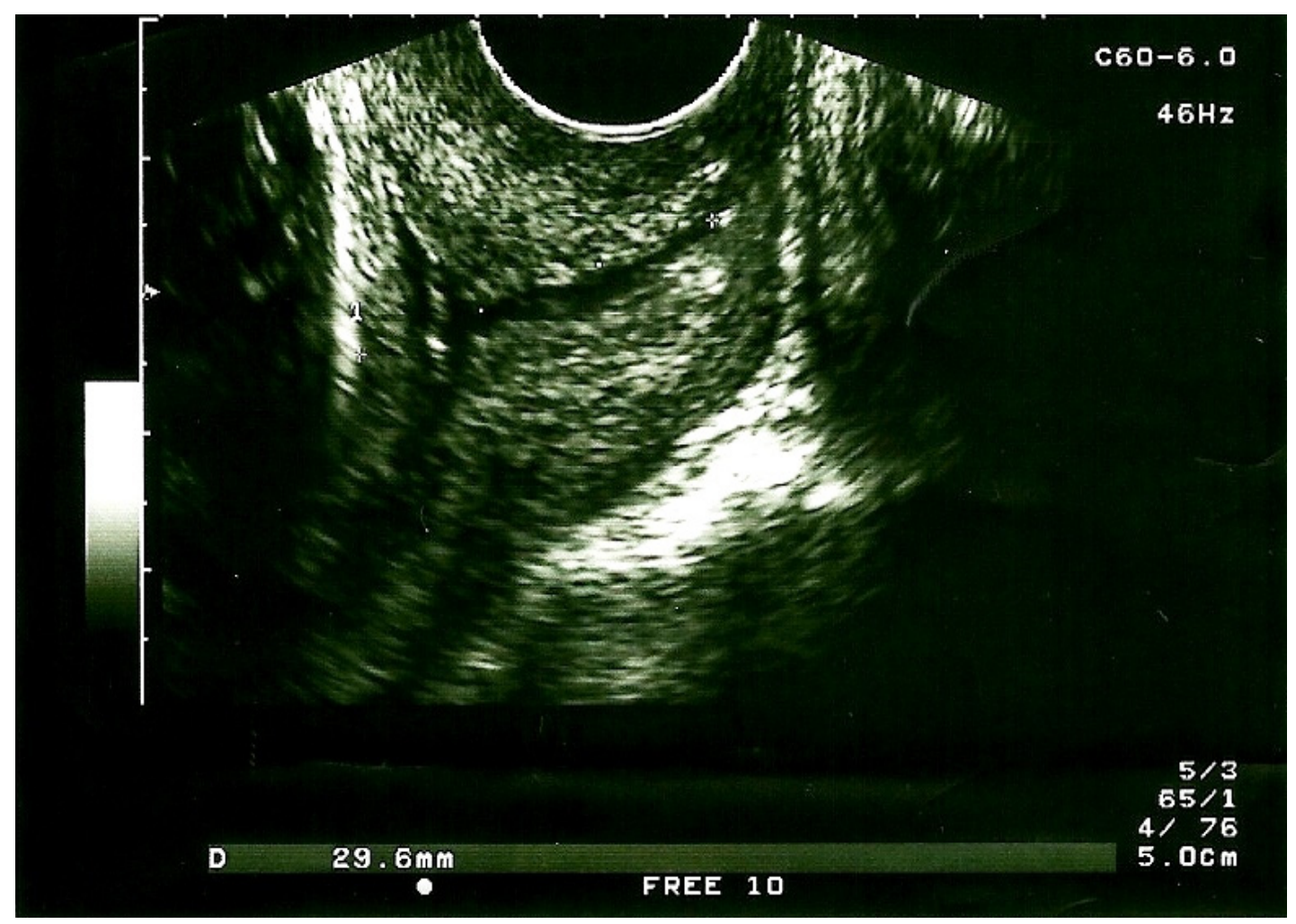

Figura 4 - Medida da distância da apresentação fetal ao OCE, pela ultrassonografia transvaginal.

4.6.4. Definição da presença do afunilamento do colo uterino (imagem em funil no $\mathrm{OCl}$ )

Após realizar a locação da sonda transvaginal como explanado anteriormente e obtido o corte sagital com visibilização de todo o comprimento cervical, identificamos a presença do afunilamento do colo uterino, ou imagem em funil no orifício cervical interno, que corresponde à imagem em $\mathrm{V}$ ou triângulo na área do $\mathrm{OCl}$ com ápice no canal endocervical $(24,29,39)$ (Figura 5). 


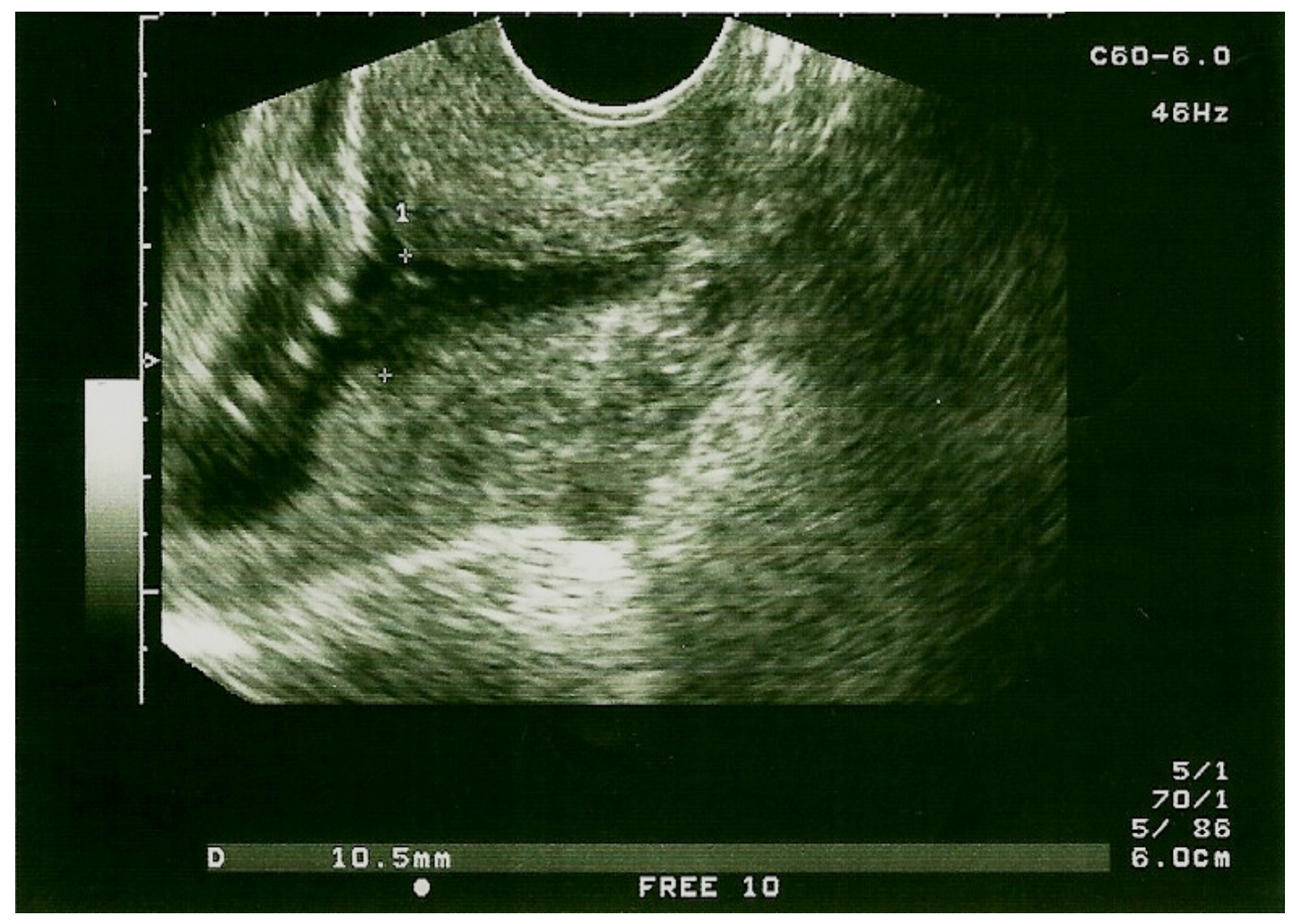

Figura 5 - Presença de imagem em funil no $\mathrm{OCl}$, pela ultrassonografia transvaginal.

\subsection{Dados Clínicos das Pacientes}

No momento da internação foram coletados e analisados posteriormente os seguintes dados das gestantes: idade, raça, paridade, idade gestacional e Índice de Massa Corpórea (IMC)(Anexo 3).

\subsection{Desfechos avaliados}

\subsubsection{Sucesso da Indução do Parto}

Este foi definido como a evolução para parto vaginal após o início da indução do parto. 


\subsubsection{Parto vaginal em 24 horas da IP}

Avaliamos também a ocorrência de parto vaginal no período até 24 horas após o início da IP.

\subsubsection{Presença de fase ativa do trabalho de parto}

Avaliaram-se gestantes que foram submetidas à indução do parto e que evoluíram ou não para a fase ativa do trabalho de parto, definida como a presença de cervicodilatação igual ou superior a $5 \mathrm{~cm}$ e contrações uterinas regulares e rítmicas (presença de 2 ou mais contrações em 10 minutos) ${ }^{(33)}$.

\subsection{Tamanho amostral}

O modelo explicativo a ser testado quanto à probabilidade de ocorrer parto vaginal após o início da indução do parto inclui seis variáveis explicativas, sendo essas a medida do comprimento cervical, a dilatação cervical, altura da apresentação fetal, presença da imagem em funil no $\mathrm{OCl}$, o escore de Bishop e a paridade. De acordo com Concato et al. (1993) ${ }^{(56)}$, para cada variável explicativa a ser testada devem ser incluídos no estudo no mínimo dez casos (no caso, dez casos de pacientes que evoluíram para parto vaginal). Desse modo, como serão testadas seis variáveis, deveriam ser incluídas no mínimo 60 pacientes cujo parto tenha sido vaginal. Além disso, o número de pacientes incluídas depende da proporção de pacientes submetidas à indução do parto e que evoluem para parto vaginal. $\mathrm{Na}$ 
literatura vigente, estudos conduzidos por Ware, Raynor (2000) ${ }^{(26)}$, Rane et al. (2005) (10), a proporção de parto vaginal foi de $69 \%$ e $64,5 \%$, respectivamente. Assim, com base nos conceitos acima elucidados e na proporção de partos vaginais em pacientes submetidas à indução de parto estimada entre 60 a $65 \%$, foram utilizadas 15 pacientes para cada variável no modelo de regressão logística. O tamanho da amostra foi então calculado utilizando-se o valor de medida de associação entre a paridade da mãe e a ocorrência de parto vaginal, admitindo diferentes magnitudes do OR e da proporção de mulheres não expostas (nulíparas), e admitindo alfa $=0.05$ e poder do teste $=80 \%$. Nesse caso, utilizando-se um OR de 2.50 (alto poder de associação e poder do teste $=80 \%$ ) e a proporção de parto vaginal entre nulíparas de 50 a 60\%, o n (tamanho da amostra) foi de 170 a 190 pacientes. Desse modo, o número de pacientes incluídas nesse estudo é de 190 gestantes.

\subsection{Análise Estatística}

Para a realização da análise estatística, primeiramente foram descritas as características das pacientes incluídas no estudo, sendo as medidas nominais expressas com o uso de frequências relativas e absolutas, e as medidas numéricas com o uso de medidas resumo ${ }^{(57)}$. As medidas nominais foram descritas segundo a ocorrência do sucesso da indução do parto, ou seja, parto vaginal ou a falha da indução cesárea, presença e ausência de fase ativa do parto, descrito anteriormente como a 
habilidade em atingir cervicodilatação de 5 centímetros e presença de no mínimo duas contrações regulares em dez minutos, e ocorrência ou não de parto vaginal dentro de 24 horas após o início da indução do parto, com o uso de frequências absolutas e relativas e verificada a existência de associação entre os desfechos e as variáveis de interesse com o uso de testes qui-quadrado ou testes da razão da verossimilhança ${ }^{(58)}$. Já as medidas numéricas foram descritas segundo os desfechos de interesse e comparadas com o uso de testes t-Student ${ }^{(57)}$ ou testes de Mann-Whitney (59), conforme distribuição dos dados previamente testada para a normalidade de distribuição com o uso de testes de Kolmogorov-Smirnov ${ }^{(59)}$.

Foram calculadas as correlações de Pearson ${ }^{(57)}$ entre o Índice de Bishop e os parâmetros ultrassonográficos para verificar a correlação existente, sendo os resultados ilustrados com o uso de diagramas de dispersão. Posteriormente, as gestantes foram estratificadas segundo o valor de Bishop: < 6 - desfavorável à IP e > 6, favorável a esta, e comparadas às variáveis ultrassonográficas segundo as categorias acima relatadas aos desfechos de interesse, com o uso de testes t-Student. Além disso, foram desenvolvidas curvas ROC ${ }^{(60)}$ para os parâmetros ultrassonográficos que se relacionaram estatisticamente ao desfecho estudado e verificado o ponto de corte para a melhor detecção do sucesso da indução do parto, fase ativa do trabalho de parto e parto vaginal em 24 horas, e verificadas as sensibilidades e especificidades e área sobre a curva 
(AUC) para cada ponto de corte. A análise multivariada foi conduzida, então, utilizando-se a construção de um modelo de regressão logística para o cálculo da probabilidade da ocorrência do sucesso da indução do parto e dos outros desfechos secundários, em função das exposições estudadas ${ }^{(60)}$. Os modelos foram construídos com e sem o Índice de Bishop, gerando para cada modelo final, para cada desfecho, uma fórmula de previsão de probabilidade. Os testes foram realizados com nível de significância de 5\%.

A reprodutibilidade das medidas ultrassonográficas foi avaliada calculando-se as correlações intraclasses com os respectivos intervalos com $95 \%$ de confiança ${ }^{(61)}$, tanto intra como interobservador, e elaborados os respectivos gráficos de Bland-Altman para cada medida avaliada ${ }^{(58)}$, sendo a variação interoperador realizada pela médica pesquisadora e seu orientador em $20 \%$ da amostra de pacientes (40 casos). As variáveis que mantiveram a significância estatística conjuntamente permaneceram nos modelos finais. No presente estudo foram utilizados os softwares Excel 2003 e SPSS 13.0, para armazenamento e análise dos dados.

\subsection{Caracterização da população estudada}

A amostra inicial foi composta de 210 gestantes que preencheram os critérios de inclusão deste estudo, sendo que quatro pacientes foram excluídas pela presença de alterações na cardiotocografia fetal, duas pela evolução espontânea para trabalho de parto ativo e quatorze pela presença 
de macrossomia fetal ao nascimento, ou seja, recém-nascidos com peso superior a 4000 g. Das pacientes que apresentaram alteração dos parâmetros da cardiotocografia, três apresentaram Desacelerações IntraParto Tipo II de repetição, e uma apresentou padrão comprimido e Desacelerações Intra-Parto Tipo III de repetição, sendo então realizada cesárea, sem a possibilidade de indução do parto. Já as pacientes que apresentaram contrações uterinas regulares e evolução para trabalho de parto ativo, culminaram com a ocorrência de parto vaginal sem a necessidade de indução deste. Desse modo, foram excluídas vinte pacientes da amostra inicial, permanecendo no presente estudo 190 gestantes.

Conforme a caracterização da amostra de pacientes desse estudo, apresentamos que a maioria das gestantes é da raça branca e estado civil casado ou acompanhado (Tabela 1).

Tabela 1 - Distribuição da raça e estado civil das 190 gestantes submetidas à avaliação do colo uterino pela ultrassonografia transvaginal para predição do sucesso da indução do parto. HU-USP, fevereiro de 2008 a fevereiro de 2010.

\begin{tabular}{lcc}
\hline Variável & Frequência & \% Total \\
\hline \hline RAÇA & & \\
\hline Branca & 96 & 50,5 \\
\hline Parda & 63 & 33,2 \\
\hline Negra & 31 & 16,2 \\
\hline ESTADO CIVIL & & \\
\hline Solteira & 82 & 43,2 \\
\hline Amasiada & 68 & 35,8 \\
\hline Casada & 40 & 21,1 \\
\hline TOTAL & $\mathbf{1 9 0}$ & $\mathbf{1 0 0}$ \\
\hline
\end{tabular}


A média +/- desvio padrão da idade materna foi de $24,58+/-5,94$ anos, sendo a mediana de 24 anos, com valores mínimos e máximos de 13 a 41, respectivamente. A idade gestacional média foi de 40,05 semanas, bem como o IMC, que apresentou média de $28,26+/-4,43 \mathrm{~kg} / \mathrm{m}^{2}$ (Tabela 2).

Tabela 2- Descrição da idade materna, idade gestacional, paridade e IMC das 190 gestantes submetidas à avaliação do colo uterino pela ultrassonografia transvaginal para predição do sucesso da indução do parto. HU-USP, fevereiro de 2008 a fevereiro de 2010.

\begin{tabular}{lcccccc}
\hline Variável & Média & DP & Mediana & Mínimo & Máximo & N \\
\hline IM & 24,58 & 5,94 & 24 & 13 & 41 & 190 \\
\hline IG & 40,05 & 1,16 & 40,29 & 37,20 & 42 & 190 \\
\hline Paridade & 1,89 & 1,34 & 1 & 1 & 7 & 190 \\
\hline IMC & 28,26 & 4,43 & 28 & 18 & 50 & 190
\end{tabular}

Nota: IM = idade materna (anos), IG = idade gestacional (semanas), IMC = índice de massa corpórea $(\mathrm{Kg} / \mathrm{m} 2)$.

Quanto à paridade, a mediana foi de um parto vaginal prévio, sendo que 102 (54\%) das gestantes eram nulíparas e 88 (46\%) eram multíparas, neste estudo definido como a presença de um ou mais partos vaginais prévios (Gráfico 1). 
Gráfico 1: Distribuição quanto à paridade das 190 gestantes submetidas à avaliação do colo uterino pela ultrassonografia transvaginal para predição do sucesso da indução do parto. HU-USP, fevereiro de 2008 a fevereiro de 2010.

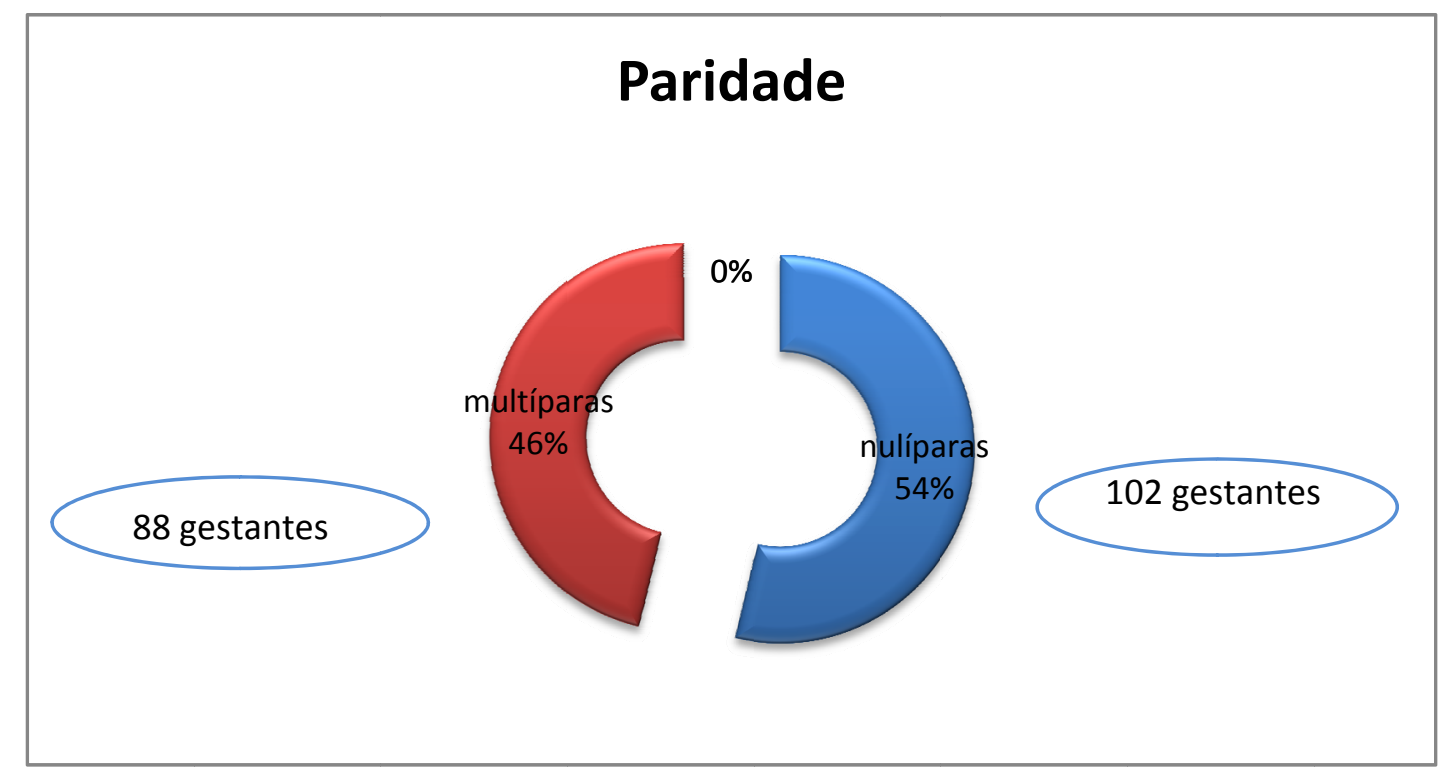

As indicações clínicas para a indução do parto no presente estudo foram: pós datismo (64/190) com 34\%, oligoâmnio (63/190) - 32,5\%, Síndromes Hipertensivas, que engloba a DHEG (doença hipertensiva específica da gestação) e Hipertensão Arterial Sistêmica (22/190) - 11,5\%, Restrição de Crescimento Fetal (RCF - 41/190) - 22\% (Gráfico 2). 
Gráfico 2: Descrição das indicações clínicas de indução do parto das 190 gestantes submetidas à avaliação do colo uterino pela ultrassonografia transvaginal para predição do sucesso da IP. HU-USP, fevereiro de 2008 a fevereiro de 2010.

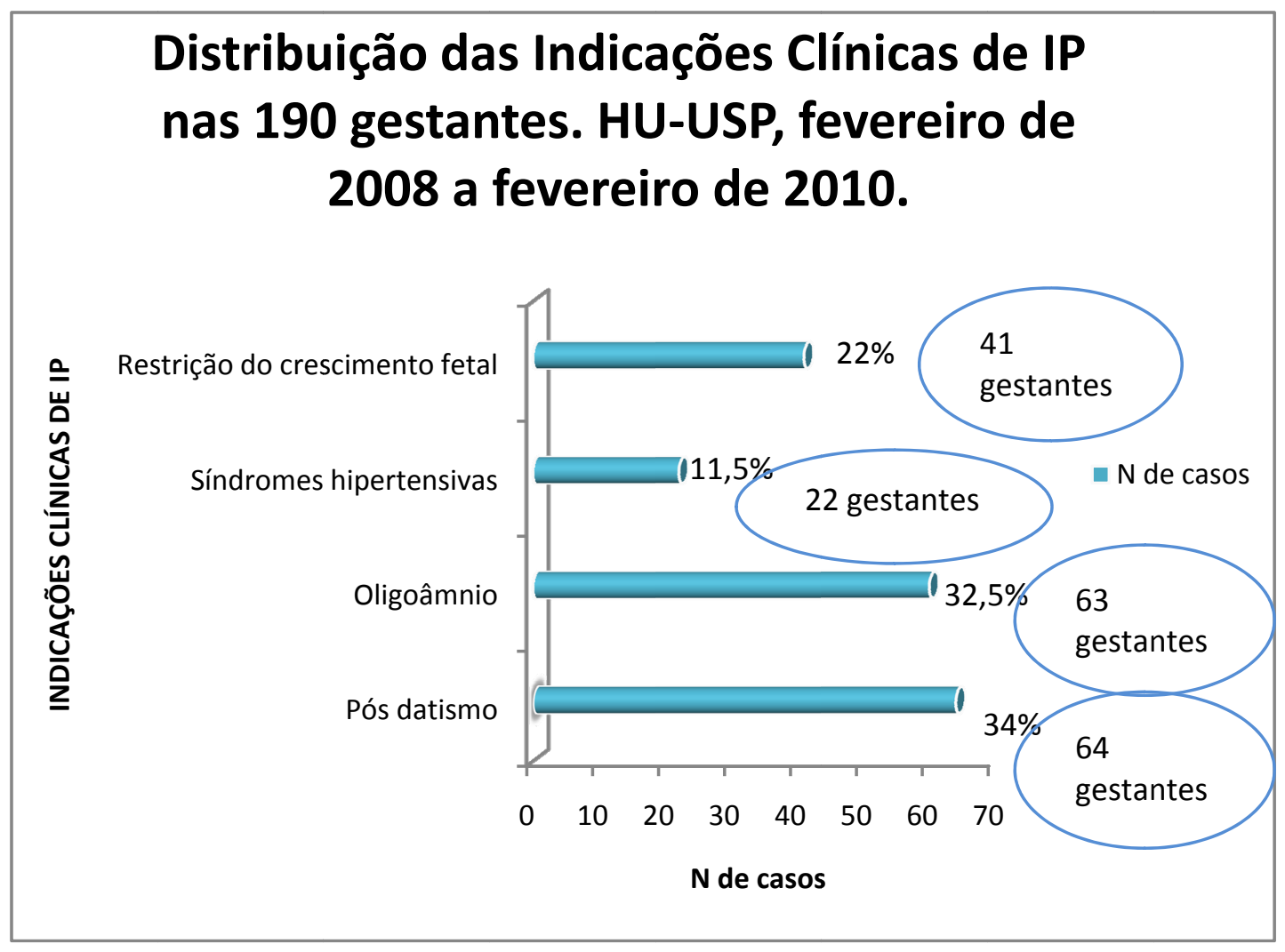

A escolha das medicações utilizadas na indução do parto, misoprostol e ocitocina, foi baseada no escore de Bishop realizado na admissão, ou seja, gestantes com escore de Bishop inferior a 6 realizaram maturação cervical com misoprostol e após ocitocina intravenosa e aminiotomia. Já para gestantes com escore de Bishop igual ou superior a 6 , a escolha era pelo uso imediato da ocitocina intravenosa. Do total de gestantes incluídas no presente estudo, $70(36,8 \%)$ utilizaram somente misoprostol intravaginal, $62(32,6 \%)$ somente ocitocina intravenosa, 
enquanto que $58(30,6 \%)$ gestantes evoluíram para o parto após uso de misoprostol intravaginal e ocitocina complementar (Gráfico 3).

Gráfico 3: Distribuição das medicações utilizadas na IP das 190 gestantes submetidas à avaliação do colo uterino pela ultrassonografia transvaginal para predição do sucesso da IP. HU-USP, fevereiro de 2008 a fevereiro de 2010.

\section{Medicações utilizadas na IP}

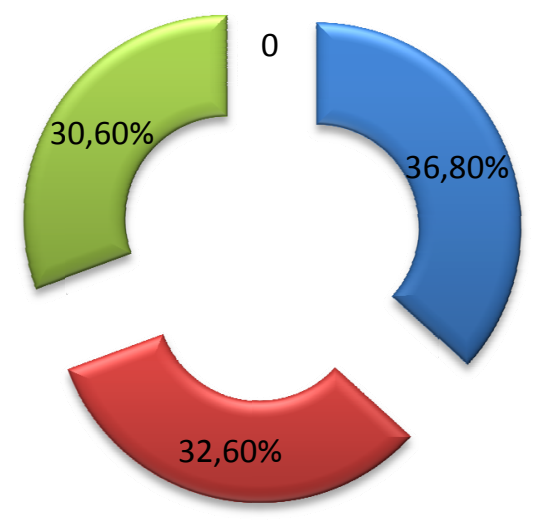

$\square$ misoprostol

acitocina 
5 RESULTADOS 


\section{Gerais}

A amostra final foi constituída de 190 gestantes com idade gestacional entre 37 e 42 semanas, submetidas à indução do parto e que foram acompanhadas e analisadas de acordo com o método proposto. $\mathrm{O}$ sucesso da indução do parto, o parto vaginal, ocorreu em 133 pacientes (70\%), sendo que em 119 pacientes (62\%) o parto ocorreu em até 24 horas do início da indução.

Gráfico 4: Distribuição quanto ao tipo de parto das 190 gestantes submetidas à avaliação do colo uterino pela ultrassonografia transvaginal para predição do sucesso da IP. HU-USP, fevereiro de 2008 a fevereiro de 2010.

\section{Tipo de parto}

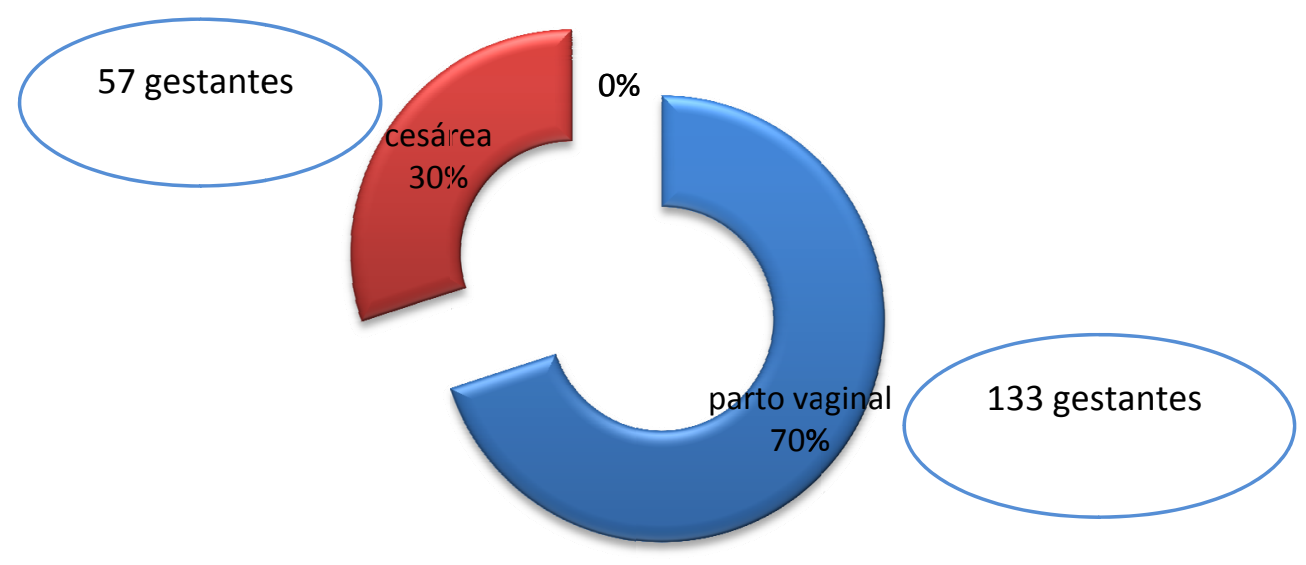


Do total, 57 gestantes evoluíram para cesárea (30\%), sendo que dessas, 25 (44\%) foram por distocia funcional; 15 (26,3 \%) por desproporção cefálo-pélvica; 7 (12\%) definidas como falha de indução do parto e 10 $(17,7 \%)$ evoluíram para cesárea por sofrimento fetal agudo (SFA ) (Gráfico $5)$.

Gráfico 5: Distribuição das 57 gestantes quanto às indicações de cesárea após a IP. HU-USP, fevereiro de 2008 a fevereiro de 2010.

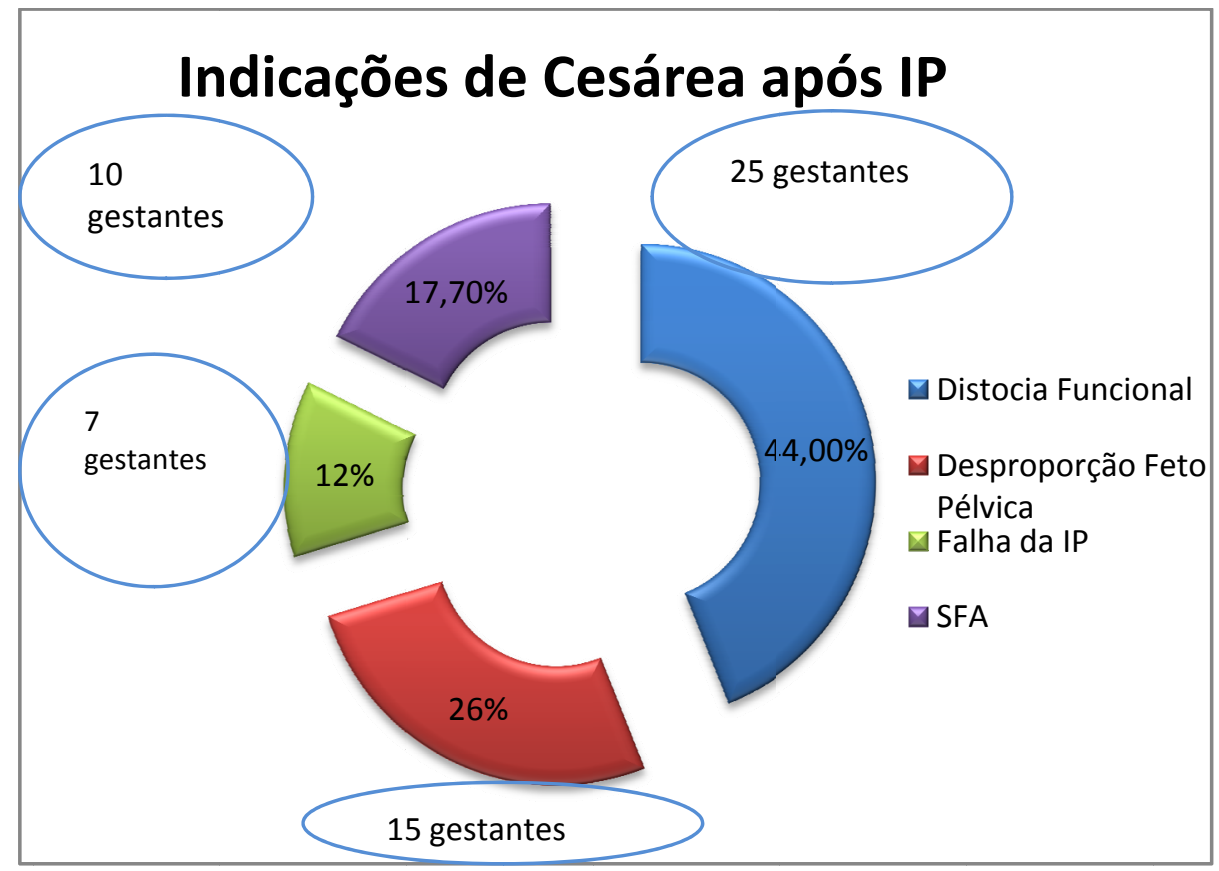

Quanto às variáveis das gestantes incluídas no estudo, o Índice de Bishop médio foi 3,61 , o tempo entre indução e parto médio foi de 14,15 horas e o tempo de trabalho de parto foi de 3,08 horas. As médias das 
medidas ultrassonográficas do colo uterino foram: $25,73 \mathrm{~mm}$ do comprimento do colo uterino, 33,79 mm para a distância da apresentação fetal ao OCE e 6,79 mm para a dilatação do colo uterino. O peso médio dos recém-nascidos foi de 3,223 gramas (Tabela 3).

Tabela 3 - Descrição do Índice de Bishop, Tempo entre IP e parto, Tempo de trabalho de parto, peso dos RN e variáveis ultrassonográficas das 190 gestantes submetidas à avaliação do colo uterino pela ultrassonografia transvaginal para predição do sucesso da IP. HU-USP, fevereiro de 2008 a fevereiro de 2010.

\begin{tabular}{|c|c|c|c|c|c|c|}
\hline Variável & Média & DP & Mediana & Mínimo & Máximo & $\mathbf{N}$ \\
\hline I-Bishop & 3,61 & 1,87 & 1 & 1 & 8 & 190 \\
\hline Comp (USG) & 25,73 & 8,39 & 25,5 & 6,8 & 47 & 190 \\
\hline Dist Ap/OCE(USG) & i) 33,79 & 8,13 & 34 & 14 & 52 & 190 \\
\hline Dilat (USG) & 6,79 & 2,69 & 6,3 & 2 & 13 & 190 \\
\hline T de TP & 3,08 & 2,3 & 3 & 0 & 14 & 190 \\
\hline T entre IP & 14,15 & 7,92 & 12,75 & 2,38 & 35,13 & 190 \\
\hline Peso dos RN & 3223,4 & 436,72 & 3272,5 & 1790 & 3998 & 190 \\
\hline \multicolumn{7}{|c|}{$\begin{array}{l}\text { Nota: Comp (USG) = comprimento do colo à ultrassonografia transvaginal (mm), Dis } \\
\text { Ap/OCE (USG) = distância da apresentação fetal ao OCE à ultrassonografia transvagina } \\
\text { (mm), Dilat (USG) = dilatação do colo uterino à ultrassonografia transvaginal (mm), T de Th } \\
=\text { tempo de trabalho de parto (horas), T entre IP = tempo ou intervalo entre o início d } \\
\text { indução e o parto (horas), peso dos RN = peso dos recém-nascidos (gramas). }\end{array}$} \\
\hline
\end{tabular}

Quanto à variável imagem em funil no $\mathrm{OCl}$, esta esteve presente em 70 gestantes $(41,6 \%)$, em detrimento de 111 gestantes $(58,4 \%)$ que não apresentaram esta imagem pela ultrassonografia transvaginal (Gráfico 6). 
Gráfico 6: Distribuição da presença ou ausência da variável ultrassonográfica, imagem em funil, nas 190 gestantes submetidas à avaliação do colo uterino pela ultrassonografia transvaginal para predição do sucesso da indução do parto. HU-USP, fevereiro de 2008 a fevereiro de 2010.

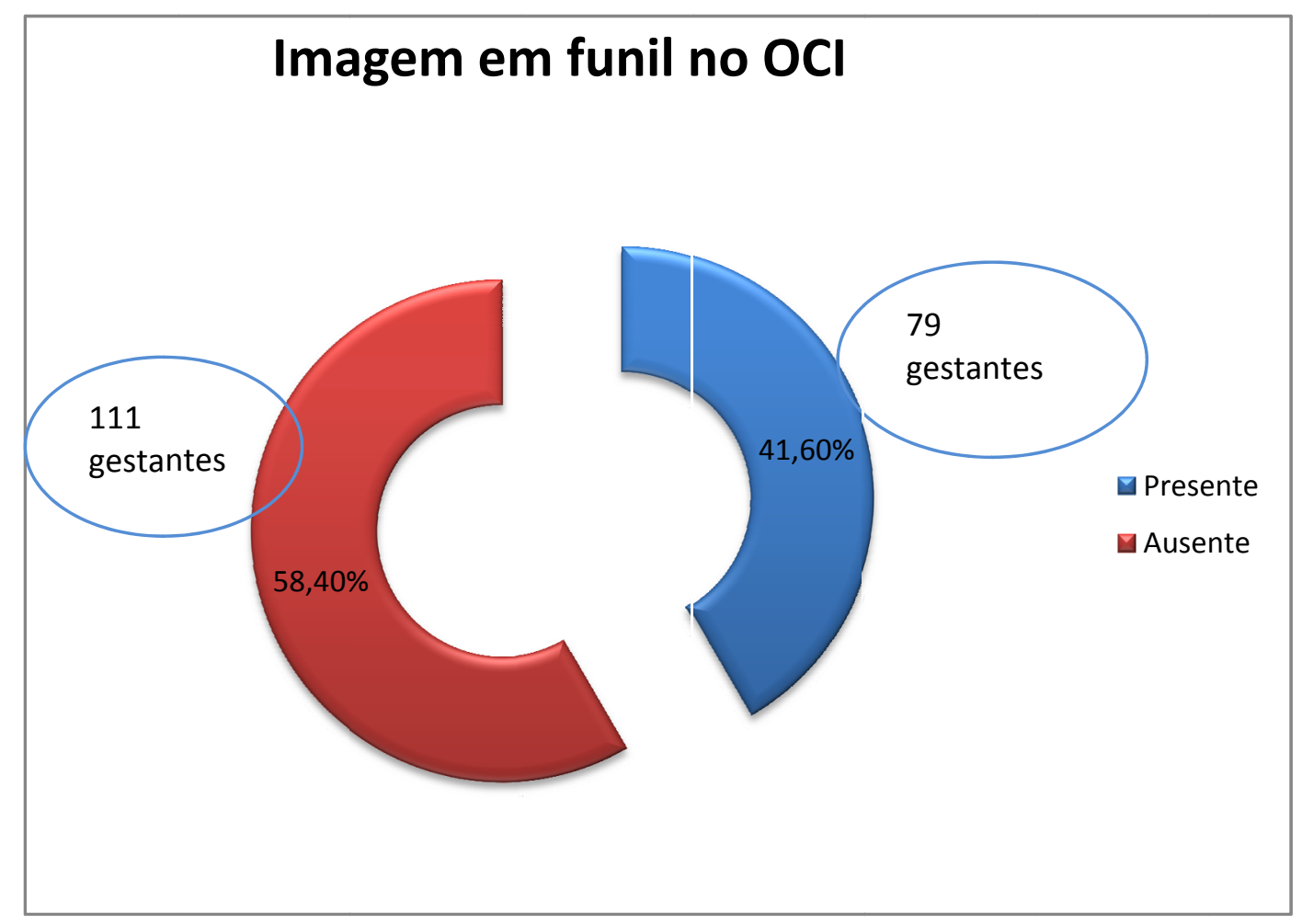

Já a presença de fase ativa do trabalho de parto foi identificada em 155 gestantes $(81,6 \%)$, em contrapartida a 35 gestantes $(18,4 \%)$ que não preencheram critérios para esse desfecho (Gráfico 7). 
Gráfico 7: Distribuição das 190 gestantes quanto à presença ou ausência de fase ativa do parto durante a IP. HU-USP, fevereiro de 2008 a fevereiro de 2010.

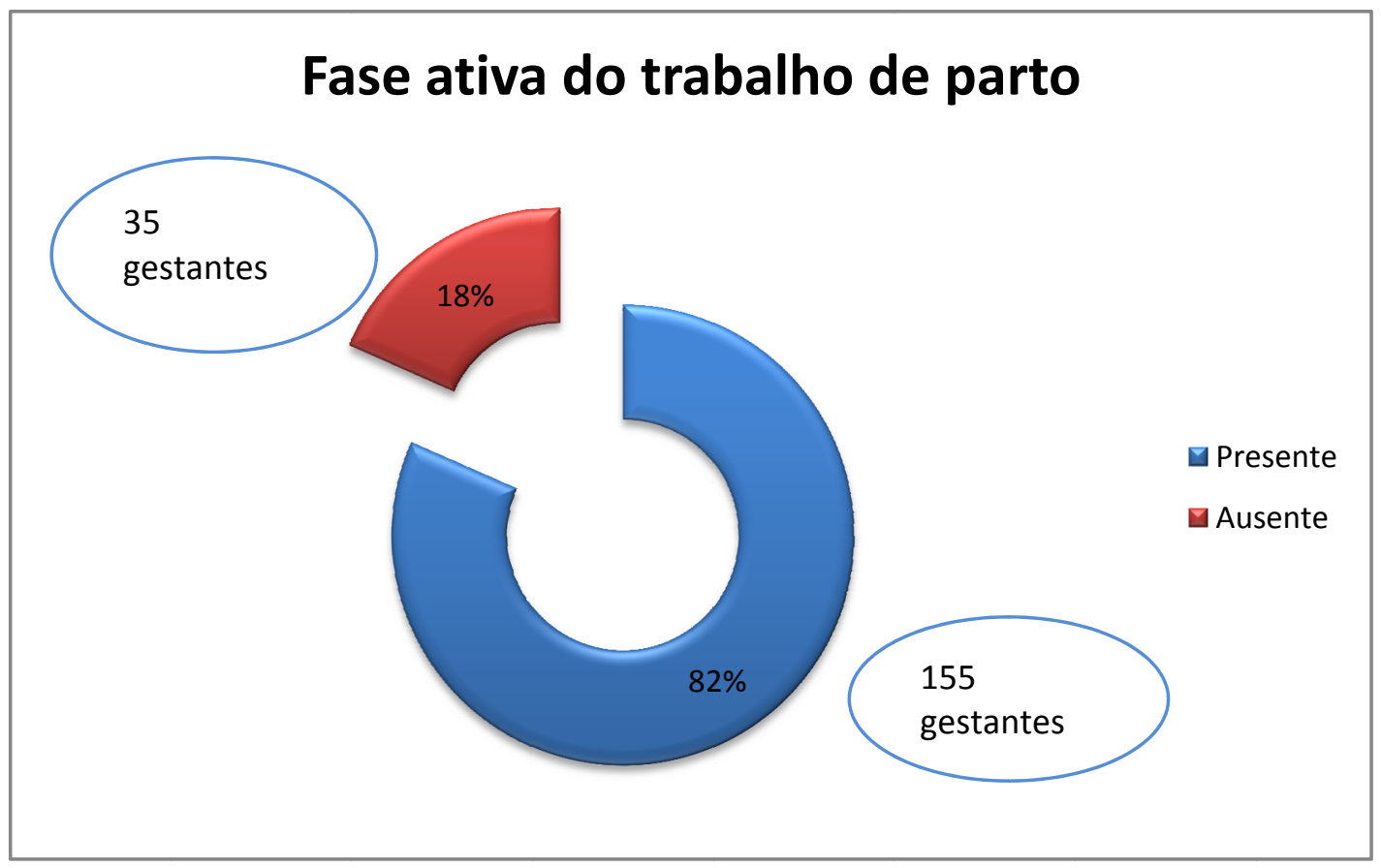

A taxa de intercorrências durante o parto foi: presença de mecôneo intraparto em 20 casos $(11,4 \%), 5$ casos $(2,6 \%)$ evoluíram com hipotonia uterina pós parto, sendo todos revertidos com o uso de ocitocina endovenosa (3 casos) e ergotrate IM (2 casos), sem necessidade de outras intervenções.

Quanto às intercorrências dos recém-nascidos: 1 caso $(0,5 \%)$ de desconforto respiratório, sendo este encaminhado ao berçário, sem necessidade de admissão em UTI, bem como os outros 189 recém-nascidos que também não necessitaram de admissão em Unidade de Terapia Intensiva. 
2. Avaliação do colo uterino pela ultrassonografia transvaginal na indução do parto

2.1. Associação do comprimento do colo uterino, distância da apresentação fetal ao OCE, dilatação cervical e imagem em funil no $\mathrm{OCI}$ ao sucesso da IP

As medidas do comprimento do colo (OR: 0,923-IC de 95\% (0,886 0,96); $p<0,001)$, a distância da apresentação fetal ao OCE (OR: 0,902 - IC de 95\% (0,861-0,944; $p<0,001)$, a dilatação cervical (OR:1,391- IC de 95\% $(1,206-1,605) ; p<0,001)$ e a presença da imagem em funil no OCI (OR: 5,93IC de 95\% (2,69-13,05); $p<0,001)$ estão relacionadas e influenciam isoladamente o tipo de parto $(p<0,05)$. O comprimento cervical médio no grupo que evoluiu para o sucesso da IP, foi de $24,12+/-7,93 \mathrm{~mm}$, a distância média da apresentação fetal ao OCE apresentou-se como 31,97+/- 7,80 mm, ambos inferiores em relação ao grupo que evoluiu para a cesárea. Já a dilatação média no grupo das gestantes que evoluíram para parto vaginal foi de 7,40+/-2,61 mm, superior à dilatação demonstrada no grupo do insucesso da IP (Tabela 4). 
Tabela 4- Descrição das medidas ultrassonográficas, segundo o tipo de parto e testes de comparação, das 190 gestantes submetidas à avaliação do colo uterino pela ultrassonografia transvaginal para predição do sucesso da IP. HU-USP, fevereiro de 2008 a fevereiro de 2010.

\begin{tabular}{|c|c|c|c|c|c|c|c|c|c|c|c|}
\hline \multirow[t]{2}{*}{ Variável } & \multirow[t]{2}{*}{ Parto } & \multirow[t]{2}{*}{ Média } & \multirow[t]{2}{*}{ DP } & \multirow[t]{2}{*}{ Med } & \multirow[t]{2}{*}{ Mín } & \multirow[t]{2}{*}{ Máx } & \multirow[t]{2}{*}{$\mathbf{N}$} & \multirow[t]{2}{*}{ OR } & \multicolumn{2}{|c|}{ IC(95\%) } & \multirow[t]{2}{*}{$p$} \\
\hline & & & & & & & & & Inferior & Superior & \\
\hline \multirow[t]{2}{*}{ C colo } & Vaginal & 24,12 & 7,93 & 24 & 8 & 46 & 133 & 0,923 & 0,886 & 0,961 & $<0,001^{*}$ \\
\hline & Cesárea & 29,47 & 8,29 & 30 & 6,8 & 47 & 57 & & & & \\
\hline \multirow[t]{2}{*}{ Dist A/OE } & Vaginal & 31,97 & 7,80 & 32 & 14 & 50 & 133 & 0,902 & 0,861 & 0,944 & $<0,001^{*}$ \\
\hline & Cesárea & 38,05 & 7,29 & 38 & 18 & 52 & 57 & & & & \\
\hline \multirow[t]{2}{*}{ Dilat } & Vaginal & 7,40 & 2,61 & 7,2 & 2,8 & 13 & 133 & 1,391 & 1,206 & 1,605 & $<0,001^{*}$ \\
\hline & Cesárea & 5,36 & 2,35 & 5 & 2 & 10,2 & 57 & & & & \\
\hline
\end{tabular}

Nota: $\mathrm{C}$ colo $=$ comprimento do colo uterino à ultrassonografia transvaginal $(\mathrm{mm})$, Dist $\mathrm{A} / \mathrm{OE}=$ distância da apresentação fetal ao OCE à ultrassonografia transvaginal $(\mathrm{mm})$, Dilat $=$ dilatação do colo uterino à ultrassonografia transvaginal $(\mathrm{mm})$. Med $=$ mediana, ${ }^{*}$ Resultado do teste t-Student. OR correspondente ao aumento de uma unidade explicativa.

A imagem em funil no $\mathrm{OCl}$ foi identificada em $88,6 \%$ das pacientes que evoluíram para parto vaginal, em detrimento de $11,4 \%$ no grupo da cesárea (OR: 5,93- IC de 95\% (2,69-13,05); $p<0,001)$. (Tabela 5). Desse modo, demonstrou-se que todas as variáveis ultrassonográficas se relacionaram ao sucesso da IP. 
Tabela 5- Descrição da variável ultrassonográfica imagem em funil, segundo o tipo de parto e testes de comparação, das 190 gestantes submetidas à avaliação do colo uterino pela ultrassonografia transvaginal para predição do sucesso da IP. HU-USP, fevereiro de 2008 a fevereiro de 2010.

\begin{tabular}{|c|c|c|c|c|c|c|}
\hline \multirow[t]{2}{*}{ Variável } & \multicolumn{2}{|c|}{ Parto } & \multirow[t]{2}{*}{ Total } & \multirow[t]{2}{*}{ OR } & IC $(95 \%)$ & $p$ \\
\hline & $\begin{array}{l}\text { Vaginal } \\
\mathrm{N}\end{array}$ & $\begin{array}{l}\text { Cesárea } \\
\text { N } \%\end{array}$ & & & inferior superior & \\
\hline
\end{tabular}

\begin{tabular}{|c|c|c|c|c|c|c|c|c|c|}
\hline \multicolumn{10}{|l|}{ I FUNIL } \\
\hline Ausente & 63 & 56,8 & 48 & 43,2 & 111 & & & & \\
\hline Presente & 70 & 88,6 & 9 & 11,4 & 79 & 5,93 & 2,69 & 13,05 & $<0,001$ \\
\hline Total & 133 & 70 & 57 & 30 & 190 & & & & \\
\hline
\end{tabular}

Nota: I funil = imagem em funil identificada no $\mathrm{OCl}$ e adentrando canal endocervical.

2.2. Associação do comprimento do colo uterino, distância da apresentação fetal ao OCE, dilatação cervical e imagem em funil no $\mathrm{OCI}$ à ocorrência do parto vaginal em até $\mathbf{2 4}$ horas após a indução do parto

O desfecho parto vaginal em 24 horas se relacionou estatisticamente à medida do comprimento cervical (OR: 0,903- IC de $95 \%$ $(0,866-0,942) ; p<0,001)$, da distância da apresentação fetal ao OCE (OR: 0,887- IC de 95\% (0,847-0,929); $p<0,001)$, sendo ambas inferiores no grupo que apresentou o desfecho esperado. O comprimento do colo uterino e a distância da apresentação fetal médios no grupo que apresentou o desfecho esperado foi de $23,34+/-7,54 \mathrm{~mm}$ e $31,29+/-7,55 \mathrm{~mm}$, respectivamente. Já a dilatação cervical média nesse grupo foi de 7,61 +/-2,61 mm, sendo que esta também se associou à ocorrência de parto vaginal em até 24 horas do início da IP (OR: 1,43- IC de 95\% (1,247-1,640); $p<0,001)$, apresentando medidas superiores no grupo de evolução para parto vaginal em até 24 
horas do início da IP (Tabela 6).

Tabela 6- Descrição das medidas ultrassonográficas, segundo o desfecho parto vaginal em até 24 horas após a IP e testes de comparação, das 190 gestantes submetidas à avaliação do colo uterino pela ultrassonografia transvaginal para predição do sucesso da IP. HU-USP, fevereiro de 2008 a fevereiro de 2010.

\begin{tabular}{|c|c|c|c|c|c|c|c|c|c|c|c|}
\hline \multirow[t]{2}{*}{ Variável } & \multirow[t]{2}{*}{ PV 24hs } & \multirow[t]{2}{*}{ Média } & \multirow[t]{2}{*}{ DP } & \multirow[t]{2}{*}{ Med } & \multirow[t]{2}{*}{ Mín } & \multirow[t]{2}{*}{ Máx } & \multirow[t]{2}{*}{$\mathbf{N}$} & \multirow[t]{2}{*}{ OR } & \multicolumn{2}{|c|}{ IC (95\%) } & \multirow[t]{2}{*}{$\mathbf{p}$} \\
\hline & & & & & & & & & Inferior & Superior & \\
\hline \multirow[t]{2}{*}{ C colo } & $\operatorname{sim}$ & 23,34 & 7,54 & 23 & 8 & 45 & 119 & 0,903 & 0,886 & 0,942 & $<0,001^{*}$ \\
\hline & não & 29,73 & 8,25 & 30 & 6,8 & 47 & 71 & & & & \\
\hline \multirow[t]{2}{*}{ Dist A/OE } & $\operatorname{sim}$ & 31,29 & 7,55 & 32 & 14 & 50 & 119 & 0,887 & 0,847 & 0,929 & $<0,001^{*}$ \\
\hline & não & 38,05 & 7,29 & 38 & 18 & 52 & 71 & & & & \\
\hline \multirow[t]{2}{*}{ Dilat } & sim & 7,61 & 2,61 & 8 & 2,8 & 13 & 119 & 1,430 & 1,247 & 1,640 & $<0,001^{*}$ \\
\hline & não & 5,41 & 2,24 & 5 & 2 & 10,2 & 71 & & & & \\
\hline
\end{tabular}

Nota: PV 24hs = parto vaginal em até 24 horas após a indução do parto, $\mathrm{C}$ colo $=$ comprimento do colo uterino à ultrassonografia transvaginal $(\mathrm{mm})$, Dist $\mathrm{A} / \mathrm{OE}=$ distância da apresentação fetal ao OCE à ultrassonografia transvaginal $(\mathrm{mm})$, Dilat = dilatação do colo uterino à ultrassonografia transvaginal $(\mathrm{mm})$. * Resultado do teste t-Student. OR correspondente ao aumento de uma unidade explicativa.

A presença da imagem em funil no $\mathrm{OCl}$ foi identificada em $84,8 \%$ das gestantes que evoluíram para o desfecho esperado (OR: 6,33 - IC de $95 \%(3,09-13,00) ; p<0,001)$, em detrimento de $15,2 \%$ no outro grupo estudado, confirmando, assim, a correlação entre essa variável ultrassonográfica e a evolução para parto vaginal em 24 horas após a IP. (Tabela 7). 
Tabela 7- Descrição da variável ultrassonográfica imagem em funil, segundo a ocorrência de parto vaginal em até 24 horas após o início da IP e testes de comparação, das 190 gestantes submetidas à avaliação do colo uterino pela ultrassonografia transvaginal para predição do sucesso da IP- HU-USP, fevereiro de 2008 a fevereiro de 2010.

\begin{tabular}{|c|c|c|c|c|c|c|c|c|c|}
\hline \multirow[t]{2}{*}{ Variável } & \multicolumn{4}{|c|}{ PV 24 hs } & \multirow[t]{2}{*}{ Total } & \multirow[t]{2}{*}{ OR } & \multicolumn{2}{|c|}{ IC (95\%) } & \multirow[t]{2}{*}{$p$} \\
\hline & não & $\%$ & sim & $\%$ & & & minerior & superior & \\
\hline \multicolumn{10}{|l|}{ I FUNIL } \\
\hline Ausente & 59 & 53,2 & 52 & 46,8 & 111 & & & & \\
\hline Presente & 12 & 15,2 & 67 & 84,8 & 79 & 6,22 & 3,09 & 13,00 & $<0,001$ \\
\hline Total & 71 & 37,4 & 119 & 62,6 & 190 & & & & \\
\hline
\end{tabular}

Nota: I funil = imagem em funil identificada no $\mathrm{OCl}$ e adentrando canal endocervical, PV 24 hs- parto vaginal em até 24 horas da IP.

2.3. Associação do comprimento do colo uterino, distância da apresentação fetal ao OCE, dilatação cervical e imagem em funil no $\mathrm{OCI}$ à presença de fase ativa do trabalho de parto após a IP

Quanto ao desfecho trabalho de parto ativo ou fase ativa do parto, os resultados demonstram que as medidas do comprimento do colo (OR: 0,881IC de 95\% (0,836-0,929); $p<0,001)$ e a distância da apresentação fetal ao OCE (OR: 0,866- IC de 95\% (0,817-0,918); $p<0,001)$ são estatisticamente significativas e inferiores em gestantes que presenciaram o trabalho de parto ativo $(p<0,05)$. Quanto à medida da dilatação cervical (OR: 1,602- IC de $95 \%(1,306-1,965) ; \quad p<0,001)$, ocorre o oposto, ou seja, pacientes que atingiram a fase ativa do trabalho de parto apresentaram medida superior às que não evoluíram para essa fase. O comprimento cervical, distância da apresentação fetal ao OCE e a dilatação médios no grupo que atingiu a fase 
ativa do parto foi: $24,25+/-7,78 \mathrm{~mm} ; 32,32+/-7,68 \mathrm{~mm} ; 7,25+/-2,60 \mathrm{~mm}$, respectivamente (Tabela 8$)$.

Tabela 8- Descrição das medidas ultrassonográficas, segundo o desfecho fase ativa do parto e testes de comparação, das 190 gestantes submetidas à avaliação do colo uterino pela ultrassonografia transvaginal para predição do sucesso da IP. HU-USP, fevereiro de 2008 a fevereiro de 2010.

\begin{tabular}{|c|c|c|c|c|c|c|c|c|c|c|c|}
\hline \multirow[t]{2}{*}{ Variável } & \multirow[t]{2}{*}{ TPativo } & \multirow[t]{2}{*}{ Média } & \multirow[t]{2}{*}{ DP } & \multirow[t]{2}{*}{ Med } & \multirow[t]{2}{*}{ Mín } & \multirow[t]{2}{*}{ Máx } & \multirow[t]{2}{*}{$\mathbf{N}$} & OR & \multicolumn{2}{|c|}{ IC (95\%) } & \multirow[t]{2}{*}{$\mathbf{p}$} \\
\hline & & & & & & & & \multicolumn{3}{|c|}{ Inferior Superior } & \\
\hline C colo & $\operatorname{sim}$ & 24,25 & 7,78 & 24 & 6,8 & 46 & 155 & 0,881 & 0,836 & 0,929 & $<0,001^{*}$ \\
\hline & não & 32,29 & 7,90 & 35 & 13 & 47 & 35 & & & & \\
\hline \multirow[t]{2}{*}{ Dist A/OE } & $\operatorname{sim}$ & 32,32 & 7,68 & 32 & 14 & 52 & 155 & 0,866 & 0,817 & 0,918 & $<0,001^{*}$ \\
\hline & não & 40,34 & 6,78 & 40 & 18 & 52 & 35 & & & & \\
\hline \multirow[t]{2}{*}{ Dilat } & $\operatorname{sim}$ & 7,25 & 2,60 & 7 & 2,8 & 13 & 155 & 1,602 & 1,306 & 1,965 & $<0,001^{*}$ \\
\hline & não & 4,73 & 2,07 & 4,1 & 2 & 9,6 & 35 & & & & \\
\hline
\end{tabular}

Nota: TPativo $=$ trabalho de parto ativo ou fase ativa do parto, $\mathrm{C}$ colo $=$ comprimento do colo uterino à ultrassonografia transvaginal $(\mathrm{mm})$, Dist $\mathrm{A} / \mathrm{OE}$ = distância da apresentação fetal ao OCE à ultrassonografia transvaginal $(\mathrm{mm})$, Dilat $=$ dilatação do colo uterino à ultrassonografia transvaginal $(\mathrm{mm})$. ${ }^{*}$ Resultado do teste t-Student. OR correspondente ao aumento de uma unidade explicativa.

Identificou-se a presença da imagem em funil no $\mathrm{OCl}$ e adentrando o canal endocervical em $97,5 \%$ das gestantes que apresentaram o desfecho esperado, em detrimento de $2,5 \%$ das que não evoluíram para a fase ativa do parto (OR: 16,29- IC de 95\% (3,78-70,25)) (Tabela 9). Desse modo, no presente estudo todas as medidas ultrassonográficas do colo uterino se associaram estatisticamente à presença de trabalho de parto ativo após a IP. 
Tabela 9- Descrição da variável ultrassonográfica imagem em funil, segundo a presença da fase ativa do parto, ou trabalho de parto ativo após o início da IP e testes de comparação, das 190 gestantes submetidas à avaliação do colo uterino pela ultrassonografia transvaginal para predição do sucesso da IP. HU-USP, fevereiro de 2008 a fevereiro de 2010.

\begin{tabular}{|c|c|c|c|c|c|c|c|c|c|}
\hline \multirow[t]{2}{*}{ Variável } & \multicolumn{3}{|c|}{ TPativo } & & \multirow[t]{2}{*}{ Total } & \multirow[t]{2}{*}{ OR } & \multicolumn{2}{|c|}{ IC $(95 \%)$} & \multirow[t]{2}{*}{$\mathbf{p}$} \\
\hline & não & $\%$ & sim & $\%$ & & & & 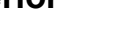 & \\
\hline \multicolumn{10}{|l|}{ I FUNIL } \\
\hline Ausente & 33 & 29,7 & 78 & 70,3 & 111 & & & & \\
\hline Presente & 2 & 2,5 & 77 & 97,5 & 79 & 16,29 & 3,78 & 70,25 & $<0,001$ \\
\hline Total & 35 & 18,4 & 155 & 81,6 & 190 & & & & \\
\hline
\end{tabular}

\section{Associação do Índice de Bishop e Indução do Parto}

O Índice de Bishop se associou significativamente à ocorrência do sucesso da indução do parto (OR: 1,721- IC de 95\% (1,363-2,172); $p<$ 0.001); evolução para parto vaginal em até 24 horas do início da indução (OR:1,747- IC de 95\% $(1,410-2,166) ; p<0.001)$ e presença de trabalho de parto ativo, ou fase ativa do parto (OR: 2,110- IC de 95\% (1,479-3,012); $p$ $<0.001$ ) (Tabela 10). 
Tabela 10- Descrição do Índice de Bishop, segundo os desfechos: sucesso da IP, parto vaginal em 24 horas após a IP, fase ativa do parto e testes de comparação, das 190 gestantes submetidas à avaliação do colo uterino pela ultrassonografia transvaginal para predição do sucesso da IP. HU-USP, fevereiro de 2008 a fevereiro de 2010.

\begin{tabular}{|c|c|c|c|c|c|c|c|c|c|c|c|}
\hline \multirow[t]{2}{*}{ Variável } & \multirow[t]{2}{*}{ Desfecho } & \multirow[t]{2}{*}{ Média } & \multirow[t]{2}{*}{ DP } & \multirow[t]{2}{*}{ Med } & \multirow[t]{2}{*}{ Mín } & \multirow[t]{2}{*}{ Máx } & \multirow[t]{2}{*}{$\mathbf{N}$} & \multirow[t]{2}{*}{ OR } & \multicolumn{2}{|c|}{ IC (95\%) } & \multirow[t]{2}{*}{$\mathbf{p}$} \\
\hline & & & & & & & & & erior $\mathbf{S}$ & uperior & \\
\hline \multirow[t]{2}{*}{ I-B } & vaginal & 4,05 & 1,90 & 3 & 1 & 8 & 133 & 1,721 & 1,363 & 2,171 & $<0,001 \#$ \\
\hline & cesárea & 2,58 & 1,32 & 2 & 1 & 7 & 57 & & & & \\
\hline \multirow[t]{2}{*}{ I-B } & PV24hs/s & 4,19 & 1,70 & 4 & 1 & 8 & 119 & 1,747 & 1,410 & 2,166 & $<0,001 \#$ \\
\hline & PV24hs/n & 2,63 & 1,35 & 2 & 1 & 7 & 71 & & & & \\
\hline \multirow[t]{2}{*}{ I-B } & TPativo/s & 3,02 & 1,88 & 3 & 1 & 8 & 155 & 2,110 & 1,479 & 3,012 & $<0,001 \#$ \\
\hline & TPativo/n & 2,26 & 1,07 & 2 & 1 & 5 & 35 & & & & \\
\hline
\end{tabular}

Nota: I-B = Índice de Bishop, PV24hs/s = parto vaginal ocorrido em até 24 horas após a IP, PV24hs/n = ausência de parto vaginal em até 24 horas após IP, TPativo/s = presença de trabalho de parto ativo/fase ativa do parto, TPativo/n = ausência de trabalho de parto ativo, \# Resultado do teste Mann-Whitney, OR correspondente ao aumento de uma unidade explicativa.

\section{Associação da paridade, IMC, idade materna e idade gestacional com o sucesso da indução do parto outros desfechos}

Das outras variáveis analisadas, a paridade materna se relacionou significativamente ao sucesso da indução do parto (OR: 1,474- IC de 95\% $(1,067-2,037) ; p<0,001)$ e a ocorrência de parto vaginal em até 24 horas da IP (OR: 1,504- IC de 95\% (1,116-2,026). A idade materna, o IMC e a idade gestacional no momento da indução não se associaram estatisticamente aos desfechos analisados (Tabelas 11,12 e 13). 
Tabela 11- Descrição da IM, IG, paridade, IMC, segundo o tipo de parto e testes de comparação, das 190 gestantes submetidas à avaliação do colo uterino pela ultrassonografia transvaginal para predição do sucesso da IP. HU-USP, fevereiro de 2008 a fevereiro de 2010

\begin{tabular}{|c|c|c|c|c|c|c|c|c|c|}
\hline \multirow[t]{2}{*}{ Variável } & \multirow[t]{2}{*}{ Parto } & \multirow[t]{2}{*}{ Média } & \multirow[t]{2}{*}{ DP } & \multirow[t]{2}{*}{ Med } & \multirow[t]{2}{*}{$\mathbf{N}$} & \multirow[t]{2}{*}{ OR } & \multicolumn{2}{|c|}{ IC (95\%) } & \multirow[t]{2}{*}{$\mathbf{p}$} \\
\hline & & & & & & & Inferior & Superior & \\
\hline \multirow[t]{2}{*}{ IM } & Vaginal & 24,61 & 5,87 & 24 & 133 & 1,003 & 0,952 & 1,057 & $0,915^{*}$ \\
\hline & Cesárea & $24 ., 51$ & 6,16 & 23 & 57 & & & & \\
\hline \multirow[t]{2}{*}{ IG } & Vaginal & 40,01 & 1,10 & 40,29 & 133 & 0,908 & 0,687 & 1,199 & $0,498^{*}$ \\
\hline & Cesárea & 40,14 & 1,29 & 40,43 & 57 & & & & \\
\hline \multirow[t]{2}{*}{ Parid } & Vaginal & 2,05 & 1,31 & 2 & 133 & 1,474 & 1,067 & 2,037 & $<0,001 \#$ \\
\hline & Cesárea & 1,53 & 1,35 & 1 & 57 & & & & \\
\hline \multirow[t]{2}{*}{ IMC } & Vaginal & 27,90 & 4,04 & 28 & 133 & 0,942 & 0,879 & 1,010 & $<0,091^{*}$ \\
\hline & Cesárea & 29,09 & 5,17 & 29 & 57 & & & & \\
\hline
\end{tabular}

Nota: IM = idade materna (anos), IG = idade gestacional (semanas), Parid = paridade, IMC = índice de massa corpórea $(\mathrm{Kg} / \mathrm{m} 2)$, ${ }^{*}$ Resultado de teste $\mathrm{t}$-Student, \# Resultado do teste de Mann-Whitney, OR correspondente ao aumento de uma unidade da variável explicativa. 
Tabela 12- Descrição da IM, IG, paridade, IMC, segundo o desfecho presença de trabalho de parto ativo após a IP e testes de comparação, das 190 gestantes submetidas à avaliação do colo uterino pela ultrassonografia transvaginal para predição do sucesso da IP. HU-USP, fevereiro de 2008 a fevereiro de 2010.

\begin{tabular}{|c|c|c|c|c|c|c|c|c|c|}
\hline \multirow[t]{2}{*}{ Variável } & \multirow[t]{2}{*}{ PV 24hs } & \multirow[t]{2}{*}{ Média } & \multirow[t]{2}{*}{ DP } & \multirow[t]{2}{*}{ Med } & \multirow[t]{2}{*}{$\mathbf{N}$} & \multirow[t]{2}{*}{ OR } & \multicolumn{2}{|c|}{ IC (95\%) } & \multirow[t]{2}{*}{$p$} \\
\hline & & & & & & & Inferior & Superior & \\
\hline \multirow[t]{2}{*}{ IM } & $\operatorname{sim}$ & 24,76 & 6,08 & 24 & 119 & 1,014 & 0,964 & 1,066 & $0,595^{\star}$ \\
\hline & não & 24,28 & 5,72 & 23 & 71 & & & & \\
\hline \multirow[t]{2}{*}{ IG } & $\operatorname{sim}$ & 40,02 & 1,06 & 40,29 & 119 & 0,948 & 0,733 & 1,226 & $0,686^{*}$ \\
\hline & não & 40,09 & 1,32 & 40,29 & 71 & & & & \\
\hline \multirow[t]{2}{*}{ Parid } & $\operatorname{sim}$ & 2,10 & 1,35 & 2 & 119 & 1,504 & 1,116 & 2,026 & $<0,001 \#$ \\
\hline & não & 1,54 & 1,25 & 1 & 71 & & & & \\
\hline \multirow[t]{2}{*}{ IMC } & $\operatorname{sim}$ & 27,91 & 4,08 & 28 & 119 & 0,953 & 0,892 & 1,019 & $0,158^{*}$ \\
\hline & não & 28,85 & 4,93 & 29 & 71 & & & & \\
\hline
\end{tabular}


Tabela 13- Descrição da IM, IG, paridade, IMC, segundo o desfecho parto vaginal em até 24 horas após a IP e testes de comparação, das 190 gestantes submetidas à avaliação do colo uterino pela ultrassonografia transvaginal para predição do sucesso da IP. HU-USP, fevereiro de 2008 a fevereiro de 2010.

\begin{tabular}{|c|c|c|c|c|c|c|c|c|c|}
\hline \multirow[t]{2}{*}{ Variável } & \multirow[t]{2}{*}{ TPativo } & \multirow[t]{2}{*}{ Média } & \multirow[t]{2}{*}{ DP } & \multirow[t]{2}{*}{ Med } & \multirow[t]{2}{*}{$\mathbf{N}$} & \multirow[t]{2}{*}{ OR } & \multicolumn{2}{|c|}{ IC (95\%) } & \multirow[t]{2}{*}{$\mathbf{p}$} \\
\hline & & & & & & & Inferior & Superior & \\
\hline \multirow[t]{2}{*}{ IM } & $\operatorname{sim}$ & 24,26 & 5,78 & 24 & 155 & 0,954 & 0,899 & 1,012 & $0,117^{*}$ \\
\hline & não & 26,00 & 6,48 & 25 & 35 & & & & \\
\hline \multirow[t]{2}{*}{ IG } & $\operatorname{sim}$ & 40,08 & 1,07 & 40,29 & 155 & 1,103 & 0,814 & 1,494 & $0,530^{*}$ \\
\hline & não & 39,94 & 1,50 & 40,29 & 35 & & & & \\
\hline \multirow[t]{2}{*}{ Parid } & $\operatorname{sim}$ & 1,90 & 1,26 & 2 & 155 & 1,044 & 0,785 & 1,390 & $0,097 \#$ \\
\hline & não & 1,83 & 1,65 & 1 & 35 & & & & \\
\hline \multirow[t]{2}{*}{ IMC } & $\operatorname{sim}$ & 28,08 & 3,94 & 28 & 155 & 0,954 & 0,882 & 1,033 & $0,382^{*}$ \\
\hline & não & 29,04 & 6,16 & 29 & 35 & & & & \\
\hline
\end{tabular}

Nota: TPativo $=$ trabalho de parto ativo após a IP, IM = idade materna (anos), IG = idade gestacional (semanas), IMC = índice de massa corpórea $(\mathrm{Kg} / \mathrm{m} 2)$, * Resultado de teste tStudent, \# Resultado do teste de Mann-Whitney, OR correspondente ao aumento de uma unidade da variável explicativa. 


\subsection{Análise de regressão logística}

Para realizar a análise da regressão logística foram desenvolvidos dois modelos incluindo as variáveis ultrassonográficas: medida do comprimento do colo uterino, distância da apresentação fetal ao OCE, dilatação do colo uterino e presença da imagem em funil no $\mathrm{OCl}$, e as outras variáveis como: o IMC, uso de misoprostol e ocitocina, paridade e Índice de Bishop. Um dos modelos incluiu o Índice de Bishop na análise, em detrimento do outro que não avaliou este índice, sendo que o primeiro modelo de regressão logística demonstrou que sem considerar a avaliação do Índice de Bishop, para todos os desfechos analisados: o sucesso do parto vaginal, parto vaginal em até 24 horas da IP e presença de trabalho de parto ativo, os modelos finais apresentaram pelo menos um dos parâmetros ultrassonográficos como preditor dos desfechos $(p<0,05)$. No que diz respeito ao sucesso da IP, a distância da apresentação fetal ao OCE (OR: $0,90$ - IC de $95 \%(0,85-0,95) ; p<0,001)$, a presença da imagem em funil no OCI (OR: 4,10- IC de 95\% (1,70-9,91); $p=0,002)$ e a paridade (OR: 8,14- IC de 95\% (3,47-19,13); $p<0,001)$ apresentaram associação significativa com a evolução para parto vaginal.

Para a presença de trabalho de parto ativo foram preditores significativos: a distância da apresentação fetal ao OCE (OR: 0,92-IC de 95\% $(0,89-0,96) ; p<0,001)$, a dilatação do colo uterino (OR: 1,74- IC de 95\% 
$(1,42-2,14) ; p<0,001)$, o uso de ocitocina endovenosa (OR: 4,28- IC de 95 $\%(1,71-10,73) ; p=0,001)$ e a paridade (OR: $2,95-$ IC de $95 \%(1,15-7,59) ; p=$ 0,024). A evolução para parto vaginal em até 24 horas da IP apresentou correlação significativa com a distância da apresentação fetal ao OCE (OR: 0,88-IC de 95\% $(0,83-0,93) ; p<0,001)$, presença da imagem em funil no OCI (OR: 4,49- IC de 95\% (1,97-10,23); $p<0,001)$ ) e a paridade (OR: 7,60IC de 95\% (3,37-17,14); $p<0.001)$ (Tabela 14). 
Tabela 14- Resultado dos modelos de regressão logística para os desfechos da IP, sem a variável Índice de Bishop, das 190 gestantes submetidas à avaliação do colo uterino pela ultrassonografia transvaginal para predição do sucesso da IP. HU-USP, fevereiro de 2008 a fevereiro de 2010.

\begin{tabular}{|c|c|c|c|c|c|c|}
\hline \multirow{2}{*}{ Variável } & \multirow{2}{*}{ Modelo } & \multirow{2}{*}{ Variável } & \multirow{2}{*}{ OR } & \multicolumn{2}{|c|}{ IC (95\%) } & \multirow{2}{*}{$\mathbf{P}$} \\
\hline & & & & Inferior & Superior & \\
\hline \multirow{10}{*}{$\begin{array}{l}\text { Sucesso } \\
\text { da IP } \\
\text {-Parto } \\
\text { Vaginal }\end{array}$} & \multirow{7}{*}{ Parcial } & Comprimento do colo & 1,03 & 0,96 & 1,12 & 0,409 \\
\hline & & Distância Ap fetal/OCE & 0,89 & 0,81 & 0,96 & 0,005 \\
\hline & & Dilatação cervical & 1,14 & 0,87 & 1,50 & 0,347 \\
\hline & & Paridade (multípara) & 7,82 & 3,28 & 18,63 & $<0,001$ \\
\hline & & Misoprostol (sim) & 0,58 & 0,19 & 1,77 & 0,340 \\
\hline & & Ocitocina (sim) & 1,14 & 0,46 & 2,83 & 0,784 \\
\hline & & Imagem em funil (sim) & 2,56 & 0,62 & 10,51 & 0,191 \\
\hline & \multirow{3}{*}{ Final } & Distância Ap fetal/OCE & 0,90 & 0,85 & 0,95 & $<0,001$ \\
\hline & & Paridade (multípara) & 8,14 & 3,47 & 19,13 & $<0,001$ \\
\hline & & Imagem em funil (sim) & 4,10 & 1,70 & 9,91 & 0,002 \\
\hline \multirow{9}{*}{$\begin{array}{l}\text { Parto } \\
\text { Vaginal } \\
\text { em até } \\
24 \mathrm{~h}\end{array}$} & \multirow{6}{*}{ Parcial } & Comprimento do colo & 1,00 & 0,93 & 1,08 & 0,940 \\
\hline & & Distância Ap fetal/OCE & 0,89 & 0,82 & 0,97 & 0,007 \\
\hline & & Dilatação cervical & 1,15 & 0,89 & 1,48 & 0,290 \\
\hline & & Paridade (multípara) & 7,19 & 3,14 & 16,44 & $<0,001$ \\
\hline & & Misoprostol (sim) & 0,49 & 0,19 & 1,23 & 0,128 \\
\hline & & Imagem em funil (sim) & 2,57 & 0,70 & 9,46 & 0,155 \\
\hline & \multirow{3}{*}{ Final } & Distância Ap fetal/OCE & 0,88 & 0,83 & 0,93 & $<0,001$ \\
\hline & & Paridade (multípara) & 7,60 & 3,37 & 17,14 & $<0,001$ \\
\hline & & Imagem em funil (sim) & 4,49 & 1,97 & 10,23 & $<0,001$ \\
\hline \multirow{11}{*}{$\begin{array}{l}\text { Trabalho } \\
\text { de parto } \\
\text { ativo }\end{array}$} & \multirow{7}{*}{ Parcial } & Comprimento do colo & 0,99 & 0,90 & 1,09 & 0,857 \\
\hline & & Distância Ap fetal/OCE & 0,88 & 0,79 & 0,99 & 0,027 \\
\hline & & Dilatação cervical & 1,30 & 0,93 & 1,82 & 0,126 \\
\hline & & Paridade (multípara) & 2,82 & 1,08 & 7,33 & 0,034 \\
\hline & & Misoprostol (sim) & 0,70 & 0,16 & 3,07 & 0,638 \\
\hline & & Ocitocina (sim) & 2,87 & 0,95 & 8,66 & 0,062 \\
\hline & & Imagem em funil (sim) & 3,62 & 0,49 & 26,61 & 0,206 \\
\hline & \multirow{4}{*}{ Final } & Distância Ap fetal/OCE & 0,92 & 0,89 & 0,96 & $<0,001$ \\
\hline & & Dilatação cervical & 1,74 & 1,42 & 2,14 & $<0,001$ \\
\hline & & Paridade (multípara) & 2,95 & 1,15 & 7,59 & 0,024 \\
\hline & & Ocitocina (sim) & 4,28 & 1,71 & 10,73 & 0,002 \\
\hline
\end{tabular}

Nota: Distância Ap fetal/OCE= distância da apresentação fetal ao orifício cervical externo, Paridade (multípara) $=>1$ parto vaginal prévio, Misoprostol $(\operatorname{sim})=$ uso de misoprostol intravaginal para IP, Ocitocina $(\operatorname{sim})=$ uso de ocitocina intravenosa para a IP, imagem em funil $(\operatorname{sim})=$ presença da imagem em funil. 
No segundo modelo de regressão logística, este incluindo o Índice de Bishop, os resultados demonstraram que a adição desse escore melhora todos os modelos finais, já que influenciou significativamente todos os desfechos analisados. Para o sucesso da IP, as variáveis que se relacionaram significativamente a esse desfecho foram: distância da apresentação fetal ao OCE (OR: 0,93- IC de 95\% $(0,91-0,96) ; p<0,001)$, a paridade materna (OR: 7,27- IC de 95\% (3,02-17,45); $p<0,001)$, a dilatação cervical (OR: 1,30- IC de 95\% (1,12-1,51); $p<0,001)$ e o Índice de Bishop (OR: 1,35- IC de 95\% (1,06-1,72); $p=0,017)$. A presença de trabalho de parto ativo se associou à dilatação do colo uterino (OR: 1,54- IC de 95\% (1,24$1,90) ; p<0,001$ ), ao uso da ocitocina intravenosa (OR: 3,04- IC de 95\% $(1,19-7,78) ; p=0,020)$, à dilatação cervical (OR: 1,54- IC de 95\% $(1,24-1,90)$; $p<0,001)$ e ao Índice de Bishop (OR: 1,60- IC de 95\% (1,10-2,31); $p=0,014)$. Já para o desfecho parto vaginal em até 24 horas da IP, a distância da apresentação fetal ao OCE (OR: 0,92- IC de 95\% $(0,89-0,94) ; p<0.001)$, a paridade (OR: 6,46 -IC de 95\% (2,83-14,75); $p<0,001)$ ), a dilatação cervical (OR: 1,33- IC de 95\% (1,15-1,53); p <0,001)) e o Índice de Bishop (OR: 1,35IC de $95 \%(1,07-1,69) ;$ p 0,010$))$, foram preditores significativos da ocorrência desse desfecho (Tabela 15). 
Tabela 15- Resultado dos modelos de regressão logística para os desfechos da IP, com a variável Índice de Bishop, das 190 gestantes submetidas à avaliação do colo uterino pela ultrassonografia transvaginal para predição do sucesso da IP. HU-USP, fevereiro de 2008 a fevereiro de 2010.

\begin{tabular}{|c|c|c|c|c|c|c|}
\hline \multirow{2}{*}{ Variável } & \multirow{2}{*}{ Modelo } & \multirow{2}{*}{ Variável } & \multirow{2}{*}{ OR } & \multicolumn{2}{|c|}{ IC (95\%) } & \\
\hline & & & & Inferior & Superior & \\
\hline \multirow{12}{*}{$\begin{array}{l}\text { Sucesso } \\
\text { da IP } \\
\text {-Parto } \\
\text { vaginal }\end{array}$} & \multirow{8}{*}{ Parcial } & I-Bishop & 1,35 & 0,96 & 1,89 & 0,086 \\
\hline & & Comprimento do colo & 1,04 & 0,96 & 1,13 & 0,306 \\
\hline & & Distância Ap fetal/OCE & 0,89 & 0,82 & 0,97 & 0,009 \\
\hline & & Dilatação cervical & 1,16 & 0,87 & 1,53 & 0,312 \\
\hline & & Paridade (multípara) & 7,08 & 2,95 & 17,01 & $<0,001$ \\
\hline & & Misoprostol (sim) & 1,10 & 0,29 & 4,20 & 0,888 \\
\hline & & Ocitocina $(\operatorname{sim})$ & 1,19 & 0,48 & 2,99 & 0,703 \\
\hline & & Imagem em funil (sim) & 2,24 & 0,53 & 9,38 & 0,271 \\
\hline & \multirow{4}{*}{ Final } & I-Bishop & 1,35 & 1,06 & 1,72 & 0,017 \\
\hline & & Distância Ap fetal/OCE & 0,93 & 0,91 & 0,96 & $<0,001$ \\
\hline & & Dilatação cervical & 1,30 & 1,12 & 1,51 & $<0,001$ \\
\hline & & Paridade (multípara) & 7,27 & 3,02 & 17,45 & $<0,001$ \\
\hline \multirow{11}{*}{$\begin{array}{l}\text { Parto } \\
\text { vaginal em } \\
\text { até } 24 \mathrm{~h}\end{array}$} & \multirow{7}{*}{ Parcial } & I-Bishop & 1,27 & 0,91 & 1,76 & 0,161 \\
\hline & & Comprimento do colo & 1,01 & 0,93 & 1,10 & 0,789 \\
\hline & & Distância Ap fetal/OCE & 0,90 & 0,82 & 0,98 & 0,013 \\
\hline & & Dilatação cervical & 1,15 & 0,89 & 1,49 & 0,278 \\
\hline & & Paridade (multípara) & 6,57 & 2,85 & 15,14 & $<0,001$ \\
\hline & & Misoprostol (sim) & 0,81 & 0,25 & 2,65 & 0,729 \\
\hline & & Imagem em funil (sim) & 2,34 & 0,63 & 8,73 & 0,206 \\
\hline & \multirow{4}{*}{ Final } & I-Bishop & 1,35 & 1,07 & 1,69 & 0,010 \\
\hline & & Distância Ap fetal/OCE & 0,92 & 0,89 & 0,94 & $<0,001$ \\
\hline & & Dilatação cervical & 1,33 & 1,15 & 1,53 & $<0,001$ \\
\hline & & Paridade (multípara) & 6,46 & 2,83 & 14,75 & $<0,001$ \\
\hline \multirow{12}{*}{$\begin{array}{l}\text { Trabalho } \\
\text { de parto } \\
\text { ativo }\end{array}$} & \multirow{8}{*}{ Parcial } & I-Bishop & 1,52 & 0,97 & 2,36 & 0,065 \\
\hline & & Comprimento do colo & 1,00 & 0,90 & 1,10 & 0,952 \\
\hline & & Distância Ap fetal/OCE & 0,89 & 0,80 & 1,00 & 0,051 \\
\hline & & Dilatação cervical & 1,34 & 0,95 & 1,90 & 0,099 \\
\hline & & Paridade (multípara) & 2,51 & 0,94 & 6,68 & 0,066 \\
\hline & & Misoprostol (sim) & 1,61 & 0,29 & 8,82 & 0,583 \\
\hline & & Ocitocina (sim) & 3,04 & 1,00 & 9,29 & 0,051 \\
\hline & & Imagem em funil (sim) & 2,87 & 0,38 & 21,63 & 0,307 \\
\hline & \multirow{4}{*}{ Final } & I-Bishop & 1,60 & 1,10 & 2,31 & 0,014 \\
\hline & & Distância Ap fetal/OCE & 0,92 & 0,89 & 0,96 & $<0,001$ \\
\hline & & Dilatação cervical & 1,54 & 1,24 & 1,90 & $<0,001$ \\
\hline & & Ocitocina (sim) & 3,04 & 1,19 & 7,78 & 0,020 \\
\hline
\end{tabular}

Nota: I-Bishop = Índice de Bishop, Distância Ap fetal/OCE= distância da apresentação fetal ao orifício cervical externo, Paridade (multípara) $=>1$ parto vaginal prévio, Misoprostol (sim) = uso de misoprostol intravaginal para IP, Ocitocina $(\operatorname{sim})=$ uso de ocitocina intravenosa para a IP, imagem em funil $(\mathrm{sim})=$ presença da imagem em funil. 
5.2. Fórmulas de predição do sucesso da IP, parto vaginal em 24 horas e trabalho de parto ativo

$\mathrm{Na}$ predição do sucesso da indução do parto, bem como da presença de trabalho de parto ativo e evolução para parto vaginal em 24 horas, desenvolvemos fórmulas matemáticas para a previsão dos desfechos avaliados,com a variável Índice de Bishop.

\section{Predição do Sucesso da Indução do Parto}

$$
P=\frac{\exp (1,98 x \text { xultípara+dilatação-0,07xdist Ap/OCE+0,30xl-Bishop) }}{1+\exp (1,98 x \text { multípara+0,26xdilatação-0,07xdist Ap/OCE+0,30xl-Bishop) }}
$$

Nota: Multípara $=1$ (>1 parto vaginal prévio) ou $0=$ nulípara, dilatação cervical em $\mathrm{mm}$, dist Ap/OCE em mm, Índice de Bishop em número absoluto

\section{Predição da ocorrência de Parto Vaginal em até $\mathbf{2 4}$ horas da Indução do Parto}

$$
P=\frac{\exp (1,87 x m u l t i ́ p a r a+0,29 x \text { dilatação-0,09xdistA/OCE+0,30xl-Bishop })}{1+\exp (1,87 x \text { multípara+0,29xdilatação-0,09xdistA/OCE+0,30xl-Bishop })}
$$

Nota: Multípara $=1$ (>1 parto vaginal prévio) ou $0=$ nulípara, dilatação cervical em $\mathrm{mm}$, dist Ap/OCE em mm, Índice de Bishop em número absoluto

\section{Predição da presença de Trabalho de Parto Ativo}

$$
P=\frac{\exp (1,11 \text { xocitocina }+0,43 x \text { dilatação-0,08xdistA/OCE }+0,47 x \mathrm{l}-\text { Bishop })}{1+\exp (1,11 \text { xocitocina }+0,43 x \text { dilatação-0,08xdistA/OCE+0,47xl-Bishop })}
$$


5.3. Curvas ROC e o sucesso da indução do parto, parto vaginal em 24 horas e trabalho de parto ativo

A análise da curva ROC para a predição do sucesso da IP demonstrou que a medida do comprimento do colo uterino que fornece a melhor especificidade e sensibilidade é $26,5 \mathrm{~mm}$, apresentando sensibilidade de $66,7 \%$ e especificidade de $65,4 \%$, com AUC (área sobre a curva $\mathrm{ROC})=0,689$ (Gráfico 8).

Gráfico 8: Curva ROC do comprimento do colo uterino para predição do sucesso da IP. HU-USP, fevereiro de 2008 a fevereiro de 2010.

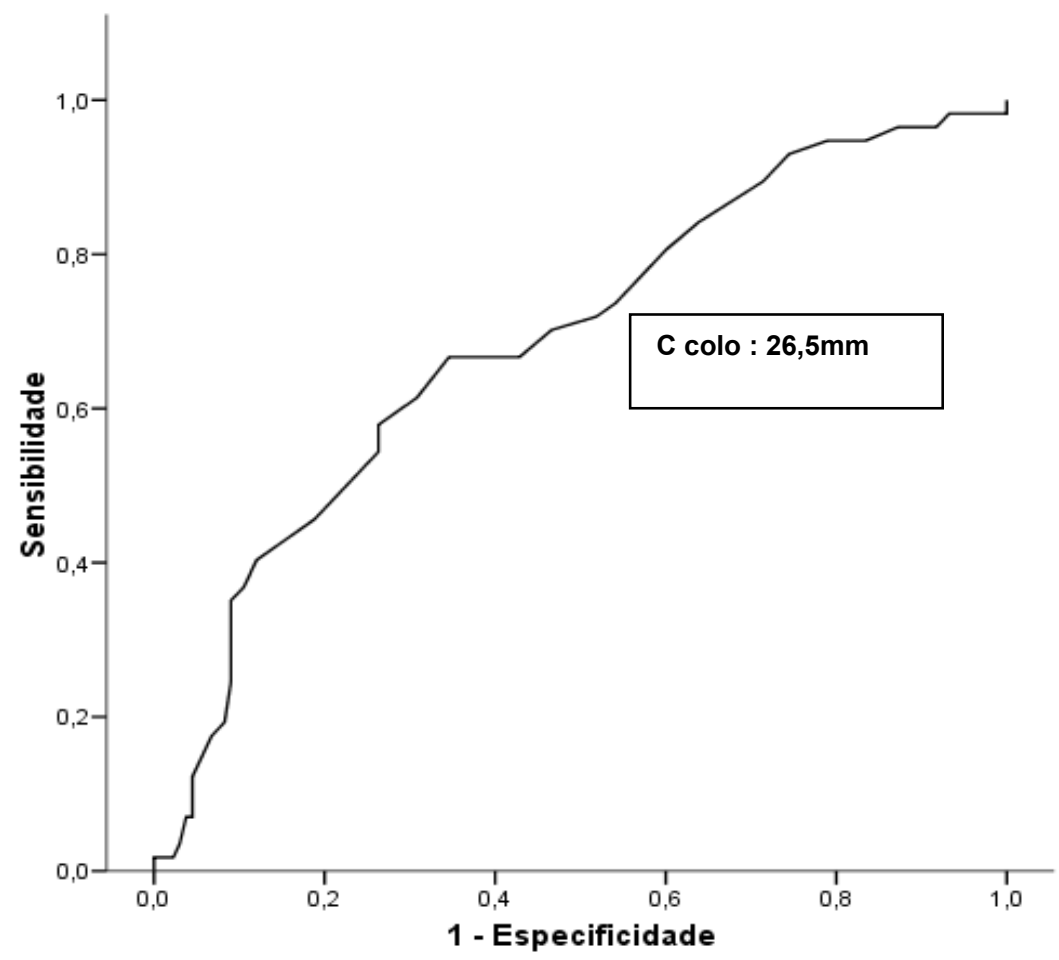


Quanto à variável distância da apresentação fetal ao OCE, o melhor ponto de corte para a predição do sucesso da IP é $34,5 \mathrm{~mm}$, que apresenta sensibilidade de 66,7\%, especificidade de 62,4\% e AUC = 0,716 (Gráfico 9).

Gráfico 9: Curva ROC da distância da apresentação fetal ao OCE para predição do sucesso da IP. HU-USP, fevereiro de 2008 a fevereiro de 2010.

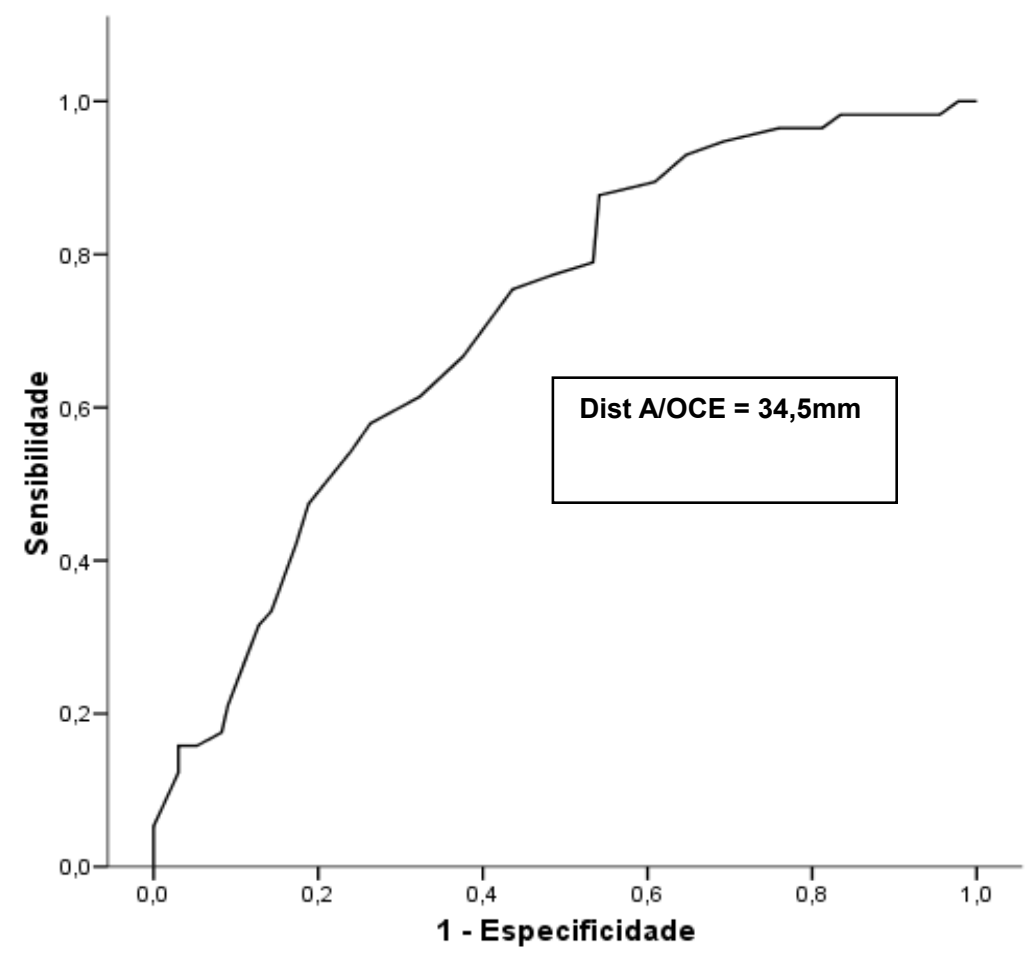

A dilatação cervical que demonstra a melhor predição do sucesso da IP é $5,85 \mathrm{~mm}$, com sensibilidade de $69,2 \%$, especificidade de $63,2 \%$ e AUC $=0,720$ (Gráfico 10). 
Gráfico 10: Curva ROC da dilatação cervical para a predição do sucesso da IP. HU-USP, fevereiro de 2008 a fevereiro de 2010.

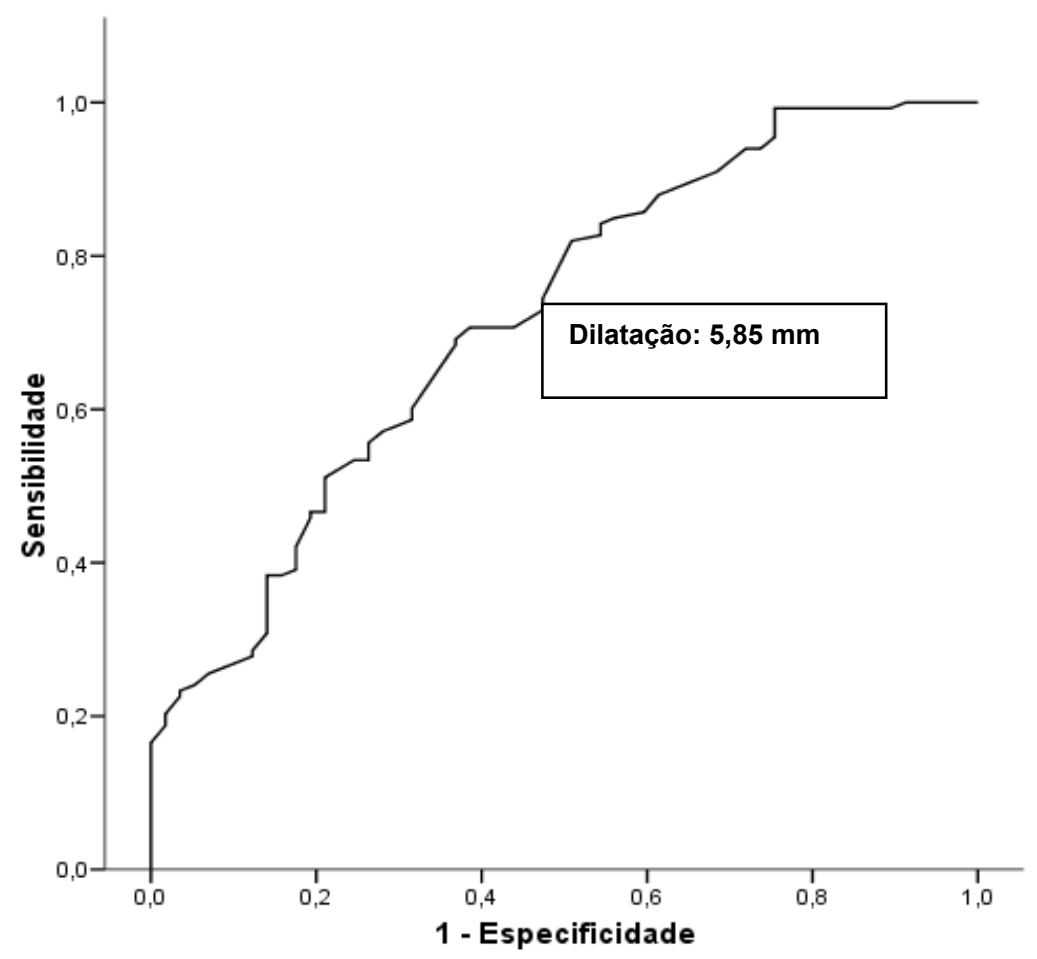

Para o desfecho parto vaginal em até 24 horas da IP, as medidas que apresentaram o ponto de corte com melhor poder de predição e sensibilidade e especificidade foram: comprimento do colo uterino de 26,5 mm (sensibilidade de 66,2\%, especificidade de 68,9\% e AUC = 0,720); distância da apresentação fetal ao OCE de $34,5 \mathrm{~mm}$ (sensibilidade de $66,2 \%$, especificidade de $65,5 \%$ e AUC $=0,736$ ) e dilatação cervical de 6,05 mm (sensibilidade de 63,9\%, especificidade de 69,\% e AUC = 0,734).

A análise das curvas ROC para a predição da presença de fase ativa do parto ou trabalho de parto ativo demonstrou que as medidas das 
variáveis ultrassonográficas com melhor sensibilidade, especificidade e estimativa do desfecho final foram: comprimento do colo uterino de $30,5 \mathrm{~mm}$ (sensibilidade de 68,6\%, especificidade de 82,6\% e AUC = 0,775); distância da apresentação ao OCE de $37,5 \mathrm{~mm}$ (sensibilidade de 77,1\%, especificidade de 76,8\% e AUC $=0,801)$ e dilatação cervical de $5,6 \mathrm{~mm}$ (sensibilidade de 69\%, especificidade de 74,3,\% e AUC = 0,775).

Desse modo, segundo a análise das curvas ROC para os desfechos estudados, o comprimento do colo uterino, a distância da apresentação fetal ao $\mathrm{OCl}$ e a dilatação cervical puderam predizer os objetivos primários e apresentaram previsibilidade semelhante, já que as áreas sobre as curvas ROC demonstraram-se próximas de 0,70.

\subsection{Análise da Variação Intra e Interobservador das medidas ultrassonográficas do colo uterino}

Conforme relatado anteriormente, para avaliar a reprodutibilidade do método por meio das medidas ultrassonográficas (comprimento do colo uterino, dilatação do colo uterino e distância da apresentação fetal ao OCE), foram realizadas avaliações intra-observador e interobservador, sendo esta realizada pela médica pesquisadora, bem como seu orientador em $20 \%$ das pacientes. Desse modo, apresentamos os respectivos resultados das correlações intra e interobservador. (Tabela 16). 
Tabela 16- Resultado das correlações intraclasse, intra e interobservadores com os respectivos intervalos de confiança, das 190 gestantes submetidas à avaliação do colo uterino pela ultrassonografia transvaginal para predição do sucesso da IP. HU-USP, fevereiro de 2008 a fevereiro de 2010.

\begin{tabular}{llllc}
\hline Reprodutibilidade & Variável & $\begin{array}{l}\text { Correlação } \\
\text { intraclasse }\end{array}$ & \multicolumn{1}{c}{ IC 95\% } \\
\hline Intra-observador & $\begin{array}{l}\text { Comprimento } \\
\text { do colo }\end{array}$ & 0,998 & 0,997 & 0,998 \\
& $\begin{array}{l}\text { Distância Ap } \\
\text { fetal/OCE }\end{array}$ & 0,983 & 0,979 & 0,987 \\
\hline $\begin{array}{l}\text { Dilatação } \\
\text { cervical }\end{array}$ & 0,971 & 0,963 & 0,977 \\
\hline Inter-observador & $\begin{array}{l}\text { Comprimento } \\
\text { do colo }\end{array}$ & 0,995 & 0,991 & 0,997 \\
& $\begin{array}{l}\text { Distância Ap } \\
\text { fetal/OCE }\end{array}$ & 0,998 & 0,996 & 0,999 \\
& $\begin{array}{l}\text { Dilatação } \\
\text { cervical }\end{array}$ & 0,959 & 0,925 & 0,977 \\
& & & & \\
\end{tabular}

Essa tabela demonstra que a reprodutibilidade das medidas ultrassonográficas realizadas foi alta, apresentando valores de correlação interclasse superiores a 0.95 , reiterando, assim, que o método ultrassonográfico utilizado é perfeitamente reprodutível. 


\subsection{Correlação entre o Índice de Bishop e as variáveis ultrassonográficas}

As variáveis ultrassonográficas comprimento do colo (correlação = 0,519; $p<0,001$ ) e distância da apresentação fetal ao OCE (correlação = 0,481; $p<0,001)$ apresentaram uma correlação inversa com o Índice de Bishop. Já a dilatação cervical (correlação $=0,358 ; p<0,001$ ) demonstrou uma correlação direta com o índice clínico (Tabela 17).

Tabela 17- Resultado das correlações de Pearson entre I-Bishop e os parâmetros ultrassonográficos das 190 gestantes submetidas à avaliação do colo uterino pela ultrassonografia transvaginal para predição do sucesso da IP. HU-USP, fevereiro de 2008 a fevereiro de 2010.

\begin{tabular}{llll}
\hline Variável & Correlação & $\mathbf{N}$ & $\mathbf{p}$ \\
\hline $\begin{array}{l}\text { USG/comprimento } \\
\text { colo }\end{array}$ & $-0,519$ & 190 & $<0,001$ \\
\hline $\begin{array}{l}\text { USG/ distância Ap } \\
\text { fetal / OCE }\end{array}$ & $-0,481$ & 190 & $<0,001$ \\
\hline $\begin{array}{l}\text { USG/ dilatação } \\
\text { cervical }\end{array}$ & 0,358 & 190 & $<0,001$ \\
\hline $\begin{array}{l}\text { Nota: USG comprimento = comprimento do colo ultrassonográfico, USG distância Ap } \\
\text { fetal/OCE = distância da apresentação fetal ao OCE ultrassonográfica e USG dilatação = } \\
\text { dilatação cervical ultrassonográfica. }\end{array}$
\end{tabular}

Os diagramas de dispersão ilustram essa correlação inversa identificada entre comprimento do colo e a distância da apresentação fetal ao OCE, e linear entre a dilatação cervical e o Índice de Bishop (Gráficos 11, 12 e 13). 
Gráfico 11. Diagrama de dispersão entre comprimento do colo e Índice de Bishop. HU-USP, fevereiro de 2008 a fevereiro de 2010.

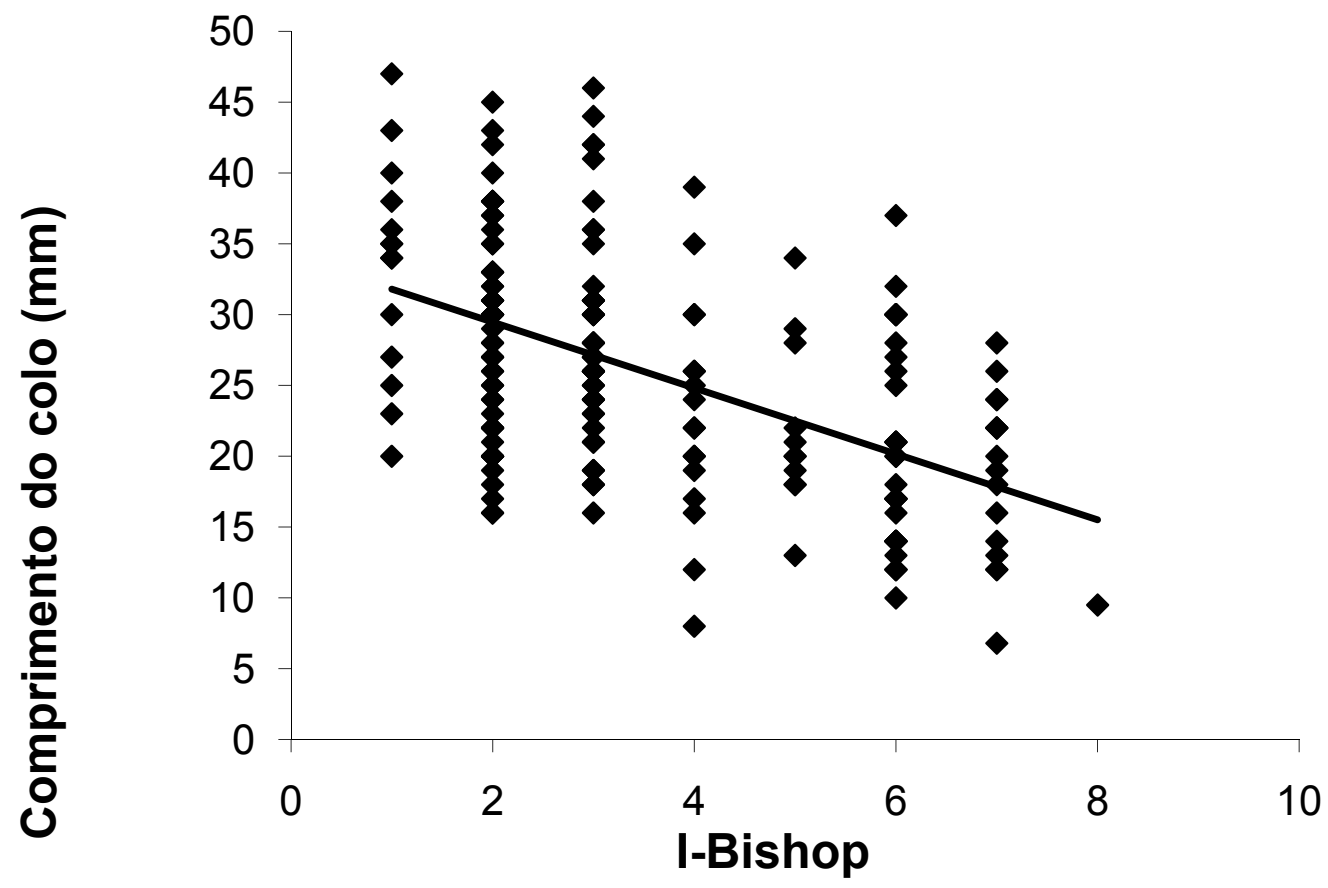

Nota: I-Bishop = Índice de Bishop

Gráfico 12: Diagrama de dispersão entre a distância da apresentação fetal ao OCE e Índice de Bishop. HU-USP, fevereiro de 2008 a fevereiro de 2010.

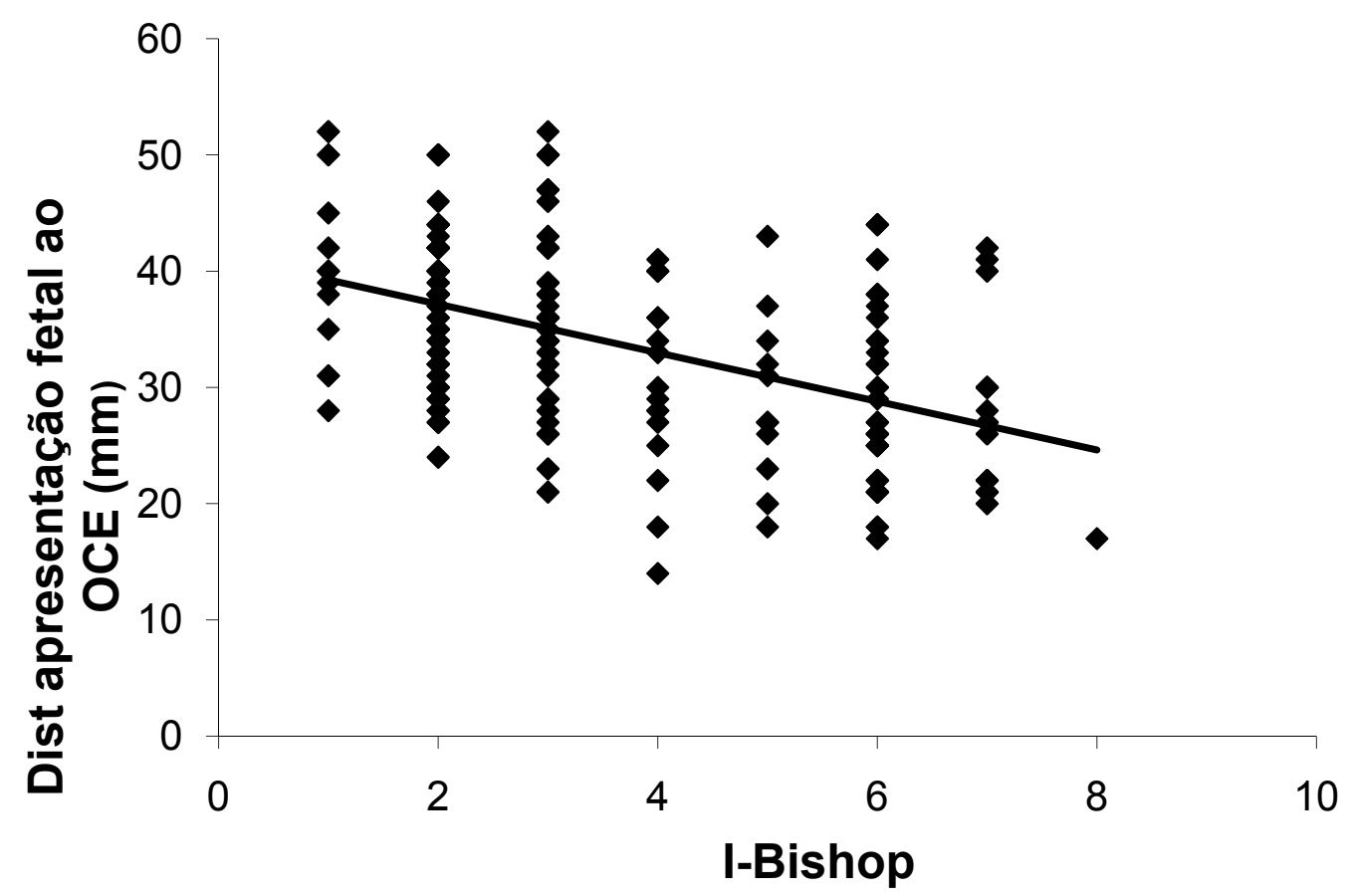

Nota: I-Bishop: Índice de Bishop. Dist apresentação fetal ao OCI: Distância da apresentação fetal ao $\mathrm{OCl}$. 
Gráfico 13: Diagrama de dispersão entre dilatação cervical e Índice de Bishop. HU-USP, fevereiro de 2008 a fevereiro de 2010.

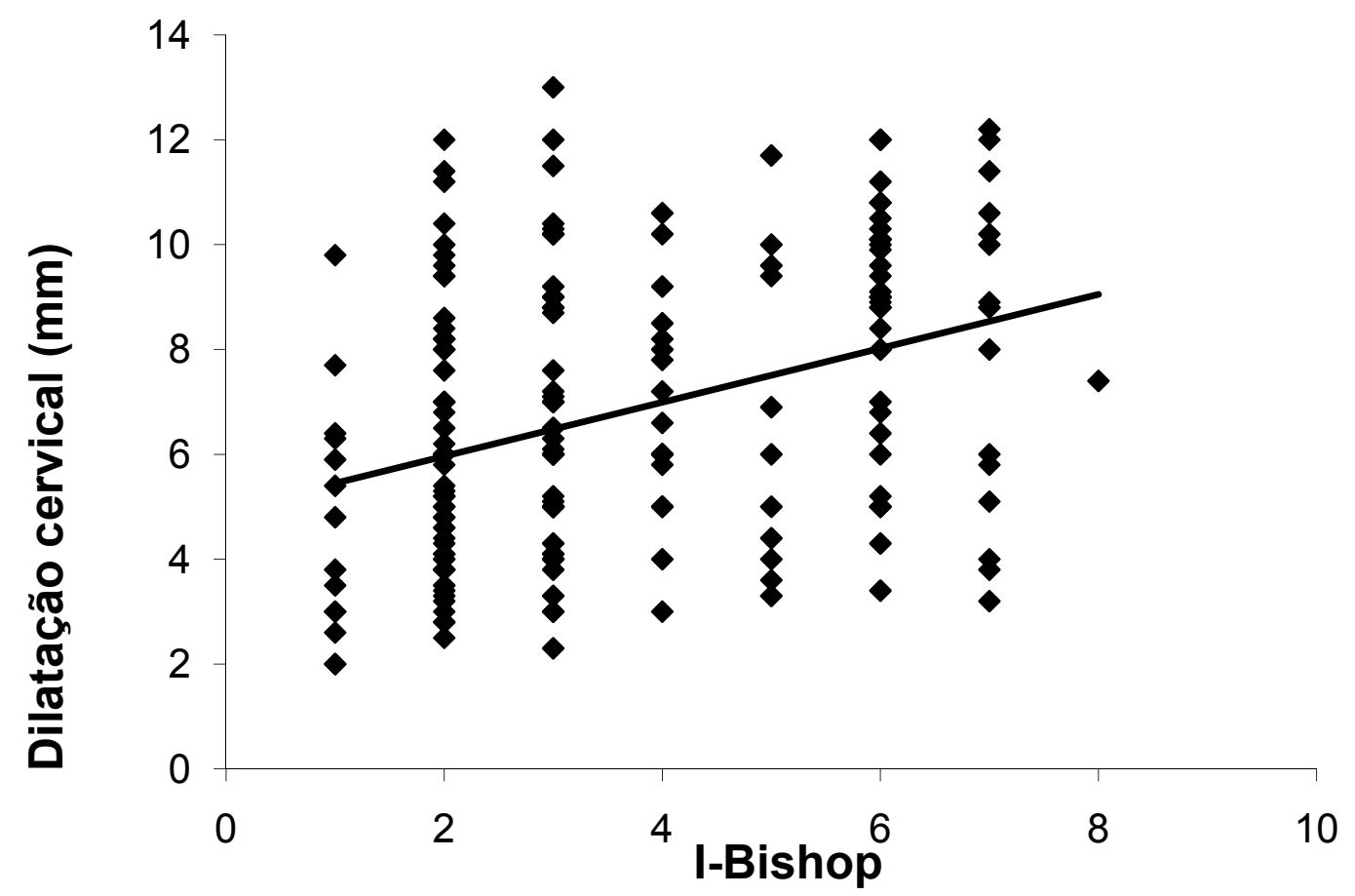

Nota: I-Bishop= Índice de Bishop.

Conforme descrito anteriormente, o Índice de Bishop (Bishop,1964) seleciona as pacientes em favoráveis à indução do parto e desfavoráveis à IP. Baseados nessa categorização, realizamos a análise e correlação das variáveis ultrassonográficas aos desfechos principais nos dois grupos de gestantes, com Índice de Bishop $>6$ (favoráveis à IP) e $<6$ (desfavoráveis à IP).

O comprimento do colo $(p=0,011)$, a distância da apresentação fetal ao OCE $(p=0,002)$ e a dilatação cervical $(p=0,001)$ em gestantes do grupo IBishop < 6 (desfavorável à IP) se relacionaram estatisticamente ao sucesso da IP, parto vaginal após IP, o que demonstra benefício da utilização das 
variáveis ultrassonográficas para a predição do sucesso da IP nesse grupo de gestantes . O mesmo não ocorreu no grupo de I-Bishop > 6 (Tabela 18).

Tabela 18- Comparação das variáveis ultrassonográficas, comprimento do colo, distância da apresentação fetal ao OCE e dilatação cervical, segundo o tipo de parto, para I-Bishop $>$ e $<6$, em 190 gestantes submetidas à avaliação do colo uterino pela ultrassonografia transvaginal para predição do sucesso da IP. HU-USP, fevereiro de 2008 a fevereiro de 2010.

\begin{tabular}{|c|c|c|c|c|c|c|c|c|c|c|c|c|}
\hline \multirow{2}{*}{$\begin{array}{l}\text { I- } \\
\text { Bishop }\end{array}$} & \multirow{2}{*}{$\begin{array}{l}\text { Variáveis } \\
\text { USG } \\
\end{array}$} & \multirow[b]{2}{*}{ Parto } & \multirow[b]{2}{*}{ Média } & \multirow[b]{2}{*}{ DP } & \multirow[b]{2}{*}{ Med } & \multirow[b]{2}{*}{ Mínimo } & \multirow[b]{2}{*}{ Máximo } & \multirow[b]{2}{*}{$\mathrm{N}$} & \multirow[b]{2}{*}{$\mathrm{p}$} & \multirow[b]{2}{*}{ OR } & \multicolumn{2}{|c|}{ IC (95\%) } \\
\hline & & & & & & & & & & & Inferior & Superior \\
\hline \multirow[b]{6}{*}{$<6$} & \multirow{5}{*}{$\begin{array}{l}\text { Dist } \\
\text { A/OE }\end{array}$} & Cesárea & 29,88 & 7,78 & 30 & 13 & 47 & 56 & \multirow{3}{*}{0,011} & \multirow{3}{*}{0,94} & \multirow{3}{*}{0,9} & \multirow{3}{*}{0,99} \\
\hline & & Vaginal & 26,49 & 7,57 & 26 & 8 & 46 & 86 & & & & \\
\hline & & Cesárea & 38,02 & 7,35 & 38 & 18 & 52 & 56 & & & & \\
\hline & & Vaginal & 33,94 & 7,36 & 34 & 14 & 50 & 86 & \multirow[t]{2}{*}{0,002} & \multirow[t]{2}{*}{0,93} & \multirow[t]{2}{*}{0,88} & \multirow[t]{2}{*}{0,97} \\
\hline & & Cesárea & 5,4 & 2,35 & 5 & 2 & 10,2 & 56 & & & & \\
\hline & Dilat & Vaginal & 6,83 & 2,54 & 6,15 & 2,8 & 13 & 86 & 0,001 & 1,28 & 1,1 & 1,48 \\
\hline \multirow{6}{*}{$>6$} & & Cesárea & 6,8 & \# & 6,8 & 6,8 & 6,8 & 1 & & & & \\
\hline & C colo & Vaginal & 19,8 & 6,71 & 19 & 9,5 & 37 & 47 & 0,062 & \# & & \\
\hline & \multirow{3}{*}{$\begin{array}{l}\text { Dist } \\
\text { A/OE }\end{array}$} & Cesárea & 40 & $\#$ & 40 & 40 & 40 & 1 & \multirow{3}{*}{0,124} & \multirow{3}{*}{0,78} & \multirow{3}{*}{0,51} & \multirow{3}{*}{1,18} \\
\hline & & Vaginal & 28,36 & 7,34 & 27 & 17 & 44 & 47 & & & & \\
\hline & & Cesárea & 3,2 & $\#$ & 3,2 & 3,2 & 3,2 & 1 & & & & \\
\hline & Dilat & Vaginal & 8,44 & 2,42 & 8,9 & 3,4 & 12,2 & 47 & 0,038 & \# & & \\
\hline
\end{tabular}

Nota: $\mathrm{c}$ colo $=$ comprimento do colo, dist $\mathrm{A} / \mathrm{OE}=$ distância da apresentação fetal ao OCE, dilat = dilatação cervical, Med = mediana, $\#$ = não foi possível calcular

A análise do desfecho parto vaginal em até 24 horas após a IP, demonstrou que para gestantes com I-Bishop $<6$ o comprimento do colo $(p<0,001)$ a distância da apresentação fetal ao OCE $(p<0,001)$ e a dilatação cervical $(p<0,001)$ se associaram significativamente ao objetivo proposto. No grupo de I-Bishop > 6 não houve correlação estatisticamente significativa (Tabela 19). 
Tabela 19- Comparação das variáveis ultrassonográficas, comprimento do colo, distância da apresentação fetal ao OCE e dilatação cervical, segundo o desfecho parto vaginal em 24 horas, para I-Bishop > e < 6, em 190 gestantes submetidas à avaliação do colo uterino pela ultrassonografia transvaginal para predição do sucesso da IP. HU-USP, fevereiro de 2008 a fevereiro de 2010.

\begin{tabular}{|c|c|c|c|c|c|c|c|c|c|c|c|c|}
\hline \multirow{2}{*}{$\begin{array}{l}\text { I- } \\
\text { Bishop }\end{array}$} & \multirow{2}{*}{$\begin{array}{l}\text { Variáveis } \\
\text { USG }\end{array}$} & \multirow{2}{*}{$\begin{array}{l}\text { PV } \\
24 \mathrm{hs}\end{array}$} & \multirow[b]{2}{*}{ Média } & \multirow[b]{2}{*}{ DP } & \multirow[b]{2}{*}{ Med } & \multirow[b]{2}{*}{ Mínimo } & \multirow[b]{2}{*}{ Máximo } & \multirow[b]{2}{*}{$\mathbf{N}$} & \multirow[b]{2}{*}{ p } & \multirow[b]{2}{*}{ OR } & \multicolumn{2}{|c|}{ IC (95\%) } \\
\hline & & & & & & & & & & & Inferior & Superior \\
\hline \multirow[b]{6}{*}{$<6$} & \multirow{5}{*}{$\begin{array}{l}\text { Dist } \\
\text { A/OE }\end{array}$} & Não & 30,14 & 7,85 & 30 & 13 & 47 & 69 & \multirow{3}{*}{$<0,001$} & \multirow{3}{*}{0,92} & \multirow{3}{*}{0,88} & \multirow{3}{*}{0,97} \\
\hline & & Sim & 25,63 & 7,14 & 26 & 8 & 45 & 73 & & & & \\
\hline & & Não & 38,13 & 7,3 & 38 & 18 & 52 & 69 & & & & \\
\hline & & Sim & 33,11 & 7,09 & 34 & 14 & 50 & 73 & \multirow[t]{2}{*}{$<0,001$} & \multirow[t]{2}{*}{0,91} & \multirow[t]{2}{*}{0,86} & \multirow[t]{2}{*}{0,95} \\
\hline & & Não & 5,43 & 2,26 & 5 & 2 & 10,2 & 69 & & & & \\
\hline & Dilat & Sim & 7,05 & 2,59 & 6,5 & 2,8 & 13 & 73 & $<0,001$ & 1,31 & 1,13 & 1,52 \\
\hline \multirow{6}{*}{$>6$} & \multirow{5}{*}{$\begin{array}{l}\text { Dist } \\
\text { A/OE }\end{array}$} & Não & 15,4 & 12,16 & 15,4 & 6,8 & 24 & 2 & \multirow{3}{*}{0,393} & \multirow{3}{*}{1,12} & \multirow{3}{*}{0,86} & \multirow{3}{*}{1,46} \\
\hline & & Sim & 19,71 & 6,76 & 18,5 & 9,5 & 37 & 46 & & & & \\
\hline & & Não & 33,5 & 9,19 & 33,5 & 27 & 40 & 2 & & & & \\
\hline & & Sim & 28,39 & 7,42 & 27 & 17 & 44 & 46 & 0,348 & 0,92 & 0,76 & 1,11 \\
\hline & & Não & 4,6 & 1,98 & 4,6 & 3,2 & 6 & 2 & & & & \\
\hline & Dilat & Sim & 8,5 & 2,42 & 8,9 & 3,4 & 12,2 & 46 & 0,03 & 2,19 & 0,83 & 5,77 \\
\hline
\end{tabular}

Nota: $\mathrm{C}$ colo $=$ comprimento do colo, dist $\mathrm{A} / \mathrm{OE}=$ distância da apresentação fetal ao OCE, dilat $=$ dilatação cervical, $\mathrm{PV} 24 \mathrm{hs}=$ parto vaginal em 24 horas, med = mediana, $\#=$ não é possível calcular.

Quanto à presença de trabalho de parto ativo, ou fase ativa do parto, novamente o comprimento do colo $(p<0,001)$, distância da apresentação fetal ao OCE $(p<0,001)$ e a dilatação cervical $(p<0,001)$ em gestantes com I-Bishop $<6$ se relacionaram estatisticamente ao desfecho analisado, em detrimento do grupo de I-Bishop $>6$, já que todas as gestantes desse grupo entraram em trabalho de parto ativo (Tabela 20). 
Tabela 20- Comparação das variáveis ultrassonográficas, comprimento do colo, distância da apresentação fetal ao OCE e dilatação cervical, segundo o desfecho trabalho de parto ativo, para I-Bishop > e $<6$, em 190 gestantes submetidas à avaliação do colo uterino pela ultrassonografia transvaginal para predição do sucesso da IP. HU-USP, fevereiro de 2008 a fevereiro de 2010.

\begin{tabular}{|c|c|c|c|c|c|c|c|c|c|c|c|c|}
\hline \multirow{2}{*}{$\begin{array}{l}\text { I- } \\
\text { Bishop } \\
\end{array}$} & \multirow{2}{*}{$\begin{array}{l}\text { Variáveis } \\
\text { USG }\end{array}$} & \multirow{2}{*}{$\begin{array}{l}\text { TP } \\
\text { ativo } \\
\end{array}$} & \multirow[b]{2}{*}{ Média } & \multirow[b]{2}{*}{ DP } & \multirow[b]{2}{*}{ Med } & \multirow[b]{2}{*}{ Mínimo } & \multirow[b]{2}{*}{ Máximo } & \multirow[b]{2}{*}{$\mathrm{N}$} & \multirow[b]{2}{*}{$\mathbf{p}$} & \multirow[b]{2}{*}{ OR } & \multicolumn{2}{|l|}{ IC (95\%) } \\
\hline & & & & & & & & & & & Inferior & Superior \\
\hline \multirow[b]{6}{*}{$<6$} & & Não & 32,29 & 7,9 & 35 & 13 & 47 & 35 & & & & \\
\hline & C colo & Sim & 26,36 & 7,23 & 26 & 8 & 46 & 107 & $<0,001$ & 0,9 & 0,85 & 0,95 \\
\hline & & Não & 40,34 & 6,78 & 40 & 18 & 52 & 35 & & & & \\
\hline & Dist A/OE & Sim & 33,98 & 7,21 & 34 & 14 & 52 & 107 & $<0,001$ & 0,88 & 0,83 & 0,94 \\
\hline & & Não & 4,73 & 2,07 & 4,1 & 2 & 9,6 & 35 & & & & \\
\hline & Dilat & Sim & 6,77 & 2,51 & 6,3 & 2,8 & 13 & 107 & $<0,001$ & 1,51 & 1,22 & 1,87 \\
\hline \multirow{3}{*}{$\geq 6$} & C colo & Sim & 19,53 & 6,9 & 18,5 & 6,8 & 37 & 48 & \# & $\#$ & & \\
\hline & Dist A/OE & Sim & 28,6 & 7,46 & 27 & 17 & 44 & 48 & $\#$ & \# & & \\
\hline & Dilat & Sim & 8,33 & 2,52 & 8,85 & 3,2 & 12,2 & 48 & \# & \# & & \\
\hline
\end{tabular}


6 DISCUSSÃO 
O presente estudo correlaciona as variáveis ultrassonográficas do colo uterino à presença de parto vaginal após a indução (sucesso da IP), parto vaginal em 24 horas da IP e presença de trabalho de parto ativo, sendo esses desfechos escolhidos por representarem justamente os principais objetivos da indução do parto. Atualmente, a iniciação artificial do parto é um elemento essencial e comum na prática obstétrica contemporânea, com incidência aproximada de $20 \%$ das gestações ${ }^{(62)}$. Apesar de a IP ser um método seguro e eficaz, ainda representa um aumento de risco de evolução para cesárea em comparação ao início espontâneo do parto, principalmente em gestantes com condições cervicais desfavoráveis à indução. Assim, a ultrassonografia transvaginal do colo uterino tem sido estudada com o intuito de melhorar ou complementar o Índice de Bishop, o acesso às condições cervicais e predizer os resultados da IP.

Diversos estudos confirmaram a baixa acurácia do Índice de Bishop na predição dos resultados da indução do parto, devido ao caráter subjetivo da avaliação digital dos parâmetros do colo uterino (63, 64, 18). A ultrassonografia, por representar uma visão direta das medidas e variáveis cervicais, representa uma ferramenta mais objetiva na avaliação cervical em relação ao escore de Bishop ${ }^{(65)}$, devido, principalmente, à visualização direta do canal endocervical e dos orifícios cervical interno e externo ${ }^{(66,29)}$. 
Desse modo, um método diagnóstico que pode melhorar a acurácia da predição dos desfechos da IP é um instrumento valioso na potencial redução do risco de cesárea envolvido no processo de indução do parto.

Inicialmente, o uso da ultrassonografia do colo uterino foi realizado para identificar e detectar as alterações cervicais ocorridas em gestantes com risco de parto prematuro ${ }^{(55)}$. Baseados nessas mudanças do colo uterino durante a gestação e próximo ao parto, iniciou-se o uso da ultrassonografia para a predição do sucesso da indução do parto. PatersonBrown et al. (21), em estudo piloto, demonstraram que o ângulo cervical posterior superior a 70 graus em gestantes com Índice de Bishop inferior a 5 se associou significativamente ao sucesso da IP. Posteriormente, diversos estudos vieram a acrescentar e contrariar esses achados, tornando ainda controversa a utilização da ultrassonografia transvaginal do colo uterino.

No presente estudo, utilizamos as variáveis ultrassonográficas, comprimento do colo uterino, distância da apresentação fetal ao OCE, dilatação cervical e presença de imagem em funil no $\mathrm{OCl}$ com o intuito de obter medidas representativas do Índice de Bishop para avaliação dos desfechos da IP. Em nossa casuística a incidência de parto vaginal após a IP foi de $70 \%$ e cesárea $30 \%$, concordante com Ware e Raynor ${ }^{(26)}$, que demonstraram $69 \%$ de parto vaginal, Park et al. ${ }^{(39)}$, com $63 \%$ e Gomez Laencina et al. ${ }^{(40)}$, com $64, \%$ de parto vaginal e $36 \%$ de cesárea, além de outros estudos ${ }^{(31,7,36)}$. Gonen et al. ${ }^{(28)}$, Bueno et al. ${ }^{(67)}$, Reis et al. ${ }^{(68)}$, 
Rovas et al. ${ }^{(35)}$ e Pandis et al. ${ }^{(7)}$ demonstraram que a incidência do desfecho parto vaginal em 24 horas da IP variou entre 70,8 e 84\%, também concordantes com os dados do presente estudo, que identificaram o parto vaginal em 24 horas da IP em 89\% das gestantes. A presença de trabalho de parto ativo em $82 \%$ das gestantes corroborou os resultados de $86 \%$ de Park et al. ${ }^{(39)}$ e $85 \%$ de Roman et al. ${ }^{(33)}$. Além disso, a predominância de nulíparas $(54 \%)$ em detrimento às multíparas (46\%) em nossa casuística

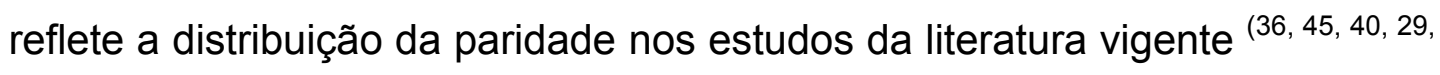
20, 37)

Diversos estudos na literatura $(43,19,39,45,69)$ destacam a relação independente entre comprimento cervical e sucesso da IP. Elghorori et al. ${ }^{(63)}$, bem como Gabriel et al. ${ }^{(19)}$ descrevem o ponto de corte de 34 e $26 \mathrm{~mm}$, respectivamente, para a predição do sucesso da IP. Em nossa casuística, o comprimento do colo uterino se relaciona e influencia significativamente o sucesso da IP, o parto vaginal em 24 horas e a presença de trabalho de parto ativo $(p<0,001)$ em gestantes submetidas à indução do parto por diversas indicações clínicas. O ponto de corte para a predição do sucesso da IP e parto vaginal em 24 horas foi de $26,5 \mathrm{~mm}$ e $30,5 \mathrm{~mm}$ para a presença de trabalho de parto ativo, sendo que a acurácia, a sensibilidade e especificidade do comprimento cervical foi superior para os dois últimos desfechos em relação ao primeiro. Isso se deve ao fato de as áreas sobre as curvas ROC para o trabalho de parto ativo, parto vaginal em 24 horas ser superior à ocorrência de parto vaginal. A sensibilidade varia entre 66 a 68\%, 
a especificidade entre 65 a 82,6\% e a acurácia das curvas ROC entre 68 e $77 \%$, confirmando valores semelhantes na literatura $(67,32,70,41)$.

As variáveis distância da apresentação fetal ao OCE $(p<0.001)$, dilatação cervical $(p<0,001)$ e presença da imagem em funil no $\mathrm{OCl}$ $(p<0,001)$ também se associam e influenciam os desfechos estudados. Destaca-se a importante correlação entre a presença da imagem em funil (OR: 16,29; IC de 95\% $(3,78-70,25)$ ) e o trabalho de parto ativo, sugerindo, assim, que essa variável pode ser um marcador da evolução para a fase ativa do parto. Boozajomehri et al. ${ }^{(24)}$ relacionaram a presença da imagem em funil no $\mathrm{OCl}$ e menor comprimento cervical à presença de fase ativa do parto e menor duração deste.

Avaliamos também o Índice de Bishop e sua relação com as variáveis ultrassonográficas e com os desfechos propostos. Notamos, por meio da correlação de Pearson, que existe uma relação inversa e estatisticamente significativa entre o comprimento cervical, a distância da apresentação fetal ao OCE e o I-Bishop, e uma relação linear deste com a variável dilatação cervical pela ultrassonografia transvaginal, sugerindo, assim, que uma combinação entre os dois métodos pode elevar a acurácia da predição dos objetivos propostos. Além disso, o I-Bishop também se relacionou significativamente ao sucesso da IP, parto vaginal em 24 horas e trabalho de parto ativo 
Após realizarmos a análise de regressão logística das variáveis que diretamente interferem e se associam aos desfechos propostos, notamos que os modelos finais, ou seja, após a análise mutlivariada e controle de fatores de confusão, apresentam ao menos uma variável ultrassonográfica, a paridade materna, o I-Bishop em todos os modelos que incluíram essa variável. O comprimento cervical não se associou a nenhum dos desfechos, a despeito da imagem em funil, distância da apresentação fetal ao OCE e dilatação cervical. A regressão logística realizada no estudo de Gonen et al. (28) identificou o I-Bishop e a paridade, não o comprimento cervical, como preditores do sucesso da IP, o mesmo definido por Reis et al ${ }^{(68)}$. Desse modo, a regressão logística sugere que os métodos clínico e ultrassonográfico são complementares na predição dos objetivos do estudo, não havendo sobreposição de um método sobre o outro.

$\mathrm{Na}$ análise das variáveis maternas que influenciam os resultados da indução do parto identificamos apenas a paridade, ou seja, a presença de ao menos um parto vaginal prévio foi preditora do sucesso da IP, parto vaginal em 24 horas e trabalho de parto ativo. Esses achados refletem a maioria dos estudos da literatura, que também comprovam o papel da paridade na indução do parto ${ }^{(29,44,28,37,68,69,1)}$.

Desenvolvemos fórmulas de predição para o sucesso da IP, parto vaginal em 24 horas e trabalho de parto ativo, utilizando as variáveis que se 
mostraram significativas após a análise de regressão logística, ou seja, os preditores independentes dos objetivos, assim como realizado e utilizado como survival time (probabilidade de sucesso da IP) em estudo de Rane et al. ${ }^{(31)}$. No presente estudo, a dilatação cervical, a distância da apresentação fetal ao OCE e a presença da imagem em funil foram preditores dos desfechos da indução do parto, a despeito do comprimento cervical. Este, isoladamente, influenciou os sucessos da indução ao parto, porém em conjunto com outras variáveis, como a paridade e o Índice de Bishop, não se mostrou estatisticamente significativo. Esses achados sugerem a superioridade das variáveis clínicas em detrimento do comprimento cervical na avaliação dos parâmetros do colo uterino pré indução do parto.

Quando categorizamos as pacientes de acordo com a favorabilidade das condições cervicais, ou seja, Bishop inferior a 6 (desfavorável à IP) e Bishop igual ou superior a 6, encontramos uma associação estatisticamente significativa do menor comprimento do colo, menor distância da apresentação fetal ao OCE e maior dilatação cervical aos desfechos propostos. Desse modo, ilustramos que as variáveis ultrassonográficas podem ser usadas e com melhor poder de predição justamente no grupo de gestantes com condições cervicais desfavoráveis, nas quais a utilização do I-Bishop apresenta baixo poder de predição.

Assim, como o objetivo do presente estudo foi correlacionar as variáveis ultrassonográficas às pacientes submetidas à IP por diferentes 
métodos de indução, conforme descrito e efetuado pela maioria dos estudos da literatura $(31,33,38,68,44,24,28,71,40,29)$, o comprimento cervical, a distância da apresentação fetal ao OCE, a dilatação e a presença da imagem em funil no $\mathrm{OCl}$ se correlacionam e influenciam os objetivos estudados. Isso é particularmente notório no grupo de pacientes com I-Bishop $<6$, desfavorável à indução do parto, sugerindo uma aplicação das variáveis ultrassonográficas em conjunto com o Índice de Bishop para melhorar a sensibilidade e o poder de predição dos desfechos relacionados à IP. 
O presente estudo, que apresentou como objetivo a avaliação da ultrassonografia transvaginal do colo uterino na predição do sucesso da indução do parto, concluiu que:

1. As medidas do comprimento do colo uterino, distância da apresentação fetal ao OCE, dilatação cervical e a presença da imagem em funil no $\mathrm{OCl}$ se correlacionaram significativamente ao sucesso da Indução do Parto, principalmente em gestantes com IBishop inferior a 6, com acurácia média de 70\%.

2. A ocorrência de parto vaginal em 24 horas após a indução se relacionou estatisticamente a todas as variáveis ultrassonográficas, principalmente em gestantes com I-Bishop inferior a 6, e apresentaram acurácia de aproximadamente $70 \%$.

3. As medidas ultrassonográficas (comprimento do colo uterino, dilatação, distância da apresentação fetal ao OCE e especialmente a presença da imagem em funil no $\mathrm{OCl}$ ) se associaram à presença de trabalho de parto ativo após a IP, principalmente em gestantes com IBishop inferior a 6, e também com acurácia média de $70 \%$. 
4. O Índice de Bishop se correlacionou inversamente ao comprimento do colo uterino e à distância da apresentação fetal ao OCE e linearmente à dilatação cervical. Foi um fator preditor significativo e independente de todos os desfechos analisados. 
8 ANEXOS 
ANEXO I

Săo Paulo, 3 de agosto de 2007 .

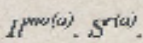

Dr. Rodrigo Ruano

Divisån de Clínica Obstétrica.

Hospital UNiversitário

UNTVERSIDADL DL SĀO PAULO

RFFERENTE: Projeto de Pesquisa "Avaliação do colo uterino pela ultra-sonografio convencional na indução do parto" - Co-Autvr(es): Prof. Marcelo Zugaib, Patricia da Rosha Pennachiotti - Registro CEP-HU/USP: $759 i 07$ - SISNEP CAAE: $0038,0.198 .015-07$

Prezado(a) Senhor( $($ )

O Comité de Ética em Pesquisa do Hospital Universitário da Universidade de Sצo Paulo, em reunião ordinária realizada no dia 3 de agosto de 2007 , analisou o projeto de pesquisa acima cilado, considerando-o como APROVADO, bem como, scu Terno de Consentimento Livre e Esclarccido.

Lembramos que cabe ao pesquisador elaborar e apresentar a este Comitĉ, relatórios anuais (purviais ou final, $\mathrm{cm}$ finç̣̆o da duraçăo da pesquisa), de acordo com a Rcsohuçăo 196/96 do Conselho Nacional de Saúde, ilem IX.2 letru o.

O primeiro relatório está previsto para 3 de agosto de 2008.

Atenciosamente,<smiles>C=CCCC</smiles>

Dr. Mauricio Seckler

Coordenador do Comité de Ética em Pesquisa Ilospital Universitáio da USP 


\section{ANEXO II}

\section{TERMO DE CONSENTIMENTO LIVRE-ESCLARECIDO \\ (Instruções para preenchimento no verso)}

\section{I - DADOS DE IDENTIFICAÇÃO DO SUJEITO DA PESQUISA OU RESPONSÁVEL LEGAL \\ 1.NOME DO PACIENTE.}

DOCUMENTO DE IDENTIDADE $\mathrm{N}^{\circ}$ :

SEXO : .M F

DATA NASCIMENTO: .......................

ENDEREÇO

$\mathrm{N}^{\mathrm{O}}$

BAIRRO

CIDADE

APTO:

CEP

TELEFONE:DDD( ...)

2.RESPONSÁVELLEGAL

NATUREZA(grau de parentesco,tutor, curador

etc.)

DOCUMENTO DE IDENTIDADE

SEXO: $M \quad F$

DATA NASCIMENTO :

$\mathrm{N}^{\circ}$

APTO:

BAIRRO: CIDADE:

CEP :

TELEFONE:DDD

II - DADOS SOBRE A PESQUISA CIENTÍFICA

1.TÍTULO DO PROTOCOLO DE PESQUISA -

Avaliação do colo uterino pela ultrassonografia convencional na indução do parto.

2.PESQUISADOR:.

Patricia da Rocha

Pennachiotti

CARGO/FUNÇÃO: .. Médico Obstetrícia

INSCRIÇÃO CONSELHO REGIONAL No …..113288 
UNIDADE DO HCFMUSP: .Clínica Obstétrica do HC- FMUSP do Departamento de. Obstetrícia e Ginecolcogia da Faculdade de Medicina da universidade de São Paulo.

\section{AVALIAÇÃO DO RISCO DA PESQUISA: \\ SEM RISCO RISCO MÍNIMO RISCO MÉDIO \\ RISCO BAIXO $X \quad$ RISCO MAIOR}

(probabilidade de que o indivíduo sofra algum dano como consequência imediata ou tardia do estudo)

4.DURAÇÃO DA PESQUISA : .....2

anos......

\section{III - REGISTRO DAS EXPLICAÇÕES DO PESQUISADOR AO PACIENTE OU SEU REPRESENTANTE LEGAL SOBRE A PESQUISA, CONSIGNANDO:}

Este estudo propõe a realização de exame de toque vaginal e de ultrassonografia transvaginal antes de iniciar as medicações necessárias para começar ou desencadear o parto. Essas medicações são: o misoprostol, que é utilizado na dose de $25 \mathrm{mcg}$ via vaginal de $\mathbf{4} \mathrm{em} 4$ horas, até o colo do útero se tornar favorável (amolecido, dilatado) ao uso da outra medicação usada, que é a ocitocina , utilizada por via endovenosa, para o desencadeamento das contrações uterinas, até o parto.0 objetivo desse estudo é poder estimar a possibilidade do sucesso do desencadeamento do parto. Os exames de toque vaginal e ultrassonografia são geralmente realizados nessa situação, assim apresentando praticamente nenhum risco á sua saúde e de seu bebê. Os benefícios do estudo é que vamos monitorizar com mais precisão os possíveis efeitos adversos do misoprostol, bem como vamos poder estimar as chances de parto vaginal das gestantes que irão ser submetidas ao desencadeamento do parto. Convidamos, portanto você gestante a participar deste estudo, garantindo o mesmo atendimento proposto para todos os casos que deverão começar o trabalho de parto. Além disso, garantimos livre acesso, a qualquer tempo as informações, procedimentos, riscos e benefícios do estudo, para esclarecer eventuais dúvidas, bem como você terá total liberdade de se recusar a participar ou continuar sua participação no estudo. Garantimos ainda, que está preservado o sigilo e a sua privacidade, e que a instituição está disponível paras dúvidas e para prestar assistência a eventuais danos á sua saúde e do seu bebê.

\section{IV - ESCLARECIMENTOS DADOS PELO PESQUISADOR SOBRE GARANTIAS DO SUJEITO DA PESQUISA:}

1. acesso, a qualquer tempo, às informações sobre procedimentos, riscos e benefícios relacionados à pesquisa, inclusive para dirimir eventuais dúvidas.

2. liberdade de retirar seu consentimento a qualquer momento e de deixar de participar do estudo, sem que isto traga prejuízo à continuidade da assistência.

3. salvaguarda da confidencialidade, sigilo e privacidade.

4. disponibilidade de assistência no HCFMUSP, por eventuais danos à saúde, decorrentes da pesquisa.

5. viabilidade de indenização por eventuais danos à saúde decorrentes da pesquisa. 
V. INFORMAÇÕES DE NOMES, ENDEREÇOS E TELEFONES DOS RESPONSÁVEIS PELO ACOMPANHAMENTO DA PESQUISA, PARA CONTATO EM CASO DE INTERCORRÊNCIAS CLÍNICAS E REAÇÕES ADVERSAS.

Pesquisador: Patricia da Rocha Pennachiotti

Pesquisador responsável : Rodrigo Ruano

Endereço: Av; Dr Eneas de Carvalho Aguiar, 255 Telefone : 30696209

Bairro: Cerqueira César

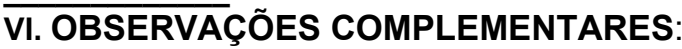

\section{VII - CONSENTIMENTO PÓS-ESCLARECIDO}

Declaro que, após convenientemente esclarecido pelo pesquisador e ter entendido o que me foi explicado, consinto em participar do presente Protocolo de Pesquisa São Paulo, de de 20 .

assinatura do sujeito da pesquisa ou responsável legal assinatura do pesquisador (carimbo ou 


\section{ANEXO III}

FICHA DE IDENTIFICAÇÃO DA PACIENTE

Telefone:

DON:

IG:

(DUM)/

Paridade:

(USG)

Indicação:

raça:

Comorbidades:

Exame Físico: $\quad \mathrm{PA}$ :

$\mathrm{AU}:$

DU:

Peso:

IMC:

CTB:

PBF - ILA :

Toque : Índice de Bishop

1 - dilatação: 0

$1-2$

3-4

total :

(zero)

(um)

(dois)

2 - esvaecimento (\%): 0-30 (grosso) total:

(zero)

40-50 (médio)

60-70 (fino)

(um)

(dois)

3 - altura da apresentação: -3 (AM)

-2 (média)

-1 ou 0 ( baixa) total:

(zero)

(um)

(dois)

4- consistência: dura

média

amolecida total:

(zero)

(um)

(dois)

5- posição: posterior

mediana

anterior total:

(zero)

(um)

(dois) 
USG:

1 - comprimento do colo:

2 - medida da distância da apresentação ao OCE:

3 - avaliação da dilatação do colo uterino:

4 - presença da imagem em funil no $\mathrm{OCl}$

INICIO ( ) MISOPROSTOL ( ) OCITOCINA

HORA:

Misoprostol: $\quad($ ) $\mathrm{CP}$

Conduta:

Parto:

Data:

Hora:

RN Sexo: ()M ()F Peso:

Apgar:

Intercorrências:

Observações: 
9 REFERÊNCIAS BIBLIOGRÁFICAS 
1. Crane J M. Factors predicting labor induction success: a critical analysis. Clin Obstet Gynecol.2006;49:574-84.

2. Martin J A, Hamilton BE, Sutton PD, Ventura SJ, Menacker F, Munson ML.Births: final data for 2003. National Vital Statistics Reports, vol 54. Hyattsville, MD: National center for Health Statistics; 2005.

3. American College of Obstetricians and Gynecologists. New U.S. Food and Drug Administration Labeling on Cytotec (Misoprostol) Use and Pregnancy. ACOG Committee Opinion No. 283.Washington, DC: Am College of Obstet and Gynecologists; 2003.

4. Cammu H, Martens G, Ruyssinck G, et al. Outcome after elective labor induction in nulliparous women: a matched cohort study. Am J Obstet Gynecol. 2002;186:240-4.

5. Vahratian A, Zhang J, Troendle J F, et al. Labor progression and risk of cesarean delivery in electively induced nuliparas. Obstet Gynecol. 2005; 105: 698- 704.

6. Molina F S, Nicolaides $\mathrm{K} \mathrm{H}$. Ultrasound in Labor and Delivery. Fetal Diagnosis and Therapy 2010;DOI :10.1159/000287588:1-7.

7. Pandis G.K, Papargeorghiou A.T, Ramanathan VG, Thompson $\mathrm{M} \mathrm{O}$, Nicolaides $\mathrm{KH}$. Preinduction sonographic measurement of cervical length in the prediction of successful induction of labor. Ultrasound Obstetrics and Gynecology .2001;18:623-28. 
8. Buist R. Induction of labour: indications and obstetrics outcomes in a tertiary referral hospital. New Zealand Medical Journal.1999;112:251-53.

9. Ugwumadu A.The role of ultrasound scanning on the labor ward. Ultrasound Obstet Gynecol.2002;19:222-224.

10. Rane S.M, Guirgis R.R, Higgins B, Nicolaides K.H. Models for prediction of successful induction of labor based on pre-induction sonographic measurement of cervical length. The $\mathrm{J}$ of Maternal-Fetal and Neonat Med.2005;17(5):315-22.

11. Crowley P. Interventions for preventing or improving the outcome of delivery at or beyond term. Cochrane Database Syst Rev.2000;2:CD 000170.

12. Glantz JC. Labor induction rate variation in upstate New Yook: what is the difference? Birth. 2003; 30:68-74.

13. Luthy DA, Malmgren JA, Zinghein RW. Cesarean delivery after elective induction in nulliparous women: the physician effect. Obstet Gynecol.2004; 191;1511-5.

14. Bishop E.H. Pelvic scoring for elective induction. Obstet and Gynecol.1964;94:600-607.

15. Hendrix N.W, Chauhan S.P, Morrison J.C, Magann E.F.,et al. Bishop score: a poor diagnostic test to predict failed induction versus vaginal delivery. South Medical Journal 1998;91:248-52.

16. Williams M.C, Kramer J, O Brien W.F. The value of the cervical score in predicting successful outcome of labor induction. Obstet Gynecol.1997;90:784-89. 
17. Burnett J E Jr. Preinduction scoring: an objective approach to induction of labor. Obstet Gynecol. 1966; $28: 495-501$.

18. Friedman EA, Niswander KR, Bayonet-Rivera NP. Relation of prelabor evaluation to inducibility and the course of labor. Obstet Gynecol.1966;28:495-501.

19. Gabriel R, Darnaud T, Charlot F, Gonzalez N, Leymarie F, Querueux C. Transvaginal sonography of the uterine cervix prior to labor induction. Ultrasound Obstet and Gynecol.2002;19;254-57.

20. Rane SM, Guirgis RR, Higgins B, Nicolaides KH. Pre-induction sonographic measurement of cervical length in prolonged pregnancy: the effect of parity in the prediction of need for Cesarean section. Ultrasound Obstet Gynecol.2003;22:45-48

21. Paterson Brown S, Fisk NM, Edmonds DK, Rodeck $\mathrm{CH}$. Preinduction cervical assessment by Bishop's score and transvaginal ultrasound. Eur J Obstet Gynecol Reprod Biol. 1991;40:17-23

22. Watson W J, Stevens D, Welter S, Day D. Factors predicting successful labor induction. Obstetrics and Gynecology 1996; 88:990992.

23. Crane JMG, Van der Hof M, Armson BA, et al. The use of transvaginal ultrasound in predicition of preterm delivery. $\mathrm{J}$ Soc Obstet Gynaecol Can.1998;20:379-86

24. Boozajomehri F, Timor-Trisch I, Chao C, Fox HE. Transvaginal ultrasonographic evaluation of the cervix before labor: Presence of cervical wedging is associated with shorter duration of induced labor. Am J Obstet Gynecol.1994;171:1081-87 
25. Munhoz H, Diaz C, Lecannelier D, et al. Ultrasound cervix evaluation in the prediction of successful labor induction. Proceedings of the Eighth World Congress of Ultrasound in Obstetrics and Gynecology. Washington, DC: Internacional Society of Ultrasound in Obstetrics and Gynecology.1997

26. Ware V, Raynor BD. Transvaginal ultrasonographic cervical measurement as a predictor of successful labor induction. Am J Obstet Gynecol.2000;182:1030-32.

27. Khoury $S$, Odeh $M$, Korshonov $M$, Wolfson $M$, Oettinger $M$. Transvaginal evaluation of the cervix before the induction of labor. Proceedings of the Eighth World Congress of Ultrasound in Obstetrics and Gynecology. Washington, DC: Internacional Society of Ultrasound in Obstetrics and Gynecology.1997

28. Gonen R, Degani S, Ron A. Prediction of successful induction of labor :Comparison of transvaginal ultrasonography and the Bishop score. Eur J Ultrasound.1998;7:183-87

29. Chandra S, Crane JMG, Hutchens D, Young DC. Transvaginal Ultrasound and Digital Examination in Predicting Successful Labor Induction. Obstet Gynecol.2001;98(1):2-6

30. Rane SM, Pandis GK, Guirgis RR, Higgins B, Nicolaides KH. Pre- induction sonographic measurement of cervical length in prolonged pregnancy: the effect of parity in the prediction of induction-to-delivery interval. Ultrasound Obstet Gynecol. 2003;22 $: 40-44$

31. Rane SM, Guirgis R R, Higgins B, Nicolaides $\mathrm{KH}$. The value of ultrasound in the prediction of successful induction of labor. Ultrasound Obstet Gynecol 2004;24:538-49. 
32. Daskalakis G, Thomakos N, Hatziioannou L, Mesogitis S, Papantoniou N, Antsaklis A. Sonographic cervical length measurement before labor induction in term nulliparous women. Fetal Diagnosis and Therapy.2004;21:34-38

33. Roman H, Verspyck E, Vercoustre L, Degre S, Col JY, Firmin JM, Caron P, Marpeau L. Does ultrasound examination when the cervix is unfavorable improve the prediction of failed labor induction? 2004;23:357-62

34. Yang SH, Roh CR, Kim JH. Transvaginal Ultrasonography for Cervical Assessment Before Inductio of Labor .J Ultrasound Med.2004; 23:375-82

35. Rovas L, Sladkevicius P, Strobel E et al. Three dimensional power doppler ultrasound assessment of the cervix for the prediction of successful induction of labor with prostaglandin in prolonged pregnancy. J Ultrasound Med.2005;24:933-39

36. Gomes F, Ramalho C, Machado AP, Calado E, Cardoso F, Montenegro N. Avaliação Ecográfica do Colo e Avaliação Tocológica Prévias à Indução do Trabalho de Parto. Acta Med Port.2006;19:109114

37. Yanik A, GüLümser $G$, Tosun $M$. Ultrasonographic Measurement of Cervical length in predicting mode of delivery after oxytocin induction.Adv Therap.2007; 24:748-56

38. Tan PC, Vallikkannu N, Suguna S, Quek NF, Hassan J. Transvaginal sonographic measurement of cervical length vs Bishop scores in labor induction at term: tolerability and prediction of cesarean delivery. Ultrasound Obstet Gynecol 2007;29 : 568-73 
39. Park KY. Transvaginal Ultrasonographic Cervical Measurement in Predicting Failed Labor Induction and Cesarean Delivery for Failure to Progress in Nulliparous Women. J Korean Med Sci.2007;22:722-27

40. Gomez Laencina AM, Sanchez FG, Gimenez JF, Martinez MS, Martinez JAV, Vizcaíno VM. Comparison of ultrasonographic cervical length and the Bishop score in predicting successful labor induction. Acta Obstetrica et Gynecologica.2007;86:799-804

41. Hatfield AS, Sanchez-Ramos L, Kaunitz AM. Sonographic cervical assessment to predict the success of labor induction: a systematic review with metaanalysis. Am $\mathrm{J}$ Obstet Gynecol.2007:186-192

42. Vankayalapati $P$, Sethina $N$, Roberts $N$, Ngeh $B$, Thilagananthan B, Bhide A. Ultrasound assessment of cervical length in prolonged pregnancy: predicition of spontaneous onset of labor and successful vaginal delivery. Ultrasound Obstet Gynecol.2008; 31:328-31

43. Eggebo TM, Okland I, Heien C, Gjessing LK, Romusntad P, Salvesen KA. Can ultrasound measurement replace digitally assessed elements of the Bishop score? Acta Obstetricia Gynecologica.2009;88:325-31

44. Park KY, Hong JS, Kang WS, Shin DM, Kim SN. Body mass index, Bishop score, and sonographic measurement of the cervical length as predictors of successful labor induction in twins gestacions. J Perinat Med. 2009;37:519-23 
45. Uyar Y, Erbay G, Demir B C, Baytur Y. Comparison of the Bishop score, body mass index and transvaginal cervical length in predicting the success of labor induction. Arch Gynecol Obstet.2009;280:357-62

46. Wing DA, Ortiz-Omphroy G, Paul RH. A comparison of intermittent vaginal administration of misoprostol with continuous dinoprostone for cervical ripening and labor induction. Am J Obstet Gynecol.1997; 177:612-8

47. Wing DA, Rahall A, Jones MM,Goodwin TM, Paul RH. Misoprostol: an effective agent for cervical ripening and labor induction. Am J Obstet Gynecol.1995; 172:1811-6

48. Farah LA, Sanchez-Ramos L, Rosa C, Del Valle GO,Gaudier FL, Delke, I et al. Randomized trial of two doses of the prostaglandin E1 analog misoprostol for labor induction. Am J Obstet Gynecol.1997;177:364-71

49. Wing DA, Ham D, Paul RH.A comparison of orally administered misoprostol with vaginally adminstered misoprostol for cervical ripening and labor induction. Am J Obstet Gynecol.1999;180:1155-60

50. Apgar V. A proposal for a new method of evaluation of newborn infant. Curr Res Anesth Analg.1953;32:260-7

51. Margulies M, Perez GC, Voto LS. Misoprostol to induce labor. (Letter). Lancet.1992:339:64

52. Francisco RPV, Fonseca ESVB, Sapienza AD. Maturação Cervical e Indução do Trabalho de Parto.In: Zugaib M. Obstetrícia. São Paulo: Manole; 2008,321-7. 
53. Andersen HF, Nugent CE, Wanty SD, Hayashi RH. Prediction of risk of preterm delivery by ultrasonographic measurement of cervical length. Am J Obstet and Gynecol.1990:163:859-67

54. Sonek JD, lams JD, Blumenfeld $M$, Johnson $F$, Landon $M$, Gabbe S. Measurement of cervical length in pregnancy: comparison between vaginal ultrasonography and digital examination. Obstet and Gynecol.1990:76;172-75

55. lams JD, Goldenburg RL, Meis PJ, Mercer BM, Moawad A, Das A. The length of the cervix and the risk of spontaneous preterm delivery. N Engl J Med.1996:334:567-9

56. Concato J, Feinstein AR, Holford I. The Risk of Determinig Risk with Mutlivariable Models. Annals of Internal Medicine.1988;3:201-10

57. Bussab WO, Morettini PA. (1987). Estatística Básica. $4^{\mathrm{a}}$. ed. São Paulo: Atual. 321p.

58. Agresti A. (1990). Categorical Data Analysis. New York. Wiley. $558 p$.

59. Conover WJ.(1980). Practical nonparametric statistics. 2a. ed. New York: Wiley. 493p.

60. Hosmer D W, Lemeshow S.H (2000) Applied Logistic Regression. 2a. ed. New York: Wiley.320p.

61. Fleiss JL (1986). The design and analysis of clinical experiments. New York : Wiley. 432p.

62. Zhang J, Yancey MK, Henderson CEUS. National trends in labor induction, 1989-1998. J Reprod Med.2002;47;120-4 
63. Elghorori MRM, Hassan I, Dartey W, Abdel-Azis E, Bradley M. Comparison between subjective and objective assessments of thr cervix before induction if labour. $J$ Obstetd and Gynecol.2006:26(6):512-6.

64. Hughey MJ, McElin TW, Bird CC. An evaluation of preinduction scoring systems. Obstet Gynecol.1976;48:635-41.

65. Goldberg J, Newman RB, Rust PF. Interobserver reliability of digital and endovaginal ultrasonographic cervical length measurements. Am J Obstet Gynecol.1997;177;853-8

66. Jackson GM, Ludmir J, Bader TJ. The accuracy of digital examination and ultrasound in the evaluation of the cervical length. Obstet and Gynecol.1992;79:214-8

67. Bueno B, San-Frutos L, Salazar F, et al.Variables that predict the success of labor induction. Acta Obstet Gynecol Scand.2005;84:1093-7

68. Reis FM, Gervasi MT, Florio P, Bracalente G, Fadalti M, Severi FM, Petraglia F. Prediction of successful induction of labor at term: role of clinical history, digital examination, ultrasound assessment of the cervix, and fetal fibronectin assay. Am $J$ Obstet Gynecol.2003;189:1361-67

69. Tan PC, Suguna S, Vallikannu N, Hassan J. Predictors of newborn admission after labor induction at term: Bishop score, preinduction ultrasonography and clinical risk factors. Singapore Med J.2008;49( 3):193-98 
70. Peregrine E, O Brien $\mathrm{P}$, Omar $\mathrm{r}$, Jauniaux E. Clinical and ultrasound parameters to predict the risk of cesarean delivery after induction of labor. Obstet Gynecol.2006;107-227-33.

71. Park KY, Hong JS, Shin DM, Kang WS. Prediction of failed labor induction in parous women at term: Role of previous obstetric history, digital examination and sonographic measurement of cervical length.2009;35:301-06. 